Florida International University FIU Digital Commons

$11-20-1998$

\title{
Social capital and high school football: a game plan for the development of human and cultural capital
}

Blane R. Dobey

Florida International University

DOI: $10.25148 /$ etd.FI15101205

Follow this and additional works at: https://digitalcommons.fiu.edu/etd

Part of the Sociology of Culture Commons

\section{Recommended Citation}

Dobey, Blane R., "Social capital and high school football: a game plan for the development of human and cultural capital" (1998). FIU Electronic Theses and Dissertations. 3068.

https://digitalcommons.fiu.edu/etd/3068 


\section{FLORIDA INTERNATIONAL UNIVERSITY}

Miami, Florida

SOCIAL CAPITAL AND HIGH SCHOOL FOOTBALL: A GAME PLAN FOR THE DEVELOPMENT OF HUMAN AND CULTURAL CAPITAL

A thesis submitted in partial fulfillment of the

requirements for the degree of

MASTER OF ARTS

in

COMPARATIVE SOCIOLOGY

by

Blane R. Dobey

1999 
To: Dean Arthur W. Herriott

College of Arts and Sciences

This thesis, written by Blane R. Dobey, and entitled Social Capital and High School Football: A Game Plan for the Development of Human and Cultural Capital, having been approved in respect to style and intellectual content, is referred to you for judgment.

We have read this thesis and recommend that it be approved.

Stephen M. Fjellman

Walter G. Peacock

Alex Stepick. Major Professor

Date of Defense: November 20, 1998

The thesis of Blane R. Dobey is approved.

Dean Arthur W. Herriott

College of Arts and Sciences

Dean Richard L. Campbell Division of Graduate Studies

Florida International University, 1999 
(C) Copyright 1999 by Blane R. Dobey

All rights reserved. 


\section{DEDICATION}

I dedicate this thesis to my grandparents, Alfred and Olivia Payne. By opening their minds and hearts, they made the improbable possible. 


\section{ACKNOWLEDGMENTS}

I wish to thank the individuals who were the subjects of this study. Without their support, generosity, and patience this project would have been impossible. My committee deserves my appreciation for among other things, sheer perseverance. Dr. Stephen M. Fjellman's words of encouragement and ability to assist me in understanding what was there but not recognized provided much needed support throughout the thesis process. I will take Dr. Walter G. Peacock's willingness to take a hard stand on an issue, accompanied by assistance and kindness, as an example to be followed. I would also like to thank my major professor, Dr. Alex Stepick, who has provided his valuable time and effort to ensure that my first few steps in social research would be successful ones. His dedication to his profession is to admired.

Of the many others who assisted me in this endeavor two are most prominent: Carol Dutton Stepick who provided timely advice and a sympathetic ear, and Michelle M. Lamarre who guided me through the absurd bureaucratic labyrinth that is graduate school. Thank you all. 


\author{
ABSTRACT OF THE THESIS \\ SOCIAL CAPITAL AND HIGH SCHOOL FOOTBALL: \\ A GAME PLAN FOR THE DEVELOPMENT OF \\ HUMAN AND CULTURAL CAPITAL \\ by \\ Blane R. Dobey \\ Florida International University, 1999 \\ Miami, Florida \\ Professor Alex Stepick, Major Professor
}

The origin of this study was twofold: a concern for the lack of human and cultural capital in many of today's adolescents and a desire to understand the role that athletic participation plays in this situation. The focus of this study is to examine the development of human and cultural capital in the Black male adolescent as a result of his participation in the high school football program. This study is based on a year-long ethnography in three Miami-Dade County high school football programs. Specifically, the social capital and the resources it makes available in each football program was examined as a significant variable in the development of human and cultural capital in the adolescent. It is my hope that this study contributes to the understanding of the process and outcome of athletic participation. 


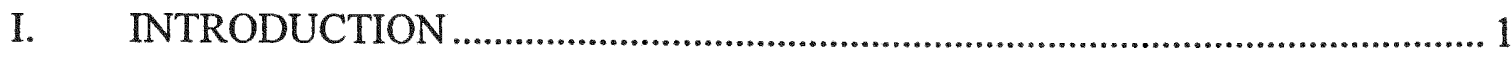

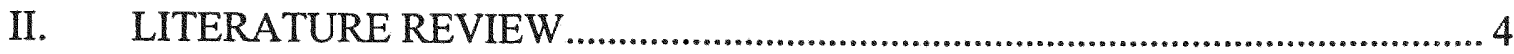

Athletic Participation ....................................................................................... 4

Academic Aspiration and Achievement........................................................ 5

Self-esteem and Character................................................................................... 6

Human and Cultural Capital.......................................................................... 7

Adolescent Socialization ............................................................................. 10

Minority Specific Research .................................................................. 12

Role of the Coach............................................................................................ 13

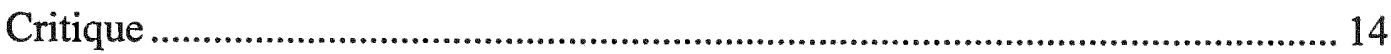

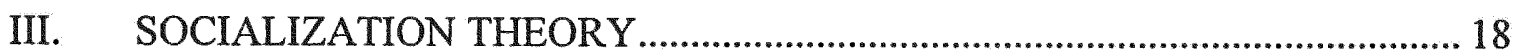

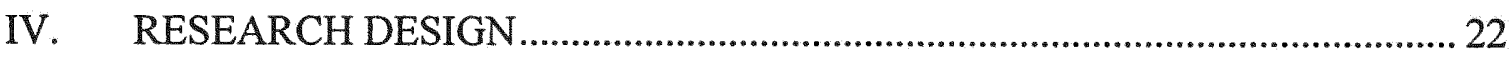

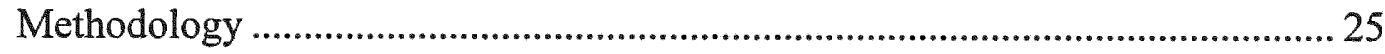

Participant Observation............................................................................. 25

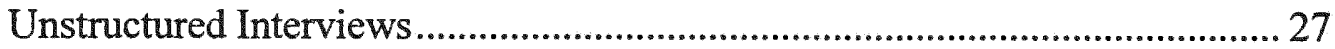

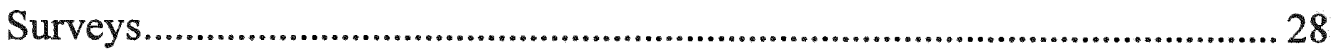

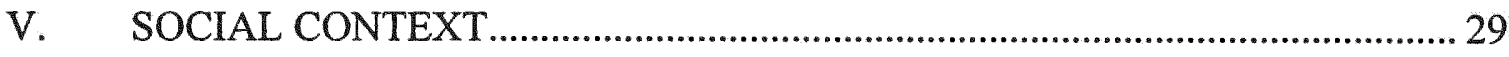

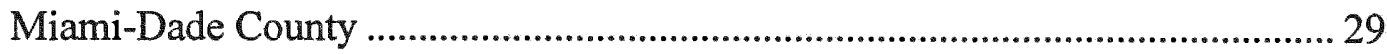

Miami-Dade County Public School System ......................................................... 31

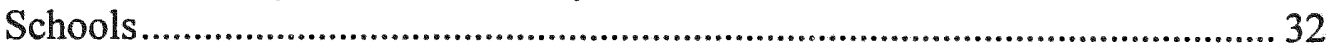

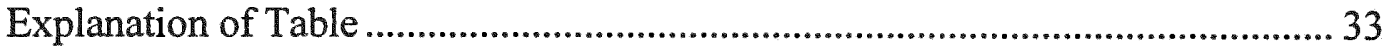

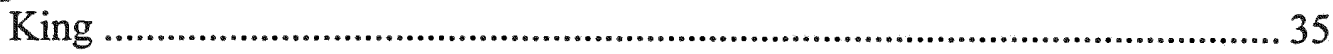

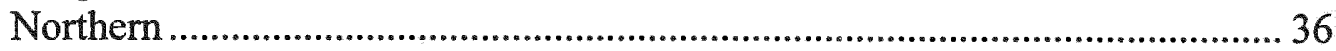

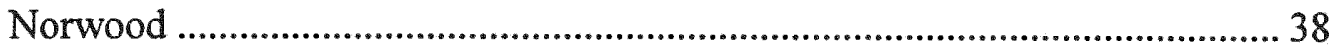

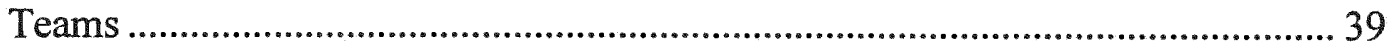

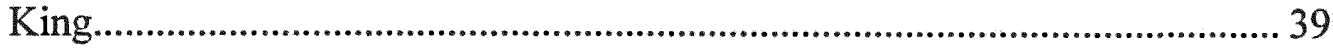

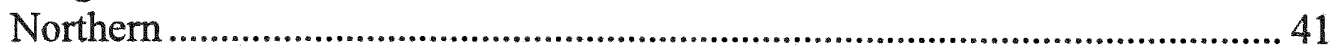

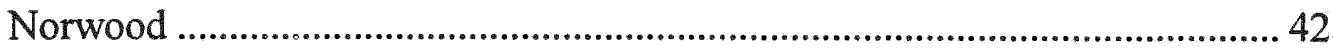

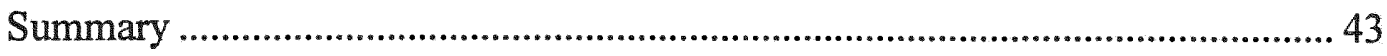

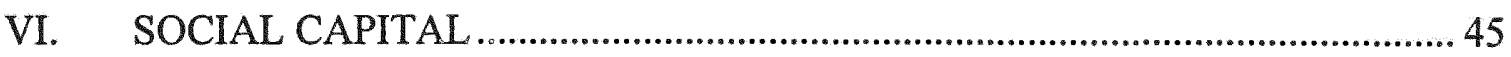

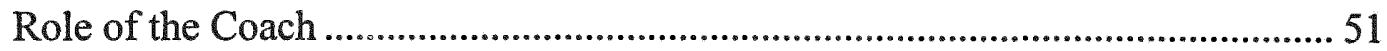

The Football Program ............................................................................................... 53

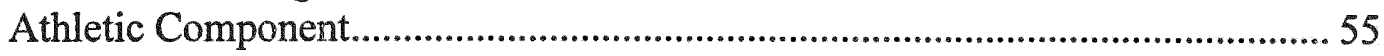

Athletic Component as a Network of Exchange ............................................55 
VI. SOCIAL CAPITAL cont.

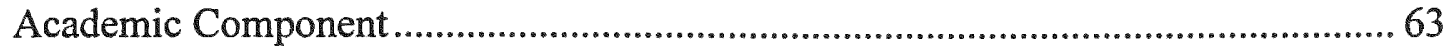

Academic Component as Information Channel ...........................................69 69

Normative Component ......................................................................................... 71

Normative Component as Creator of Norms and Effective Sanctions ............. 78

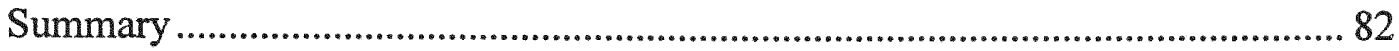

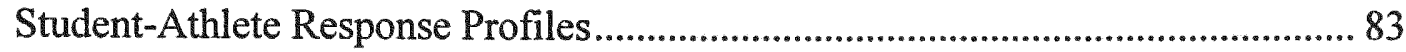

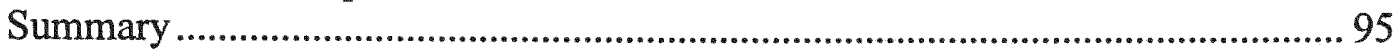

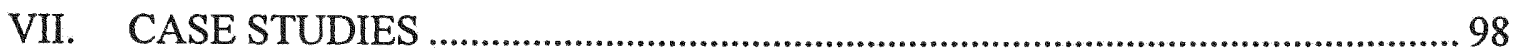

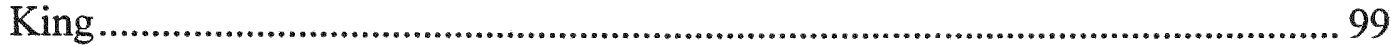

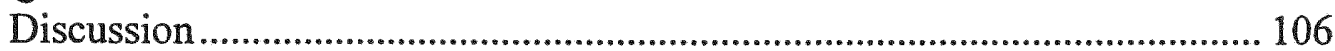

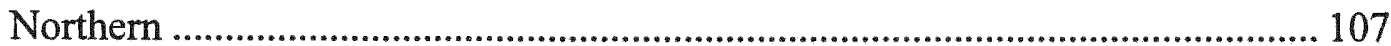

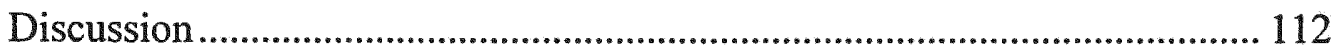

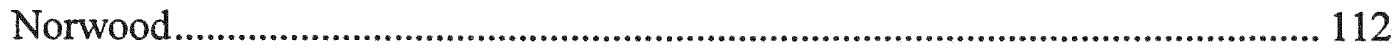

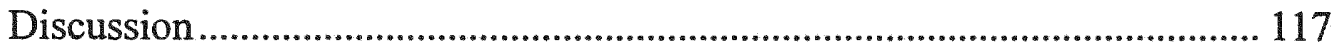

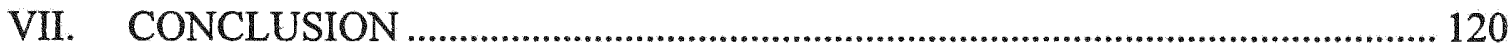

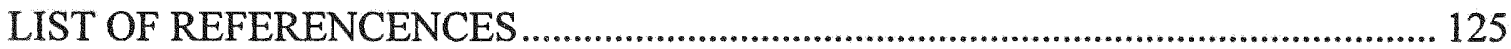

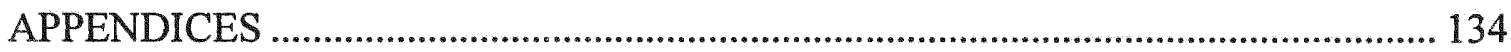




\section{Chapter I: INTRODUCTION}

Coach Dwayne Thom is an African-American head football coach at Norwood High, a predominately Black high school. He believes that it was his participation in football, both at the high school and college levels, that saved him from leading a destructive life:

When I was 12 I watched my step-father knife my mother to death. After that I lived with other family members, never really settling down. I was a real hell raiser let me tell you. You name it I was doing it. I didn't care about school, I was taking drugs, hurtin' people. A few of my kids are like that. They remind me of who I was. The only thing I was doing was football. I was a big kid, so I could always play. Well let me tell you, it was football that got me out of all that. My high school football coach took me under his wing. He introduced me to my savior Jesus Christ, and got me a scholarship to play football. Once I got away things got a lot better. My coaches were like my fathers and my teammates were my family. I have a family of my own now but I'll never forget what a difference they made for me. That's why I coach. If I can help a kid out, that's what it's all about. These kids need the help. I'm here for them. I've sent a bunch of guys off to college, they all come back and thank me. That's the good part about it all. Unfortunately, not all high school football experiences are positive. Instead of increasing interest in education or building an adolescent's character, participation in high school football can lead to negative developments. Such is the case with Reggie, an African-American student-athlete on the Norwood High football team. 
During the summer off-season football program, a student-athlete named Reggie was physically harassing (shoving, arm punching) some of the younger players in the weight room. When some of these student-athletes ran out on the practice field to tell the supervising assistant Coach Diego, Reggie followed them outside to deny the accusations. When the coach asked the offending player to leave for the day, Reggie responded by hurling threats and racial epitaphs such as, "I'll kick you ass, you fat little 'spic!" at Coach Diego. The coach responded to these taunts with challenges such as, "Well then come and get it!" After repeatedly being asked to leave, the player lunged at the coach and a shoving match ensued. Fortunately, no punches were thrown, but the confrontation divided the team into those who supported Reggie (primarily the older players) and those who backed Coach Diego. Reggie was suspended from the team, but subsequently re-instated after being required to apologize to the coaching staff and the team. Throughout the year of this study Reggie continued to exhibit negative behavior that was detrimental to his academic standing and representative of his lack of character development. These behaviors were tolerated, if not reinforced, by his coaches and teammates because of Reggie's excellent athletic abilities.

High school athletics, like any other institution in American society is a complicated, often contradictory proposition. This is evident in the situations described above, as well as in the lack of conclusive results in sports sociology research. To treat athletic participation as a singular experience is a mistake that obscures a wide range of possible scenarios both within and among football programs. This differentiation can have a profound effect on the development of human and cultural capital in the studentathlete that occurs as a result of his participation in high school football. 
This thesis attributes the differentiation to the quality and quantity of resources made available to the student-athlete through the football program. This access to resources, referred to as social capital, affects the decisions and actions of the studentathlete. Resources that are conducive to academic achievement, athletic prowess, or the development of norms that can lead to success in the majority society can be thought of as positive or productive resources. The lack of access to these resources, or access to resources that are contrary to these, can lead to actions and decisions that have a negative impact on the development of human and cultural capital.

It is the purpose of this thesis to describe the differentiation among three football programs, using social capital and the resources it makes available as key variables in the development of human and cultural capital. The response of the student-athlete to these resources will be taken into account as both an indicator of the effects and a variable in the creation and maintenance of social capital. Given the high participation rates of Black minority males in high school football and the difficulties they face both academically and socio-economically it is this group that is the focus of this study. 


\section{Chapter II: LITERATURE REVIEW}

\section{Athletic Participation}

Sponsorship of interscholastic sport programs is a major feature of American high schools and yet the social and educational consequences for the participant are not fully known or understood. Supporters of interscholastic sport programs point to research that indicates participation improves grades, keeps students in school, builds character, and raises student-athletes' educational expectations (Braddock, 1991; Fejgin, 1994; Soltz, 1986). Detractors counter with literature showing that sports participation deflects time and energy away from the classroom and fosters negative social behavior in the studentathlete (Coleman, 1961; Haynes, 1990; Ruffin, 1986). This disparity in research findings has allowed proponents of both viewpoints to use the results of social research to support their positions. Subsequently, the issue of whether interscholastic sport programs support or interfere with the social and educational mission of American high schools continues to be a point of serious debate in the social sciences (Lapchick, 1989; McPhereson, 1986) The last three decades have witnessed a strong interest by a growing number of researchers to understand the social and educational consequences of the interscholastic sport experience. The literature pertinent to high school sports falls into four main categories: academic aspiration and achievement, character and esteem development, minority specific research, and the coach's role in the socialization process. In this chapter I outline the conclusions as well as the deficiencies in all four areas. The first two areas are closely related to the concepts of cultural and human capital now being used in the social sciences. In the case of academic achievement and minority specific 
research I will introduce developments in these areas that point to the need for new research.

\section{Academic Aspiration and Achievement}

Beginning with James S. Coleman's seminal work Adolescent Society, researchers have focused on the educational correlates of high school athletic participation (1961). Research in this area addresses two primary questions: Does athletic participation affect academic aspirations? And does it affect academic achievement?

The first question addresses the athletes' orientation towards academics, while the latter measures actual attainment. There is a consensus that athletic participation positively affects academic aspirations (Coleman, 1961; Hanks and Eckland, 1976; Marsh, 1993; Otto and Alwin, 1977; Sprietzer and Pugh, 1973). The effect on athletic aspirations may be attributed to students' plans to use athletic prowess as "human capital" in gaining access to college (Snyder and Spreitzer, 1990). Or, it may be that athletic involvement affects educational aspirations indirectly through increased selfesteem, locus of control, and discipline (Fejgin, 1994).

Unfortunately these aspirations do not always translate into attainment. Evidence from research supports the expectation that participation in interscholastic sports and academic achievement is related, but the results are far from consistent. Some empirical data indicate that participation in athletics is indeed related to low academic achievement (Coleman,1961; Landers, et al, 1978; Picou, McCarter, and Howell,1985). These empirical findings lead some to argue the amount of time and effort that is consumed by athletics takes away from the pursuit of academics (Coleman,1961). On the other hand, 
other studies have reported that high school athletes have higher GPAs than non-athletes

(Fejgin; Hanks and Eckland, 1976; Marsh, 1993; Otto and Alwin, 1977; Sprietzer and Pugh, 1973).

\section{Self-esteem and Character}

Most of the research in sports sociology analyzes the development of self-esteem and character. This socialization aspect of participation in high school sports has traditionally been referred to as "building character" or "learning how to play the game of life" (Edwards, 1973). Sports participation is commonly believed to develop character and self-esteem and to instill a culture's moral ideals (Coleman, 1961; Coakley, 1978; Edwards, 1973). Harry Edwards labels the type of character and moral ideals that are supposedly developed by sports participation the "American Sports Creed" (1973). Edwards identified seven central themes in the American Sports Creed: character and discipline, competition, mental and physical fitness, religiosity and nationalism. In many ways the tenets of the American Sports Creed reflect Robin Williams' assessment of the predominant American values and are the reasoning behind much of the support for athletic participation (1970). ${ }^{1}$

\footnotetext{
${ }^{1}$ Edwards developed this concept through a content analysis of the value statements in journal, magazine, and newspaper articles dealing with the expressed beliefs about the world of sports in America. These seven themes are as follows: 1. Character: general statements pertaining to clean living, proper grooming, "red-bloodedness," loyalty, and altruism (brotherhood, unselfishness, or self-sacrifice). 2. Discipline: statements that relate sport to self-control and social order. 3. Competition: statements that relate sport to the development of fortitude and preparation for life in the sense of facilitating subsequent success for the individual. 4. Physical Fitness: statements that relate sport to health and physical conditioning. 5. Mental Fitness: statements that relate sport to mental alertness and educational achievement. 6 . Religiosity: statements that relate sport to traditional American Christianity. 7. Nationalism: Statements that relate sport to patriotism and love of country (Snyder and Spreitzer, 1989: 47). These themes are closely related to the slogans posted by coaches in athletic dressing rooms that provide proverbs, aphorisms, maxims and adages in an attempt to influence the players behavior (Snyder,1972). These two studies indicate a close relationship between the desired ideals of sports and the ideals of the majority culture.
} 
Again the research shows mixed results. While sports participation positively affects the valuing of academic achievement, self-esteem, and affiliation to the school and school values, it also plays a role in developing some antisocial behavior such as irritability and reduced belief in being honest, developing self-control and in social responsibilities (Rees et al, 1990). Using data from the 1986 follow-up edition of the 1980 High School and Beyond longitudinal study, Herbert W. Marsh states that "participation in sport leads to an increased commitment to, involvement with, or identification with school and school values but has no effect on locus of control, general self-esteem, or discipline" (1993:35). Throughout sports sociology literature there is no consistent pattern of findings showing that sport builds character, contributes to moral development, makes good citizens, reduces prejudice, develops leaders, enhances social adjustment, affects self-esteem, or creates valued personality traits (Coakley, 1978; Frey and Eitzen, 1991; McPherson, Curtis and Loy, 1989; Rees, Howard, and Miracle, 1990).

\section{Human and Cultural Capital}

These issues of academic achievement and orientation, self-esteem, and character are central to concepts of human and cultural capital being used in the social sciences. Pierre Bourdieu "conceptualizes resources as capital when they function as a 'social relation of power' by becoming objects of struggle as valued resources" (Swartz, 1997:43). He uses this concept of capital to explain how different resources are allocated to perpetuate existing social stratification. This represents the sociological conflict perspective that emphasizes group membership and the shared meanings of group culture as the key factors in the allocation of rewards and privileges (Collins, 1994). James S. 
Coleman also sees capital as a resource, albeit in a more functional argument, as means available to the actor to be used for gain and advancement (1988). The view corresponds with the functional perspective used by both sociologists and economists to stress the role of the individual's abilities in an open competition for rewards and privileges.

Regardless of the ideological differences between the two, they agree that capital is a resource. And while it has been common in our lexicon to name material resources as capital, theorists now also apply that term to non-material resources. These nonmaterial resources, unlike material capital, can be embedded in the individual (Granovetter, 1985). Human and cultural capital are some of these non-material resources as represented by the assets and skills that adolescents develop as they prepare to become adults. ${ }^{2}$

Human capital includes an individual's formal education, work experience, and health (Becker, 1964; Coleman, 1988; Havighurst, 1972; Stepick, 1998). Formal education, as represented by educational certification, and the work experience aspect of human capital are recognized to be key factors in the ability of the individual to attain economic success. An adolescent's health, or lack of same, can be translated into a level of human resource as his/her ability to perform necessary tasks is either enhanced or

\footnotetext{
${ }^{2}$ Coleman does not differentiate between human capital and cultural capital. He defines human capital as "being embodied in the skills and knowledge acquired by an individual..." (1987:100). Bourdieu includes the components of human capital in his concept of embedded cultural capital (Swartz, 1997:74). Congruent with their respective concepts of capital, Coleman's focus is on the return for the individual as a holder of human capital, while Bourdieu concentrates on the distribution of types of cultural capital as they affect the reproduction of social stratification. The atomistic/functional perspective held by Coleman fails to account for inequalities in the social system that hinder the ability of lower-class minority groups to attain capital. In contrast the cultural/conflict perspective promoted by Bourdieu appears to maintain that individual performance does not affect stratification outcomes. I have chosen to make the distinction between the two forms of capital and to construct them in the above manner in hopes of integrating the two perspectives.
} 
diminished (Becker, 1964). Cultural capital can include an individual's personal and inter-personal skills, habits, verbal facility, procedural information, and value system (Bourgois, 1995; DiMaggio, 1982; Farkas, 1996; Swartz, 1997; Swindler, 1986; Taylor, 1997). As part of an individual's cultural capital, personal and inter-personal skills such as learning how to handle anger (both other's and one's own), taking responsibility for one's actions, and the ability to successfully interact with others, are vital to an adolescent's maturation into adulthood (Taylor, 1997).

An adolescent's habits, such as studying, being on time, and class participation can have a direct influence on the adolescent's success in school and in adult life (Farkas, 1996). Verbal facility, in the form of proper language style, can be a form of cultural capital as the adolescent attempts to communicate with others and can act as a cultural label between ethnic, racial, or economic groups(Swartz, 1997). Procedural information represents a working knowledge of the laws and regulations of bureaucratic systems (i.e. schools and governments) that allows an adolescent both access to resources and the facilitation of goals (Bourgois, 1995; Swartz, 1997). An adolescent's value system plays a significant role in the decisions he/she makes. A value system that puts importance on ideas and concepts that allow the adolescent to mature into an adult can be thought of as an asset in the majority culture (DiMaggio, 1982). Values such as equality, morality, freedom, hard work, success, individualism, self-responsibility and external conformity have long been associated with the majority American culture (Coleman, 1961; Giroux and Purpel, 1983; Rice, 1987).

A value system that is contrary to these values and that conflicts with norms of the majority society can impede the success of the individual in that society. For both 
human and cultural capital it is possible for an individual to develop capital that while productive within one culture or subculture is non-productive or even detrimental in the majority American culture. ${ }^{3}$ And while this aspect of capital will be discussed later, it is the development of resources that facilitates the achievement of an individual in the majority American society that is the definition of capital germane to this research.

\section{Adolescent Socialization}

Adolescence is a critical period in the development of human and cultural capital. Developmental theorists indicate that in American society there are certain developmental stages in which the individual is both interested in learning certain tasks and the society demands that the tasks be learned (Rice, 1987). R.J. Havighurst outlines eight major tasks that an adolescent needs to master to mature into an adult:

1. Accepting one's physique and using the body effectively.

2. Achieving new and more mature relations with age-mates of both sexes.

3. Achieving a masculine or feminine social-sex role.

4. Achieving emotional independence from parents and other adults.

5. Preparing for an economic career.

6. Preparing for marriage and the family life.

7. Desiring and achieving socially responsible behavior.

8. Acquiring a set of values and an ethical system as a guide to behaviordeveloping an ideology.

(Rice, 1987: 111)

\footnotetext{
${ }^{3}$ For an insightful look at the development of cultural and human capital that is not applicable to majority American society, please see Phillipe Bourgois, In Search of Respect: Selling Crack in El Barrio (1995).
} 
These developmental tasks closely mirror the aspects of human and cultural capital discussed earlier. Preparing for an economic career is associated with both education and work experience. An individual's personal and interpersonal skills are bound to one's ability to form relationships with other individuals and to develop ones' own physical, mental and emotional self. The development of an ideology that stresses the importance of these tasks as well as the achievement of socially responsible behavior is essential as it provides the building blocks of our cultural blueprints, social scripts, and value systems. The fulfillment of these developmental tasks, as well as the creation of human and cultural capital, is a dynamic process in which the passage through the life cycle, access to resources, new experiences, and the reinterpretation of prior experiences can affect an adolescent's ability to succeed.

This dynamic process is most effective when it takes place in the context of a primary group. Primary groups, which are characterized by intimate and enduring affective relations, are the most powerful settings for socialization (Ritzer, 1996). Examples of primary groups include families, peer groups, and sports teams (Coakley, 1978). Along with these important agents of socialization, the mass media, schools, and religious institutions can play a major role in the socialization of our youth. Mastery of these adolescent developmental tasks leads to the development of human and cultural capital, maturity, and the incorporation of the individual into adult society. Failure can result in anxiety, social disapproval, and social disruption (Farkas, 1996). 


\section{Minority Specific Research}

A third area of sports research pertinent to this thesis is that which is minority specific. The great majority of sport participation studies have focused on white males and, to a lesser extent, on white females (McPherson,1980 ; Melnick, Vanfossen, and Sabo, 1988). Only a handful of studies have examined the effects of high school athletic participation on African-American youth. Most of these concentrate on males. Even fewer studies have looked at the impact of sport participation on Hispanic or immigrant youth.

Like the studies focused on the majority white culture, the studies that have examined the effects of high school athletic participation on African-American male youth show that the benefits of participation in sports are not clear cut. Sports participation seems to have a positive affect on educational aspirations (Braddock, 1980, 1981; Hanks, 1979; Picou, 1978; Picou and Wang, 1982; Wells and Picou, 1980), competitive orientation (Wells and Picou, 1980), self-esteem (Braddock, 1981; Hanks, 1979), college enrollment and graduation (Braddock, 1981), and adult earnings (Picou, McCarter, and Howell, 1985). Sports participation for African-American youth has mixed affects on grades (Braddock, 1981; Picou, 1978; Wells and Picou; 1980), numbers of years of post-secondary education (Braddock, 1981; Hanks, 1979; Picou, McCarter, and Howell, 1985), and no affect on occupational status (Picou, McCarter, and Howell, 1985). 


\section{Role of the Coach}

In considering how athletes are influenced by their participation in high school sports, the coach has a central role. Two different aspects of the high school coach's role have been studied: the tensions inherent in the set of roles played by a high school coach and the role of the coach in the socialization of the student athlete (Nixon and Frey, 1996).

On a very general level, a role refers to a set of rights and obligations associated with a specific position within a social structure. There is a set of interrelated norms that provides general guidelines for the behavior of an individual who takes on a particular role. In reality there are often conflicts within a role that cause an individual to deviate from these guidelines. There can also be situational influences that affect the actual behavior of an individual in any particular role. For coaches, their role set includes two major obligations: they are expected to mold youngsters into model young adults while maintaining a respectable win-loss record (Coakely, 1978). At first glance these two obligations are not intrinsically oppositional, but an overemphasis on either obligation can negatively affect the other. The classic scenario places the major emphasis on the win-loss record at the expense of youth development. This situation is primarily a function of the extreme emphasis on winning as an evaluation criterion for a coach's job performance (Sage, 1987). This concern for win-loss records can lead to coaching behaviors that are detrimental to the development of the youth in their charge such as: the encouragement of positive deviance (Lapchick, 1989; Scott, 1971), the subversion of academic goals (Haynes, 1990; Lapchick, 1989), the condoning of illegal tactics (Edwards,1973), and discrimination based on athletic talent (Snyder,1975). For a coach 
who is facing pressure from the administration, fans, and players, these deviations from the role norms can be a way to help ensure victory (Edwards, 1973).

Coaches must develop intense and extensive relationships with their athletes to mold the adolescent's character (Snyder, 1975). Research has not yet determined that high school coaches are character builders (Nixon and Frey, 1996). However, research has shown that when coaches take the time to give personal advice to their athletes about critical decisions, such as educational and occupational plans, and the athlete has no other significant source of advice, coaches can have substantial influence (Sage, 1987). There is also evidence that players from less advantaged backgrounds are more likely to say that their coach was influential in their educational and occupational planning (Snyder, 1972).

\section{Critique}

There have been two major types of criticisms of past research: those pertaining to theoretical issues and to methodological problems (Coakley, 1978; Greendorfer, 1987; McPherson, 1986). A majority of the research done in the sociology of sport is concerned with the product of socialization, not the process. This is a result of the predominance of structural-functional theory in the field of sports sociology. Recently, there has been a movement towards a "new wave" of sports research that incorporates theoretical perspectives, such as symbolic interactionism, phenomenology, and ethnomethodology to examine the socialization processes that bring about the disputed outcomes (McPherson, 1986).

Methodological problems include design, misinterpretation of correlation findings for cause-and-effect relationships, inherent weaknesses of cross-sectional research designs, and the failure to control for intelligence and social class. I will be primarily 
addressing the problem of the misrepresentation of correlation findings for cause-andeffect relationships. For example, critics of the developmental model point to the idea that high school sports attract highly motivated and successful individuals, thus effectively filtering out low achievers (Soltz, 1986). This so-called filtering process would negate the positive socializing effects of sport participation by attributing both aspirations and attainment to prior socializing experiences. Therefore, the higher academic aspirations, g.p.a.'s, and strong character and self-esteem found in some athletes are not attributable to sports participation. This apparent contradiction in research findings has been exacerbated by the predominance of cross-sectional survey work in this field (McPherson, 1986). In their pursuit of proof that sports participation is either beneficial or detrimental researchers have not seen the need to use methods that would describe the processes that bring about a particular outcome (Greendorfer, 1987; McPherson, 1986). It is my hope that by using ethnography as my primary research method, I will be able to better understand why sports participation differentially influences young athletes.

Along with the need for change in theoretical approaches and methodologies, there have been two developments that seem to necessitate new research: the changing demography of our population and increased academic standards at both the secondary and college level. In a nation in which one out of every three people will be a member of an ethnic minority by the year 2000 , the glaring lack of research involving these groups begs for correction. This is especially true in Miami-Dade County where Hispanics constitute a majority of the general population and that of the school system and Blacks represent a large minority (Stepick, Bowie and Dutton-Stepick, 1995). With recent 
research indicating that there is a disproportionately large number of at-risk kids in the urban minority population, the lack of minority-oriented research takes on more than just theoretical implications (Dryfoos, 1998; Cote and Allahar, 1994). New figures released from the U.S. Census Bureau estimate that in Miami-Dade County $32 \%$ of children between the ages 5-17 live under the poverty level (The Miami Herald, 1999; 5[B]). Reports indicate that Black adolescents, both native-born and immigrants, are the most likely to fall into the at-risk category (A Nation at Risk, 1983; Dryfoos, 1998; Hewlitt, 1991; Males, 1996). ${ }^{4}$

Not only have the Black adolescents been neglected in sports research despite their growing numbers, they also have an immediate need for assistance in the form of remedial class work, counseling, and other services not being provided to them in their communities. For these reasons it is the Black adolescent population that will be the focus of this research. More specifically, I will be concentrating on Black males.

The other recent development involves the increase of academic requirements for both participation in athletics and graduation at the high school level and the increase for admissions into college athletics. ${ }^{5}$ The bulk of the work done on athletic aspiration and attainment was done before the implementation of these higher standards or uses data that was compiled before the effects of these policies could be realized (McPhereson, 1986).

\footnotetext{
${ }^{4}$ For the remainder of this thesis the term "Black adolescent" will refer to both native-born AfricanAmericans and immigrant African-Caribbean adolescents. While I do acknowledge important differences between the two groups I have consolidated the groups for two reasons. The literature on segmentary assimilation suggests that the differences between the two are less of an issue in many of the inner-city areas where the groups interact (Portes and Zhou, 1993; Stepick, 1998), and pragmatically, the term "Black adolescent" is much less cumbersome and allows a more concise writing style.

${ }^{5}$ For a complete review of the increased standards please see appendix A.
} 
These changes in the formal requirements must be examined from not only the perspective of its affect on the student-athlete, but also in terms of how they affect the role of the coach.

Given the lack of consensus on the effects of athletic participation and the changes in both demographics and academic requirements, there needs to be a reexamination of the issue of athletic participation and it's effects on Black adolescents. The key to this analysis will be a theoretical model which is as concerned with understanding the process by which adolescent socialization occurs or doesn't, as it is with the outcome of this process--in other words, what is happening within the athletic arena that is affecting the development of human and cultural capital. 


\section{Chapter III: SOCIALIZATION THEORY}

In the social sciences there had traditionally been a dichotomy in the explanation of the socialization process (Ritzer,1996). The "collectivist" orientation stressed the social structure, role learning through internalization by a passive individual, and conformity. The emphasis tends to be on the product (i.e. a particular skill, attitude or role) and the degree to which socialization has occurred. In this structural model, functional theoretical perspectives such as social learning theory, role theory, and cognitive and social development theories are most prominent (Wentworth, 1980). The "individualistic" perspective concentrated on moral, cognitive, and ethical learning with the individual having an active role in the process. In this model it is the process by which individuals decide how to act that is the concern. In this agency model, theoretical perspectives that stress individual interaction as a major determinant such as exchange theory, ethnomethodology and symbolic interactionism prevail (Nord, 1973). In recent years there has been a move to integrate the two levels to better understand the socialization process (Ritzer, 1996). This integrative approach has been necessitated by three interrelated developments. First is the recognition that there must be an explanation for both the transmission of culture and for the development of autonomous human beings. Second is the acceptance that socialization is a life-long process and at different ages and situations alternate perspectives are most appropriate. Finally, there is the revived debate on whether an individual is "over" or "under" socialized has required a closer examination of differentiated mechanisms in the socialization process (McPherson, 1986). 
These developments led theorists to postulate that social structural elements impinge upon the individual who is an active participant in the socialization process. In light of this, any research attempting to explain the socialization process must distinguish between socialization as internalization and socialization as interaction. That is, whereas internalization is primarily a cognitive process in which the individual passively accepts the elements of the social world, interaction is an active, reciprocal process between the socializer and the socialized and between the self and the environment (Wentworth, 1980). The former is the process by which an individual learns different behavioral patterns. It is this latter process in which the socialized exhibits specific behavior, thus showing the extent and nature of their socialization. There also needs to be a greater emphasis on the social context or social situation in which socialization occurs. In other words, a greater focus is needed on the interactional or ecological setting (Bronfenbrenner, 1979).

For this paper I will be using three theoretical perspectives to help understand the process by which adolescent socialization occurs--social learning theory, rational choice theory, and exchange theory. The task of using these in combination is made easier by the common ground they share and the complimentary nature of their weaknesses and strengths (Wentworth, 1980; Ritzer, 1996). Social learning theory uses the concepts of conditioning and imitation to explain the socialization process (Bandura, 1977). Rational choice theory presumes a rational, thinking individual who makes decisions about how to act based on the resources available to him/her (Coleman, 1990). Social exchange theory is concerned with the interaction of individuals as they exchange these resources (Ekeh, 
1974). Each perspective is helpful in understanding the two main components of socialization--the learning of social behaviors and the enactment of specific behaviors. But, because social learning theory is most applicable to the first component of socialization, and both rational choice and exchange theory are primarily concerned with the second, these three theories fail to fully explain the process of socialization when they stand alone. Social learning theory fails to identify the constraints on an adolescent's choice of action. Rational choice theory does not explain how social interaction can affect an adolescent's decisions. Neither rational choice nor social exchange theories demonstrate how an individual might learn specific behaviors. However, in combination these three approaches create a working model for the examination of the socialization process.

Before I continue I would like to introduce the concept of social capital as an important variable within this socialization model. Pierre Bourdieu defines social capital as "the aggregate of the actual or potential resources which are linked to possession of a durable network of more or less institutionalized relationships of mutual acquaintance or recognition--or in other words, to membership in a group" (1985: 248). Their function is to facilitate the dissemination of the other types of capital. There is not a single type of social capital, but a variety of different types with two common elements. They all consist of some aspect of social structures, and they facilitate certain actions of actors within the structure (Coleman, 1988). Again there is incongruity between the two theorists. Bourdieu concentrates on the resources themselves as the key component, while Coleman focuses on the effects on the agency of the actor. But there is a "growing consensus in the literature that social capital stands for the ability of actors to secure 
benefits by virtue of memberships in social networks or other social structures" (Portes,

1998: 6). ${ }^{6}$ From this consensus social capital can be deconstructed into two main elements: first, the social relationship itself that affords the individual access to resources possessed by other members of the group, and second, the quantity and quality of those resources. I will discuss social capital in more detail later, but it is clear that this concept can be a useful tool in the examination of socialization.

This model identifies a number of important aspects of socialization that must be accounted for to understand and predict an adolescent's actions and development. These include but are not limited to the following: the behaviors an adolescent is exposed to; the costs and benefits to the adolescent of exhibiting a specific behavior; the resources available to the adolescent; and the relationships in which the adolescent is engaged. By examining these aspects of the adolescent's environment, it is my belief that it is possible to both understand and make hypotheses about an adolescent's behavior. It is my contention that social capital and the resources it makes available must be considered a significant variable when examining the processes of socialization and the developmental consequences of athletic participation.

\footnotetext{
${ }^{6}$ While there is some contention in regards to the extent of social capital, there is agreement that it represents the resources an individual can obtain through relationships that can be used in some manner to the benefit of the individual (Coleman,1987:100; Robinson and Godbey,1997:168; Stepick, 1998:20; Swartz,1997:74).
} 


\section{Chapter IV: RESEARCH DESIGN}

Through the discussion of social learning, rational choice, and social exchange theories I have developed a basic model with which to study the process of socialization. Within this model I have identified social capital as a significant variable in the development of human and cultural capital in the adolescent. I will now apply these concepts to the study of the effects of high school athletic participation on Black adolescent males.

First, there must be a focus on the social environment student-athletes interact within as a result of their team membership. Although there are a number of high school sports that I could have examined, I have chosen to focus my research on high school football programs. I have done this for a number of important reasons, some based on the literature and others of a more practical nature. Being one of the high profile sports in the high school, as well as in our culture, there is a great deal of emphasis put on the on-field performance of the football team (Lapchick, 1989). This stress on winning can cause the human and cultural development of the adolescent to be de-emphasized. But this position as a high profile sport can also lead to high school football attracting minority adolescents who see it as way of boosting their prestige, or as a way out of their present situation (Lapchick, 1989). And as stated above, it is the minority adolescent who apparently suffers from the greatest amount of resource deprivation. On a practical level, since I am male I would have limited access to vital areas, such as the locker room, if I were to focus on a female sport--not to mention any difficulties I might encounter based on gender issues. Also, having played football for ten years, I have a wealth of knowledge and experience that may enable me to better understand and integrate myself into the research 
situation. But, I must also note that this familiarization with the research topic may cause me to overlook certain aspects others would uncover. While I am a stranger to this particular athletic team, I am not a stranger to athletics. Nevertheless, I feel comfortable with this choice as my research topic.

Sociological research in the area of sports has been hindered by the reluctance of those in coaching to open their gyms, playing fields, and locker rooms to the questioning presence of social scientists (Coakley, 1978). This is not surprising, given that most people are not eager to let outsiders "backstage" when there is a chance of an unfavorable evaluation (Goffman, 1959). Unfortunately this has relegated much of the research done in this area to survey work and the analysis of secondary data (McPhereson, 1986). As mentioned earlier, the reliance on this type of methodology in conjunction with the use of primarily functional and conflict theoretical perspectives has produced an almost exclusive emphasis on the outcome of sports participation and not the process. This ethnography addresses a number of the shortcomings of past research by stepping into the world of sports in an attempt to better understand both the process and outcome of sports participation on Black male adolescents.

I conducted the majority of the work for this comparative analysis of three Miami-Dade County high school football programs over a one-year period, from April 1997 to April $1998 .^{7}$ These dates correspond to one full cycle of the football program, from spring practice to spring practice, and allowed me the opportunity to better comprehend the complexities of the entire football program. While primarily a cross-

\footnotetext{
${ }^{7}$ In 1998 the name of Dade County was changed to Miami-Dade County.
} 
sectional analysis of the three programs, the length of time spent in the field did provide a limited longitudinal perspective.

This study was officially authorized by the Miami-Dade County Public School System. This process was facilitated by my association with Alex and Carol Dutton Stepick. The reputation and good will they had earned in the community and schools through past and ongoing research afforded me a legitimacy I may not have been able to achieve on my own. However, this authorization did not ensure access to the schools, much less the football programs. It was necessary to obtain permission from both the principal and head coach at each school before the study could proceed. In each case the principal deferred to the coach as to whether I was to be allowed to conduct my study. At this point I was fortunate to have gained the assistance of Coach Peter Evans (a pseudonym). I had met and interviewed the head football coach of King High during an earlier research project. When I let him know I was interested in conducting this study he contacted each head coach and personally vouched for me. There was full disclosure of my intentions to all individuals involved in this project and pseudonyms were used to assure confidentiality.

In this chapter I begin with a discussion of the methodology used to obtain the bulk of the data that are presented in this thesis. This is followed by a description of the external social environment in which these student-athletes are located. By external I mean that environment outside the football program. This includes a synopsis of the urban and school environments to contextualize the adolescent's situation and access to resources. 


\section{Methodology}

The research on which this thesis is based was obtained using a multiple technique approach known as triangulation (Babbie, 1995). In addition to the analysis of secondary data necessary for the literature review and research design, I conducted participant observation, unstructured interviews, and survey work in all three schools. The use of multiple collection techniques is useful in that they have " non-overlapping weaknesses... [and] complementary strengths" (Brewer and Hunter 1989:17). The use of multiple collection techniques affords the researcher the opportunity to gain a more holistic view of reality and can assist in eliminating researcher bias.

\section{Participant Observation}

As mentioned earlier, the choice of football gave me an opportunity to observe the effects of interaction of athletics and academics on Black male adolescents. My football experience both influenced my choice and facilitated my inclusion in the team culture. I was able to act as coach and tutor for the football teams at all three schools. These positions allowed me access to the players, coaches, and faculty and enabled me to build the relationships necessary to perform my research.

Beginning in April of 1997 with Spring practice and ending after Spring practice of 1998 , I was engaged as a participant observer in all three football programs. I typically spent one day a week of up to five hours a day at each high school. This allowed me to observe the full range of activities existing in the football programs. It also afforded me the opportunity to conduct impromptu informal interviews as different situations and opportunities presented themselves. Over time, because of both my desire and the needs of the programs, I became an observing participant. As tutor, study hall 
supervisor, coach, and weightlifting partner I was able to transform my role. This is not to say that I became an "insider". I still felt certain constraints applied to me in specific situations. The football game between King and Norwood High on October 9, 1997 was a prime example. Since I worked at both schools, I felt it necessary to try to be impartial as to the outcome and show my support for both teams. Having access to the sidelines, I would spend a quarter on one side then switch at the changeover. During the third quarter I was on the Norwood side observing the adjustments being made by the offensive line coach as he instructed his players. I was standing behind the seated players, the coach with his chalkboard facing the players with his back to the game. In the middle of explaining a new blocking scheme he looked up at me, back down at the scheme, and slowly lowered the chalkboard out of my view. Embarrassed, I hustled to another part of the sideline before any of the lineman could become aware of the situation. After the game, a Norwood victory, I spoke the coach and explained to him that I would in no way jeopardize my position by relaying game plans. He was kind enough to apologize and said "I know man, it was just the game you know. So close and all. I got a little carried away." The attitude corresponded to Coach Thom's belief that since I was involved with two rival teams I shouldn't participate in practices beyond casual observance; but nonetheless he often allowed me to be involved in coaches' meetings and practices. This contrasted with the attitudes of Coach Alexander and Coach Prince who both welcomed and encouraged my involvement in practices. Coach Prince even went as far as offering the offensive line coach position to me--an offer I regrettably had to refuse. None of the coaches broached the subject of the other two teams in an attempt to gain an upper hand in an athletic contest. The product of this participant 
observation, both observations and informal interviews constitute the majority of the field data used for this thesis.

\section{Unstructured Interviews}

Unstructured interviews were conducted throughout the study. All head coaches and academic advisors were interviewed in this manner. These interviews were designed to gain insight into the role of the individual, the reasons behind his/her involvement, the perceived need for hi/her efforts, and any difficulties encountered in performing these roles. The student-athletes were chosen based on their ability to represent the characteristics of each team. These characteristics included ethnicity, academic and athletic achievement, and orientation towards the program. At least three members of each team were chosen for interviews. Student-athletes were questioned about their future goals, what they thought of the football program, their family life, and what they expected to get by playing football.

Throughout the year I took any opportunity to sit down with these individuals on a one-to-one basis. These interviews were conducted in the classroom, coaches' office, guidance office and locker rooms, wherever it was possible to allow the interviewees an opportunity to open-up and express themselves in their own terms. A number of the students became reticent about talking about themselves when the interview was conducted away from their teammates. I had much more success when I conducted the interviews while in the general presence of other players. The exact opposite was true for the coaches and staff. I had to remove them from a position of access for them to have any opportunity to elaborate on their answers. Otherwise there would be a constant stream of student-athletes with pressing issues both significant and trivial. 


\section{Surveys}

To survey the student-athletes I used a supervised, self-administered questionnaire method $(\mathrm{N}=113)$. Surveys were conducted in November of 1997 to student-athletes presently on the three football teams. By this stage of the research the ethnographic work I had completed was sufficient to suggest the questions necessary to be able to get an overall profile of the three teams. This was also the last opportunity that I would have to address the teams as complete units before the end of the season and the subsequent scattering of many of the senior research subjects. At each school, a team meeting was convened at the behest of the coach for the purpose of completing the questionnaire. I encouraged participation in the survey and expressed thanks for the team's cooperation by supplying pizza and sodas. Those student-athletes that were not present were asked to complete the questionnaire at a later date. I was unable to obtain three surveys, one at Northern and two at Norwood. This fixed my survey count at $\mathrm{N}=110$.

The survey consisted of fifty-six questions. ${ }^{8}$ The questions were a mix of closedended and open-ended items. Subject areas included family and personal statistics, orientation towards the football program, perceived affects of the program, locus of control, and future plans. It is my intention to use these surveys to compile a profile of each player and team. This will facilitate my cross-sectional analysis.

I did not survey the coaches and staff because their numbers were sufficiently small to use unstructured interviews.

\footnotetext{
${ }^{8}$ For questionnaire see Appendix B.
} 


\section{Chapter V: SOCIAL CONTEXT}

\section{Miami-Dade County}

Miami-Dade County is a strategic research site for addressing the effects of sports participation on minority male adolescents. The combination of a large Black population, both native and foreign-born, and a rich tradition of high school football creates a unique situation in Miami-Dade County.

Much of the area now known as Miami-Dade County was originally envisioned as a winter resort for wealthy Northern tourists. Today Miami-Dade County has the highest proportion of foreign-born residents of any major metropolitan area in the U.S. Beginning in the late fifties periodic influxes of Caribbean Hispanics, predominately Cuban, have dramatically changed the cultural, political, and economic mix of MiamiDade County. In 1990 Hispanics represented $49.2 \%(953,000)$ of the county's population, compared to $5.3 \%(50,000)$ in 1960 (Portes and Stepick, 1993:211). Starting in the late 1970s African-Caribbean immigrants, particularly Haitians, began to arrive in large enough numbers to significantly affect the overall Black population. By 1990 the Black population of Miami-Dade County had reached 369,000 or about $19.5 \%$ of the population, an increase of almost 100\% from the 1970 mark of 190,000 (15\%) (Portes and Stepick, 1993:211). The increase in both Hispanic and Black populations has been accompanied by a severe reduction in the White population. Commonly referred to as "white flight" the overall White population in Miami-Dade County has dropped from a high of 779,000 in 1970 to 586,000 in 1990 , a 25\% decrease in twenty years (Portes and Stepick, 1993:211). This rapid shift in the demographics of Miami-Dade County has created ethnic tensions on several fronts. As Cubans break the hegemonic rule of the 
county's Anglo population, competition for political and economic power becomes embittered. Blacks, having been economically and politically leap-frogged by the Cubans, find themselves a weak third in the county's hierarchy. This situation is exacerbated by a lack of solidarity within the Black community. Divisions based on ethnic and class lines have decreased this group's ability to become a viable force. Although African-Caribbean immigrants find themselves being considered as part of the Black community by both the Hispanic and Anglo communities, neither they nor African-Americans are comfortable with that grouping. African-Caribbean immigrants are loathe to be associated with a minority group that has been stereotyped by the host society as lazy and uneducated (Stepick, 1998). African-Americans regard AfricanCaribbean immigrants as a threat in the economic sphere and a infrequent ally in political situations (Portes and Stepick, 1993). Faced with subordination to both Hispanics and Anglos, and hindered by infighting within the Black community, Miami-Dade's nativeborn and immigrant blacks find themselves being excluded from the economic and political power structure (Portes and Stepick, 1993). This creation of a Black urban underclass has ominous overtones not only for the ethnic groups involved, but also for all of Miami-Dade County.

Miami-Dade County football teams have been 3-1-1 in Class $6 \mathrm{~A}$ state championships since 1991. That's five state championship games in seven years. Florida State Coach Bobby Bowden has called Miami-Dade County, "the best place to find high school talent in the country" (Fonteboa,1997). Florida has moved past traditional high school powerhouses Pennsylvania and California, and is only behind Texas in the number of high school athletes being recruited into the college ranks (Lapchick, 1989). Over the 
last two years over 100 athletes from Miami-Dade County have been awarded college athletic scholarships (Dienhart, 1997). This current success is part of a rich tradition that included eight state championships in fifteen years from 1963 to 1977 . During the 1980's while Miami-Dade County was experiencing a population explosion and the talent pool was thinned as new high schools were opening up, the county went $0-5$ in state championship games. In explaining Miami-Dade's recent success Jim Kroll, a head coach in the county for the past 20 years says, "we've completed our growing pains and now it's time for other parts of the state to feel the effect. As long as we have the players we have now, Dade will be in the state-title game for a while" (Fonteboa, 1997).

\section{Miami-Dade County Public School System}

The Miami-Dade County Public School (MDCPS) is the fourth largest system in the nation behind only New York City, Los Angeles, and Chicago in the number of enrolled students $(345,861)$ and teachers $(17,687)$. Over the last ten years MDCPS has grown more than 33\% (MDCPS Official Internet Site). Each year new enrollment increases the student population by over 13,000 students. This rapid and continued growth has put a strain on the MDCPS budget that manifests itself in overcrowded schools, the use of portable classrooms, and a lack of fundamental educational resources such as books.

MDCPS is an ethnically diverse school system. The teaching staff consists of 41.1\% White non-Hispanic, 31.7\% Hispanic, 26.3\% Black, and .9\% Asian/American Indian. MDCPS estimates that its student population is $13 \%$ White Non-Hispanic, 
33.5\% Black Non-Hispanic and 51.9\% Hispanic and 1.6\% Asian/American Indian. ${ }^{9}$ As compared to the overall county population, White Non-Hispanics are under-represented, while Black Non-Hispanics are over represented. This may reflect the propensity and ability of the White population to enroll their children in private schools. Geographically, this student population reproduces the segregation found in Miami-Dade county with inner-city schools being primarily Black and the suburbs being White and Hispanic.

\section{Schools}

The three high schools included in this study vary on significant dimensions. King High is an inner-city school in a poor neighborhood with an overwhelmingly Haitian student body. Northern High is an older suburban high school in a working and middle class neighborhood, with a student population that is primarily African-Caribbean while Norwood is part of un-incorporated Miami-Dade County and has a predominately lower middle-class African-American and Jamaican-American student body. These schools were chosen in an effort to represent the diversity within the Black community. Each neighborhood, school, and student body has characteristics that make the high school experience unique.

\footnotetext{
${ }^{9}$ MDCPS does not differentiate between African American blacks and those of other national origins. (MDCPS Official Internet Site)
} 
TABLE 1

SCHOOL CARACTERISTICS

\begin{tabular}{|c|c|c|c|c|c|c|c|c|c|c|c|c|c|}
\hline \multirow{3}{*}{$\begin{array}{l}\text { School } \\
\text { Stud. Pop. } \\
\% \text { of Cap. }\end{array}$} & \multicolumn{6}{|c|}{ Ethnic Characteristics * } & \multirow{3}{*}{$\begin{array}{c}\text { Sub. } \\
\text { Lun. } \\
\%\end{array}$} & \multirow{3}{*}{$\begin{array}{l}\text { Eng. } \\
\text { Prf. } \\
\%\end{array}$} & \multicolumn{5}{|c|}{ Student Achievement } \\
\hline & \multicolumn{3}{|c|}{ Faculty \% } & \multicolumn{3}{|c|}{ Student \% } & & & & & FWA & $\overline{\mathrm{HS}}$ & $\mathrm{T}^{* *}$ \\
\hline & $\overline{\mathrm{W}}$ & B & $\overline{\mathrm{H}}$ & $\bar{W}$ & $\overline{\mathrm{B}}$ & $\mathrm{H}$ & & & $\overline{\mathrm{R}}$ & $\bar{M}$ & Comp & $\mathrm{C}$ & $\mathrm{M}$ \\
\hline \multirow{2}{*}{$\begin{array}{l}\text { King } \\
N=2397 \\
112 \%\end{array}$} & $\overline{42}$ & 36 & 22 & \multirow[t]{2}{*}{1} & \multirow[t]{2}{*}{92} & \multirow[t]{2}{*}{7} & \multirow[t]{2}{*}{40.2} & \multirow[t]{2}{*}{22.2} & \multirow[t]{2}{*}{11} & \multirow[t]{2}{*}{17} & \multirow[t]{2}{*}{3.1} & \multirow[t]{2}{*}{38} & \multirow[t]{2}{*}{38} \\
\hline & \multicolumn{3}{|c|}{$\begin{array}{c}\mathrm{N}=120 \\
\text { F/S ratio } 1: 20\end{array}$} & & & & & & & & & & \\
\hline \multirow{2}{*}{$\begin{array}{l}\text { Northern } \\
\mathrm{N}=3390 \\
155 \%\end{array}$} & 56 & 28 & 12 & \multirow[t]{2}{*}{6} & \multirow[t]{2}{*}{76} & \multirow[t]{2}{*}{16} & \multirow[t]{2}{*}{29.7} & \multirow[t]{2}{*}{17.5} & \multirow[t]{2}{*}{22} & \multirow[t]{2}{*}{29} & \multirow[t]{2}{*}{3.2} & \multirow[t]{2}{*}{63} & \multirow[t]{2}{*}{64} \\
\hline & \multicolumn{3}{|c|}{$\begin{array}{c}\mathrm{N}=149 \\
\text { F/S ratio } 1: 28\end{array}$} & & & & & & & & & & \\
\hline \multirow{2}{*}{$\begin{array}{l}\text { Norwood } \\
N=2352 \\
108 \%\end{array}$} & 62 & 29 & 9 & \multirow[t]{2}{*}{2} & \multirow[t]{2}{*}{92} & \multirow[t]{2}{*}{5} & \multirow[t]{2}{*}{21.3} & \multirow[t]{2}{*}{1.3} & \multirow[t]{2}{*}{35} & 36 & 3.5 & 61 & 55 \\
\hline & $\mathrm{F} / \mathrm{S}$ & $\begin{array}{l}\mathrm{J}=10 \\
\text { ratio }\end{array}$ & :22 & & & & & & & & & & \\
\hline
\end{tabular}

Miami-Dade County Public Schools, Management and Accountability, District and School Profiles 1997-98.

* Some rows in the faculty and student $\%$ sections do not total $100 \%$. This is a result of small Asian/American Indian populations not represented in this table. $W=W$ hite; $B=B l a c k ; H=H i s p a n i c$

** These percentages are from the 1996-97 school year.

F/S ratio- Faculty to Student ratio

Sub. Lun.- Subsidized Lunch

Eng. Pro.- Limited English Proficiency

SAT- Stanford Achievement Test

FWA- Florida Writing Assessment

HSCT- High School Competency Test

\section{Explanation of Table}

Percentage of capacity represents the actual number of students attending each school divided by the official recommended capacity. The recommended capacity does not include portable classrooms used to handle the overflow of students. All three schools are operating above capacity levels, with Northern High having over half again as many students as it was designed for. This over-enrollment at each school places undue strain on the resources of each school. 
The ethnic characteristics of each school have been divided into student and faculty sub-sections. Each sub-section is divided into White non-Hispanic, Black, and Hispanic categories. The student population represented in the table does not include a small Asian/American Indian population, while the faculty numbers represent only principals, assistant principals, classroom teachers, exceptional student teachers, and guidance counselors. Ancillary staff members such as security guards and custodial workers are not included. This allows for a faculty/student ratio that reflects institutional restrictions on faculty/student interactions. MDCPS does not differentiate between ethnic groups within each racial category.

The subsidized lunch program is designed to provide free or reduced priced lunches to those students who are economically disadvantaged. This percentage is an indicator of the economic differentiation between the three schools. King High has the highest percentage of students in this program (40.2\%), which reflects the lack of economic capital available to these adolescents.

Limited English proficiency indicates the percentage of those students whose primary or home language is other than English, are not judged to be independent in English and are currently enrolled in an appropriate ESOL course. A high percentage of limited English proficiency points to a large immigrant student population that may be lacking in cultural capital in their new country. This is especially true for King High (22.2\%) which has an overwhelmingly Haitian student body. The rate for all of MiamiDade County is $15.9 \%$.

Student achievement is measure by three standardized tests. These are the Stanford Achievement Test, the Florida Writing Assessment, and the High School 
Competency Test. The SAT measures reading comprehension and mathematics skills. It is administered to ninth and eleventh grade regular students. The SAT is scored on a scale of 1 to 100 with 50 being the national median. The purpose of the FWA test is to obtain information about students' ability to organize and clearly express thoughts in writing. This test is given to tenth grade students. The HSCT is a multiple-choice test that measures the application of basic skills in communication and mathematics to everyday life situations. This test is administered to eleventh grade high school students. The average scores in Miami-Dade County were $67 \%$ for communications and $66 \%$ for the mathematics portion.

\section{King}

Built in 1917, King High was one of Miami's first high schools. In 1978 King High was moved a block away to a new building that most closely resembles a fort. This large two-story building has no windows and the front of the school resembles a large turret that is emblazoned with the school mascot. This contrasts sharply with the newly renovated former high school, now a middle school, with its large ornate windows, courtyards, and mosaic tile. This new fort-like design may be appropriate given the school's surroundings, which includes an interstate less that 20 yards from school as well as abandoned homes.

Originally King was a White high school. Following desegregation, it quickly became Black since it lies adjacent to Liberty City, an area with Miami's largest residential Black concentration. During the 1980s, King High became majority Haitian, as the adjacent area known as Little Haiti became Miami's largest Haitian neighborhood. Both neighborhoods are among the poorest in Miami-Dade County with a poverty rate of 
nearly $44 \%$ (Stepick, Bowie and Stepick, 1996). The poverty rate of the individuals in a two-mile radius of King High is $40 \%{ }^{10}$ With the highest percentage (40.2\%) of students receiving subsidized lunches of all three schools, the students at King High clearly reflect the economic levels of the surrounding areas.

Official statistics record that King High is majority Black (92\%). I estimate that at least $80 \%$ of the Black students are Haitian or Haitian-American, whereas about $10 \%$ are African-American and the remainder being of other Caribbean backgrounds. Since MDCPS does not keep statistics on national origin, this estimate is derived from conversations with school officials and my own observations. With the highest percentage $(36 \%)$ of Black faculty and the lowest faculty to student ratio $(1: 20)$, the staff at King High is seemingly in the best position of the three schools to provide the type of relationships necessary to create social capital. But the high level of limited English proficiency students $(22.2 \%)$ may inhibit the ability of many Black faculty members to connect to immigrant members of the student body. In addition while Hispanics and Whites constitute only $8 \%$ of the student population they make up $64 \%$ of the staff.

King High consistently has the lowest average standardized test scores of any high school in MDCPS and as of the school year beginning Fall of 1997 is on Florida's list of critically low performing schools.

\section{Northern}

Dedicated in 1951, Northern was built to serve the growing suburbs of North Miami. Northern sits in the middle of housing developments whose homes match Northern's functional, box-like and inexpensive design. The high school sits adjacent to

\footnotetext{
${ }^{10}$ U.S Census data provided by the GIS lab at Florida International University.
} 
a county park, which gives Northern's students access to both a swimming pool and tennis courts. The neighboring homes, while not stunning, are clean and well kept as befits this working class neighborhood.

Northern originally provided an education to the Anglos and Jewish Whites of North Miami. By 1990, the area had become one of upwardly mobile Blacks, especially foreign-born Blacks such as Haitians and West Indians, Whites and Hispanics. Many of these Haitians have come from Little Haiti as they begin to establish themselves economically in their new country. The neighborhood is predominately lower middleclass, with a relatively low $15 \%$ poverty rate within a two-mile radius of the high school. However, this rather large drop in the poverty rate, as compared to King High, is not fully reflected the percentage of student $(29.7 \%)$ receiving subsidized lunches.

Northern is the most racially diverse of the three schools but still has a majority (76\%) Black population. Based on my observations and interviews of school staff, I estimate that Haitian and Haitian-Americans comprise the majority of the Blacks within the student body of Northern High. The lower percentage of limited English proficiency students $(17.5 \%)$ would indicate that while a majority, Haitians compose a smaller percentage of the student population than at King. The remaining Black students are either African-Americans or West Indians. Northern High also has a relatively large percentage (16\%) of Hispanic students as compared to King and Norwood. The faculty at Northern is predominately White (56\%) and has the lowest percentage of Black teachers (28\%) among the three schools. But what is most alarming is the high (1:28) faculty to student ratio. This is a result of Northern operating at $155 \%$ of its carrying capacity. 
While portables have been added, the number of teachers has not been able to keep pace with Northern's growth.

Northern High has an International Baccalaureate magnet program that consists of a two-year pre-university course and allows its students to quality for scholarships at Florida's public universities and to receive up to thirty semester university credits. Despite this, Northern still ranks well below the national median on the Stanford Achievement Test and falls just short of the district averages on the High School Competency Test.

\section{Norwood}

Norwood High was built in 1958, as the suburbs of Miami extended west. The surrounding area, which includes a sports stadium and a horse racing track, is now part of unincorporated Miami-Dade County. The high school itself, which is similar in construction to Northern, is tucked back from the main road in a Black middle-class neighborhood called Norwood.

Until recently Norwood was an African-American community. An influx of West Indian immigrants, primarily Jamaican, has served to gradually change the ethnic makeup of the community over the past few years. The neighborhood is primarily a mix of lower-middle and middle class homes. Of the three areas, Norwood has the lowest poverty rate $(13 \%)$, which correlates with the lowest subsidized lunch percentage $(21.3 \%)$ of the three schools.

Norwood High has a predominately Black student-body (92\%). Based on interviews of school staff, the majority of the Black population is African-American but there has been an increase in the immigrant population. But, unlike the other two schools 
where the influx of immigrants has been primarily Creole-speaking Haitians, the majority of the new immigrant students has been English-speaking West Indians. This is reflected in the extremely low limited English percentage (1.3\%). Norwood has the highest percentage of White faculty (62\%) of the three schools. It also has the widest disparity between percentage of Black faculty (29\%) and Black student population $(92 \%)$. Norwood is operating at $108 \%$ of capacity, the lowest among the three schools, but has a 1:22 faculty/student ratio due to a lack of classroom teachers. While having only 47 fewer students than King High, Norwood has 13 less classroom teachers.

Between the three schools, Norwood has the highest scores on both the SAT and the FWA, but still falls below national and district averages. Norwood is second to Northern on the HSCT among the three schools.

\section{Teams}

Each of the three football teams in this study has a unique profile. This profile consists of a number of variables including ethnic composition, staff, and winning traditions, that affects the character of the team. The following is a brief description of each team that will help orient the reader to the team's characteristics and identify significant individuals within each program each team, such as the head coach and academic advisor.

\section{King}

The head coach at King High School is Steve Alexander. Coach Alexander is an African-American in his mid-to-late 20's. He is approximately 6' and 200lbs with an athletic build that suggests his playing days at a major southern university. For such a 
young man he carries himself with a quiet dignity and ease that demands respect. He is a man with a ready smile and a firm handshake, who looks you in the eye when he talks to you. While he can't be described as talkative, he is more than willing and available to open up and discuss himself and the team. This is his first year as a head coach, but he has more than five years of coaching experience. He took over the program from Coach Evans, who had made a reputation for himself as a strong proponent of developing what I have labeled human and cultural capital in his student-athletes. Unfortunately Coach Evans was not able to develop a winning tradition at King, having won only one game in the previous two seasons.

The King High football team has forty players. Of these seventeen ( $43 \%$ of the team) are African-American and fifteen (38\%) are Haitian-American. ${ }^{11}$ There are five (13\%) Bahamians and one White, one Hispanic, and an Asian student-athlete. AfricanAmericans constitute a disproportionate percentage of the team as compared to the demographics of the student body. This is possibly due to football being an almost exclusively American sport to which a large part of the Haitian students may not be familiar.

Ms. Johnson, White and 37, is a large, friendly woman. She is a guidance counselor at King and after ten years here she has been given the position of head of guidance. She has been the academic advisor to the athletic program for the past five years. In this role Ms. Johnson has counseled the coaches and athletes on entrance exams, college application requirements, curriculum choices, and helped organize individual tutoring. 


\section{Northern}

The head coach at Northern is Walter Prince. Coach Prince is a Haitian-American in his late 20 s to early $30 \mathrm{~s}$. Born in Haiti he moved to Miami when he was twelve. He has lost any appreciable accent or mannerism that would easily identify his ethnicity, and he never mentions his ethnicity in normal conversation. My first impression was that he had been born in the U.S. and was African-American. He is a little under six feet tall, muscular but with a bit of a gut. He is an extremely intense and at times an abrupt individual. And yet there is an undeniable charm that surfaces when he needs something. His normal demeanor is one of quiet intensity that just dares people to challenge him and his authority. This is his second year as head coach at Northern, and he has several years of coaching experience before coming to Northern. Last year the team went 3-7. The team has not had a winning record in the past five years.

The thirty-one student-athletes on the Northern High football team reflect the racial and ethnic diversity found in the student population. The team is comprised of eleven (35\% of team) African-Americans, ten (32\%) West Indians, six (19\%) Haitians, three (10\%) Hispanics, and one individual from Guyana. The West Indies are represented with five Jamaicans, four Bahamians, and one player originally from Trinidad. The cacophony of languages and accents in the locker room is enough to make your head spin.

At about five feet tall Ms. Webb is more than a match for any group of high school kids. She is a strong-minded individual who doesn't easily get flustered and can

11 Ethnic designations were constructed by using official school records and information from the student surveys. Second-generation immigrant youth were classified as part of their parents' national category. 
handle a class. "At 52, being as small as I am AND white, some of these kids get the idea they can have their way with me. They learn their lesson quickly." She has been an English teacher for over 25 years. This is her primary role at Northern. In addition she is the Senior class advisor, Prom advisor, Activities advisor, and the Athletic Academic advisor. The administration recognizes these positions by requiring Ms. Webb to teach one less class than is customary to partially provide time to carry out these roles. Ms. Webb has been working with both the basketball and football teams for four years. Her duties as Athletic Academic advisor include English tutoring, as well as counseling on college applications, college entrance exams, curriculum, and health and nutrition.

\section{Norwood}

The head coach at Norwood High is Dwayne Thom. Coach Thom is an AfricanAmerican in his late 30 s to early 40 s. Having played small college ball, his $5^{\prime} 11^{\prime \prime}, 250 \mathrm{lb}$ frame appears large without being obese. He has an open, gregarious manner that he uses to make people feel comfortable around him. When he shakes your hand, you look down to see your hand enveloped in his only to look back up to be assured by his ready smile. He has been head coach at Norwood for eleven years, and has over 12 years of total coaching experience. The team has had winning seasons for most of his career and went $7-3$ the year prior to this study.

The Norwood High football team is primarily African-American. Of the fortytwo student-athletes only six (17\%) are not African-American. There are four (10\%) West Indians, two Haitian-Americans, and one Hispanic. Coach Thom attributes much of his success as compared to the other two teams on this study to the fact that the majority of his players have been playing football since they were young kids. He feels 
that the typical African-American athlete, having been exposed to football either directly or indirectly, has a distinct advantage in football over the immigrant athlete.

Mr. Flagg is a tall, 6’3", White man with a big mop of curly gray hair. He has an abrupt conversation style, and is confident if not obdurate of his opinions. He has been a math teacher for over 20 years, and is currently the advisor to the Honor Society, Math club, and Athletic program. As the Academic Advisor he counsels the athletes on curriculum choices, college entrance exams and applications, and coordinates individual tutoring. He has worked with Coach Thom and the football team for the past eight years including the 1997-1998 school year.

\section{Summary}

In the preceding discussion I have attempted to illustrate the social environment that the Black male adolescents of this study find themselves a part, while also showing some characteristics of this adolescent population. At this point it would be easy to make statements of cause and effect, but because that would be an overly deterministic simplification, I will merely state that the discussion clearly indicates two areas of concern. First, the families, communities, and schools of these adolescents lack many important resources, as reflected in the relatively high although varying poverty rates.

Second, the relatively low test scores in these schools reflects that many of these Black adolescents show a lack of human and cultural capital that inhibits their ability to function, much less succeed, in our schools and society. These conclusions reiterate the necessity of research, such as this, that examines aspects of the Black adolescent's lives in an attempt to understand how they affect the adolescent's development--and more 
specifically how resources that are made available to the student-athlete as a result of his participation in high school football affect his development of human and cultural capital. 


\section{Chapter VI: SOCIAL CAPITAL}

As discussed earlier, social capital is a resource that allows an individual to obtain other resources or benefits by virtue of his being a member of a group or network. As illustrated in the previous chapter many of the student-athletes in this study find themselves in the double-bind of not only lacking important human and cultural capital, but also being part of a social environment that is lacking in economic capital. Bourdieu points to the interrelation of the two deficits when he states that "it is after all economic capital that makes possible the investment in cultural capital by making possible the investment of time needed to accumulate cultural capital" (Swartz, 1997:80). But, the mere physical presence of a parent or adult significant other are not by themselves enough to develop human and cultural capital in an adolescent. James Coleman argues in Social Capital in the Creation of Human Capital, "it is also necessary to examine the effort spent by the adult to create productive relationships between themselves and the adolescent" (1988: s110). Social capital, by allowing access to resources, increases the chances that the adult's relationship with adolescents can be a productive one.

In the context of this thesis social capital will be defined as the ability of the student-athlete to access resources and benefits through the social networks he is a part of as a result of his membership on the football team. It can be seen as the aspect of a network of the student-athlete, his coaches, teachers, peers, school, and other socializing agents that give that adolescent access to resources that will enable him to develop successfully in the majority culture. The impact of social capital is dependent not only on the nature of the relationships within these networks, but also the amount and quality of the resources. This definition of social capital has three important ramifications. First, 
the low level of social capital can inhibit the transference of human, cultural, economic, and physical capital that might otherwise be available to the student-athlete. This would mean that regardless of the resources that an adult, such as a coach or teacher in the adolescent's life possesses, its potential benefit to the youth is affected by the level of social capital present. Secondly, it also implies that no matter the quantity of relationships, or density of the social networks that the student-athlete is a part, if resources are not available within those networks social capital is non-existent. This would mean that regardless of the desire of the coach to provide tutoring to the studentathlete, if he can't do it and can't find anyone else that will there is no resource to be accessed and therefore no social capital. And finally, while the adolescent may have access to resources through his social networks, these resources may not be helpful in developing human and cultural capital that is productive in the majority society. For example, as part of the football team the student-athlete is taught by his coach to physically and verbally abuse those teammates who do not perform well, then he enacts that behavior so as to fit into this sub-culture. These resources and therefore the social capital by which he obtained them can not be considered of the quality or type that can be seen as beneficial in the majority culture. And as stated earlier, for this thesis capital is taken to mean a resource that is beneficial to the individual in the majority culture.

Social capital provides an important link in the theoretical model developed earlier. Social capital itself is a vital resource that facilitates the development of human and cultural capital in the adolescent by making available to him other necessary resources, such as information, money, or access to college. The availability of resources may affect the actions as well as the decisions of the adolescent. The following examples 
illustrate this point. If an adolescent believes that neither he nor his parents have the necessary economic resources for him to attend college he may not see the necessity to achieve academically and may very well develop a negative orientation to the pursuit of an education. In other cases where there is a desire and economic means to attend college, a lack of information concerning curriculum requirements or college admissions may inhibit his decisions about which high school courses meet college requirements and his ability to correctly navigate the intricacies of applying to college. This lack of resources may cause the adolescent to make what could be termed an "irrational decision," but in reality he is merely acting upon the resources available to him. His choice of an elective course in the hopes of making an A and increasing his g.p.a., as opposed to choosing a math course that fulfills college requirements would be a result of his lack of information not an irrational act. He believed he was making a rational choice in an attempt to increase his g.p.a., but his lack of knowledge of college requirements caused him to make a choice that will possibly be detrimental to his academic goals. This does not necessarily indicate irrational behavior or even lack of socialization, but a lack of resources, in this case procedural information concerning college academic requirements. The ability to access information through the network is a primary function of social capital (Bourdieu, 1985; Coleman, 1988; Portes, 1998).

This model can also be applied to more traditional socialization concerns such as an adolescent's social behavior. It is common to consider limiting the definition of a resource to those items external to behavior that influence an adolescent's choice of action. I will extend that definition to include types of behaviors themselves as a resource vital to the decision-making process of the adolescent. In other words, not only 
does access to resources such as money, information, or job opportunities affect an adolescent's behavior, but also access or knowledge of appropriate types of social behavior. Again, by appropriate I mean to indicate those behaviors that are accepted in the majority culture. For example, how does an adolescent learn the appropriate way to handle his anger if he has never been instructed in the proper behavior or has seen those around him behave violently and not be negatively sanctioned. Furthermore, if he does learn the appropriate behavior what is his incentive to enact it if there is a lack of social control regulating his actions toward acceptable behavior? The willingness of adults, and others, to spend time and effort to modify an adolescent's behavior is an important consideration when determining the resources or benefits available to the adolescent (Coleman, 1988; Swartz, 1997). While this example may seem primarily within the parameters of social learning theory, it is better understood within the framework of a more integrated model that takes into account social capital. This assertion is based on the idea that not all adolescents are exposed to the same behaviors and are subject to the same level or type of social regimentation. The adolescent can lack either the necessary behavioral information or the impetus to enact it-or both- when there is a lack of social capital. Both access to the information about different types of behavior and the social control that is created by tight group networks can be considered a result of social capital (Coleman,1988).

In the examples above, the adolescent's relationships or social networks were not providing the necessary resources or benefits for the adolescent to behave in a manner that would be deemed "rational" to the majority society. While he may have access to resources that might help in certain sub-cultures, such as the adolescent or inner-city, and 
therefore possess social capital, these resources do not allow him to develop the necessary human and cultural capital to succeed in the majority culture. When his networks do provide the resources and benefits that will help him develop this type of capital, he then possesses social capital of a different quality by virtue of his membership in that network. He is now in relations with others who possess the necessary resources and are willing to make them accessible to him. It is this type of social capital and these resources that are best suited for the development of human and cultural capital. By understanding the decisions and actions of the adolescent in this manner we may be better able to understand the process and consequences of his socialization as a result of his participation in high school football.

But why do people create social capital? Why do they agree to give others access to their resources? Why do some lay claim to certain resources and not others? The existence of networks of exchange is not a natural given. Unlike economic capital or even human capital, the benefits of investment in social capital do not necessarily accrue to the creator of the social capital, but in this case to the student-athlete who makes claims on the resources of the network. Portes uses the concepts of consummatory and instrumental motivations which differentiate between the internalization of norms and the expectation of the individual that the obligations will be repaid as sources of motivation (1998). Coleman discusses the public good aspect of social capital in much the same manner (1988). While both give important insight into the motivations to create social capital, they tend to neglect the motivations of the claimants, assuming that they are understandably willing to use the resources made available to them. Bourdieu addresses this issue in a concise yet comprehensive statement: " the network of relationships is a 
product of investment strategies, individual or collective, consciously or unconsciously aimed at establishing or reproducing social relations that are directly usable in the short or long term..." $(1985 ; 249)$. These social relations are usable to achieve goals and fulfill the needs of the individuals who agree to give access to their resources, as well as useful to those who lay claim to those resources. The student-athlete must see benefits in investing his time and effort into the football program. Without his participation there is no social network. And without his willingness to lay claim to the resources, the social capital created by the coach goes unused and can dissolve (Coleman, 1990). The coach gives his time, effort, and football expertise in the hopes of winning games. He creates tutoring programs to keep his players eligible and monitors their behavior to maintain discipline primarily to fulfill his obligation to develop a successful program. These could be called instrumental motivations. This is not to say that the coach doesn't desire to help guide his players through adolescence or get a better education, but it must be recognized that these too are goals and needs. Social approval, allegiance, and the satisfaction of helping others can be intangible repayments of the coach's investment in social capital. An example of these expressive motivations is illustrated in a head coach's explanation of why he coaches high school football:

I've always played football. I thought I would go to the pros maybe. But by the time I got to college I started to realize that I might not make it. I had two coaches in college. The first one was all about winning. That was it. He didn't care if you went to class. The players were constantly getting into trouble and everyone would hush it up. This was college football in the South. I hated it. There was no discipline. After a few years it caught up to him and he was asked 
to leave. Now the second coach was a completely different story. You went to class, you behaved yourself. He didn't take crap from anyone, but he was also there for you if you really needed it. It felt good to play for him. Ilearned a lot. He got me my first coaching job. He got me into coaching. I'm trying to bring what he had down here to these kids. It's not like playing but there are some real rewards for helping these kids.

This discussion of social capital makes it clear that when analyzing the effects of social capital it is important that we do not confuse social capital, the ability to obtain resources, with the resources and benefits it allows access to. Also we must differentiate those who initiate the creation of social capital from those who are the primary beneficiaries of it. Thus a systematic treatment of the concept must distinguish among:

(a) the possessors of social capital (those making claims); (b) the sources of social capital (those agreeing to these demands); and (c) the resources and benefits themselves (Bourdieu, 1985; Portes, 1998). This means that to analyze social capital within the football program there needs to be a discussion of the roles and motivations of: (a) the student-athlete as a demander of resources, (b) the head coach and school staff as creators of access; and an evaluation of, (c) the resources and benefits available to the studentathletes. As you will see in the upcoming discussions, these distinctions can be capricious, but they do provide a heuristic model with which to begin.

\section{Role of the Coach}

The head football coach is in a unique position to provide both access to resources as well as be a source of resources to the Black student-athlete. These assertions are 
based on three aspects of the coach's position that can make his role unparalleled in a student-athlete's life.

First, with the exception of their peers and possibly family, no other individual spends more time in contact and direct supervision of the student-athlete than the coach (Coakley,1978; Edwards, 1973). Moreover, the coach and student-athlete interact throughout the entire year and possibly through the full four years of an adolescent's high school career (Gallon, 1980). The coach, therefore, has the opportunity to establish a sense of trust and establish long-term relationships with the adolescent. This impression of trust and continuity is vital for a positive educational experience (Nodding, 1992; Ogbu, 1987) and the development of social capital (Coleman, 1988).

Secondly, the coach, as the head of the football team, is the significant other in a primary group (Nixon and Frey, 1996). In this role he is in a critical position to influence the development of the adolescent through the environment that he creates and his own actions (Bandura, 1977). Furthermore, the student's participation in athletics is voluntary. The student sees benefits in the participation in athletics. These benefits can be selfesteem, prestige, access to higher education, or an opportunity for a career (Edwards,1973; Lapchick, 1989; Snyder and Spreitzer, 1989). This can be especially true for minority males (Braddock, 1981; Kennedy, 1995). This puts the coach in a position of controlling resources that the adolescent values--participation on the team and the knowledge necessary to improve performance. Further, as discussed in social exchange theory, an individual must value the item being exchanged for them to initiate an exchange (Homans, 1974). It must also be noted that the student-athlete has resources that are valuable to the coach. Namely these resources are athletic talent, effort, desire, 
and academic eligibility (Edwards, 1973). Without these resources the coach is unable to fulfill his primary responsibility: to win games.

Finally, the coach as both teacher and head of the football team is in a unique position in the school structure to create a network between the student-athlete and the resources available within the school. As discussed above he is in a position to build a relationship with the student-athlete not available to other adults in the school, but he also has a working relationship with the other teachers and staff and the resources that they possess. This position at the nexus of the two groups presents the coach with an opportunity to act as a reagent within the school structure to create social networks, and possibly social capital, where none existed before.

\section{The Football Program}

At the high school level, football and the activities associated with it are a yearround endeavor. From summer training to college preparation the school staff, coaches and student-athletes are constantly interacting in pursuit of institutional, team and individual goals. A majority of these goals are conducive to the objective of developing human and cultural capital in the Black male adolescent. Among the three teams there is a striking similarity between the types of strategies that have been applied in the pursuit of these goals. All three are in the process of developing and expanding their programs in an attempt to increase the success of the team and develop the student-athlete. This is not to say that there is parity in the quality of the implemented programs or a similarity in results. There is in fact a wide disparity between the three schools in both the extent and 
quality of social capital and resources actually available to the student-athlete. This disparity will be illustrated in a later chapter.

To enable a systematic analysis of the social capital present in the three football programs it is first necessary to develop a conceptual model of the football program. This model must typify the ways in which the coach attempts to build networks to provide resources and benefits to the student-athletes, the nature of those resources and benefits, the responses of student-athletes to those resources and benefits, and the motivations of the actors involved. This typology has been constructed from my observations of the three programs and is intended to be a heuristic tool, not a recommendation of policy.

I have divided the football program into three components: athletic, academic, and normative. This taxonomy indicates the primary emphasis of the programs and activities within each category. It is my assertion that there is a similarity between these three categories and the three forms or functions of social capital as put forth by James Coleman: the generation of obligations and expectations, the transference of information, and the development of norms and effective sanctions (1988). For this thesis the three athletic components will be considered synonymous to the three types of social capital. The athletic component can help create a set of obligations and expectations between the coaching staff and the student-athlete. This set of obligations and expectations can become a network for the exchange of other resources (i.e. information and norms). The academic component has been expressly designed to become an informational channel between the student-athlete and his coaches and teachers. The normative component is primarily aimed at creating norms and effective sanctions. These are not distinct and 
mutually exclusive categories. In every interaction between the coach or teacher and the student-athlete there is an aspect of each of these functions of social capital. For example, the athletic component of the football program conveys both information and norms to the student-athlete. As you will see the three components of the football program can also build upon each other and be mutually reinforcing. After this discussion I will present a typology of student responses to these forms of social capital.

\section{Athletic Component}

It is the athletic component of the high school football program that garners the most attention. Each week during the Fall the football team becomes the most visible symbol of the high school. The games are social events in which the players become either heroes or goats and the fans yearn for victory. For the student-athlete this part of the football program also means hours of practice, lifting and running in preparation for those games. In return they expect the opportunity to play and to achieve victory.

There are six distinct parts of the athletic year:

1. Summer off-season

2. Double sessions

3. Fall practice

4. Games

5. Spring off-season

6. Spring practice and Jamboree

As you can see this part of the football program runs year-round. I have chosen to begin my description with the summer off-season program because this is when many 
incoming students get their first exposure to the football program. This is not to say that others do not or cannot join the team at another time, but that this is the most typical.

\section{Summer off-season workout program}

The summer off-season workout program runs from the end of school in mid-June to mid-August. The workouts can take place either during the day, the night, or in some cases both. These workouts last 1-3 hours and are held 3 to 5 times a week between Monday and Friday. The Florida High School Athletic Association (FHSAA) prohibits any drills or instruction that are specifically related to football during the summer sessions. The workouts are therefore limited to weightlifting and conditioning in preparation for the upcoming season. These workouts are supervised by one or more coaches who are responsible for the activities in the weight room and for running the conditioning exercises. While the off-season program is ostensibly voluntary, it is commonly understood that if a student-athlete does not participate throughout the summer he will diminish his chances of playing time in the fall.

\section{Summer double-session practices}

Beginning in mid-August and ending at the beginning of the school year, usually lasting approximately two weeks, double-session practices are probably the most physically grueling aspect of football participation. These practices are held twice a day, hence the name, usually from 8-10 a.m. and again at 2-4 p.m. The coaches use the first two days (consisting of four practices) for orientation and evaluation of off-season progress. These first two days the athletes are in helmets and shorts, while the rest of the double session practices they are outfitted in full uniform. The practices consist of positional drills, which teach the athletes basic skills, and team drills, where the offense 
and defense work on plays and assignments in preparation for the upcoming season. At the end of each practice there are conditioning skills, which are a continuation of the offseason program. Between sessions the weight room is often available to those with the energy and desire to workout. These practices are mandatory for any student- athlete who wishes to play football that year.

\section{Fall practice}

Fall practice begins at the start of the school year in late August or early September and runs until mid-November. This parallels the course of the football season, which normally runs ten games, and can be extended if the team goes to the playoffs. There are four to five practices a week, depending on which day the game is, and these practices are held after both classes and study hall are completed. The practices normally last between two and three hours. In a week where the game is on Friday the structure and content of the practices on Monday, Tuesday, and Wednesday, closely resemble that of the practices during double sessions, with the exception of instruction specific to the upcoming opponent. On Thursday, the athletes are in shorts and pads and there is an emphasis on teaching and learning the game plan for the upcoming game. On game day there is no practice and depending on whether the game is home or away the studentathlete will report at a specific time to prepare for the game. On Saturday the players are brought in to analyze the previous game's films and begin to prepare for the upcoming game by watching game film of their next opponent. If the game is on Thursday, there is often no practice on Friday, but there is still film work. If the game is on Saturday, there is an extra day of full-pad practice on Thursday and film work is handled on Monday. 
All practices and film work are mandatory. If a student-athlete does not attend, there is a strong chance he will not play in that week's game.

\section{Games}

There are ten football games in the regular season. Often there is a bye week so that the season can last 11 weeks, starting in September and ending in mid-November. If the team goes to the playoffs the season can run into mid-December. The games are held on Thursdays, Fridays, and Saturdays, to accommodate the large number of schools and the small number of fields available. Each high school does not have a field on campus and must share its home field with other schools. Along with the actual game itself there are pre-game preparations, half-time adjustments, and post-game conferences that afford interaction between the coaches and student-athletes.

\section{Spring off-season workout program}

Beginning as school reconvenes in January, the Spring workout program is similar to the summer program. The major difference being that there is only one workout session a day, usually between 3 and 5 p.m. after school. These workouts are held Monday through Thursday with Friday workouts being more sporadic. Again, the program is nominally voluntary, but if a student-athlete wants a chance to play he is encouraged to participate.

\section{Spring practice and Jamboree}

Spring practices are held in April and are limited by the FHSAA to twenty practices in total. At the end of these practices a jamboree is held where four to eight teams come together to play exhibition football games. These "games" are only fifteen minutes long, and each team plays two of these games each against a different opponent. 
There are no winners of a jamboree, although a team who has won two games has certainly been more successful than a team who has lost both, and the results of the individual games do not count towards records or standings. Therefore, spring practice emphasizes the fundamentals of football--tackling, blocking, running and passing--and not on the running of plays, scrimmaging or preparation for an upcoming game. For the first two days of practices the athletes are normally dressed in shorts and helmets, with the rest of the practices being held in full pads. Spring practices are mandatory.

\section{Athletic Component as a Network of Exchange}

The athletic component of the football program could arguably be seen as performing any of the three functions of social capital. But in the development of human and cultural capital its primary purpose is to build obligations and expectations between the coaching staff and the student-athlete. In this capacity the athletic component acts as a network of exchange between the two groups. In networks of exchange, where an individual performs some service for another with the expectation that the obligation will be repaid, there are two important elements: the trustworthiness of the social environment and the extent of the obligations held and owed (Coleman, 1988). The element of trustworthiness of the social environment symbolizes the extent to which an individual can be sure that an obligation will be repaid. A lack of trustworthiness would seriously inhibit the social exchange of goods (Coleman, 1990).

The athletic component both relies on trust and can engender trust in the social structure. The two groups must have at least nominal trust in each other to begin the exchanges and as the obligations and expectations are fulfilled, or not, the level of trust can increase or decrease. The sources of this nominal trust are the norms and institutional 
regulations governing high school football. The extent to which this network of exchange is developed influences the football program's ability to act as an information channel or as a creator of norms and sanctions. In other words the athletic component is the core of a social network that can be used to give access to other resources. A lack of trust between the coaches and the student-athlete can have a debilitating effect. A high level of trust can facilitate the development of human and cultural capital in the adolescent by aiding the creation of social capital.

This assertion is illustrated by comments made by both the head coach and a student-athlete at King High. Coach Alexander is the first year head coach at King High. He takes over a program that, while it has been successful in promoting academics and obtaining athletic scholarships for its student-athletes, was $0-10$ on the field in the previous season. When I asked him how he planned on turning the on-field program around, he had this to say:

I believe games are won or lost in the off-season. With conditioning and practice you can prepare a team to win. I plan on working these kids hard. I believe they want it. They want a chance to win, to feel good about themselves. They want a chance to go to college. That's what I've got to offer them. But they're going to have to give me everything they've got and I'll do the same. That's what it's all about. Giving all you got.

Adrian is a 17 year old African-American at King High, who in his senior year wants to become the starting quarterback. During the off-season the quarterback position is unsettled, with three players competing for the starting slot. While talking to Adrian during one of the summer off-season workout sessions, I asked him why he was willing 
to put himself through a grueling workout five times a week while most of his friends were enjoying their summer vacation:

I want to start. I know I can get the job done. If I don't come to these things I don't have a chance. But, if I work hard coach will give me a chance. That's all I want. It's tough. Only one guy can play quarterback. But if I work hard that'll be me. I deserve the chance if I work hard. Coach Alexander will be straight. The relationship between the student-athlete and the coach becomes an exchange of obligations and expectations. First, the coach communicates what he expects from the members of his team, in this case participation and effort in the off-season workout sessions. The student-athlete knows that he must meet these expectations to achieve his personal and team goals. If his expectations are met the coach realizes he now has an obligation to do everything possible to help this student-athlete. The fulfillment of this obligation can lead to a relationship of trust that can foster future exchanges. Defaulting on an obligation can lead to a disintegration of the relationship.

The extent to which obligations are exchanged also plays a large role in determining the level of social capital for both the structure and the individual. If, because of lack of need or resources, the existence of alternative sources of aid, or cultural differences in the tendency to lend or ask for aid there are only a small number of obligations outstanding, the level of social capital available within the social structure is diminished. (Coleman, 1990). A small number of obligations diminishes the opportunities to build a network of exchange and lessens the access to resources by those members in the group. 
For adolescents, the lack of this form of social capital can limit the access to resources and benefits they can expect to receive by virtue of their membership on the football team. Fortunately there is a major incentive for the coach to create this type of social capital. By providing the student-athlete with year-round access to the weight room, conditioning, his expertise in football, and the opportunity to play football at the high school and possibly college level the coach is increasing his chances of winning games. In both the literature and from comments by the coaches and administrations of all three schools, the bottom line for the coach is the win-loss record (Coakely, 1978; Edwards, 1973; Lapchick, 1989). This incentive normally provides sufficient incentive to create this type of access to resources. If it doesn't there is a mechanism that tends to eventually bring about the necessary changes to facilitate the development of a social network that affords access--a losing record and the replacement of the coach.

If the motivation is present, but the coach is unable to find individuals to help him supervise the workouts, or he is not able to successfully coach the team then the results are basically the same. In this instance social capital is not created because the resources do not exist. The coach will likely be replaced with someone who can provide these types of resources, or these resources must somehow be made available to him.

I found that the motivations of the student-athlete to lay claim to these resources are three-fold and are similar to the reasons given in sports literature for adolescent participation. First, the immediate benefits that can result from playing football at the high school level. These benefits can range from social acceptance to the physical satisfaction of playing (Coleman,1961; Eckert, 1989). The social acceptance can come from the team, inside the school or in the community itself, and be in forms ranging from 
lack of negative sanctions to hero-like popularity. Secondly, the belief that football, and athletics in general, are a viable and lucrative alternative to normal career paths. This is especially prevalent in inner-city, minority youths (Edwards, 1973; Lapchick, 1989). And finally, there is the acknowledgment of many adolescents and their families that a football scholarship represents the student-athlete's best hope of obtaining a college education (Lapchick,1989). These incentives to join the team and then participate in the activities described above are complemented by peer pressure exerted by the studentathlete's teammates, as well as reinforced by the coach's verbal reminders and disciplinary measures.

These incentives, either singly or in combination, must motivate the studentathletes to expend time and energy in the numerous programs developed by the coach. If they do not then the benefits the student-athletes receive from team membership are diminished. Depending on the component, athletic, academic, or normative, the emphasis of motivation may change from one to another, but the types stay the same.

\section{Academic Component}

The academic component consists of three related areas: curriculum reinforcement, procedural information and college admission assistance. The main function of all three areas is the transference of information, and the main goals include increased g.p.a., athletic eligibility, high school graduation, and admission to college. Study halls, tutoring and the preparation for the standardized tests can be considered curriculum reinforcement. Curriculum counseling, the filing of admission and financial papers and instructions on test taking can all be considered the transference of procedural 
information. While all of the above can be considered assistance to college admission, the active involvement of the coaches and academic advisors with the college recruiters on behalf of the student-athlete is also vital.

\section{Study hall}

Study halls are conducted during the Fall football season. They are held between the end of school and the beginning of football practice and last approximately an hour. Although the study halls are nominally supervised by a coach, they tend to be selfdirected study sessions in which the student-athlete is left to his own discretion on what materials to study. The coaches are present primarily to take attendance and maintain order. Attendance is mandatory.

\section{Tutoring}

Tutoring takes place in both the Fall and Spring. In the Fall these tutoring sessions are held Monday through Thursday, while in Spring the sessions are scheduled less frequently. Unlike the study hall, tutoring is instructor-directed and is based on the student-athlete's needs. Tutoring sessions are held between the end of school and the beginning practice in the Fall and after school in the Spring. In the Fall tutoring sessions last approximately an hour and can be attended in lieu of study hall. In the Spring, tutoring sessions can last up to three hours depending on the student-athlete's needs and the availability of instructors. These instructors are most often teachers at the school, but often they can be other students. The tutoring program is organized by the academic advisor to the football team with input from the head football coach. The tutoring sessions are not mandatory, but can be strongly recommended by the coach. 


\section{Curriculum counseling}

When a student-athlete joins the football team the academic advisor creates a file that includes the student's academic and conduct records. This allows the advisor to assess the present situation of the student-athlete and advise him about the classes he will need to meet the requirements for both graduation and entrance to college programs. The advisor counsels each student-athlete before the beginning of each semester about which classes will meet the necessary requirements. The student-athlete is not required to take these classes and may choose his own class schedule.

\section{Standardized testing}

Entrance to many college programs and all college football programs hinges on a combination of the student's grades and standardized test scores. The two tests that are accepted as gauges of the student-athlete's academic abilities are the SAT and ACT. Tutoring for these two tests is year round. The academic advisor and other faculty are responsible for this instruction. The student-athletes are educated in test-taking skills and strategies, tutored in subject matters most pertinent to the tests, and given multiple practice tests to improve their scores.

In study sessions geared exclusively to the standardized tests, student-athletes are instructed to read the directions and questions carefully, answer the easy questions first, and use a process of elimination for the answers to the harder questions. The studentathlete is also instructed that guessing on the SAT is not an appropriate strategy. Unlike the ACT, which does not penalize the test-taker for a wrong answer, the SAT subtracts a fraction of a point from the test-takers score of correct answers for every incorrect answer. The student-athletes are tutored in specific subject areas, such as fractions and 
vocabulary that are found in all SAT and ACT tests. This instruction is aided by the use of study guides and practice tests that are provided through both testing agencies and private companies. ${ }^{12}$ Practice tests, under simulated test conditions, are given once a semester to prepare the student-athlete for the rigors of a three-hour test. The studentathlete is also encouraged to take the actual tests as many times as possible. Test scores can increase dramatically from the first time a student-athlete takes the test to subsequent attempts. In the case of Thomas Murray, an African-American student-athlete at Northern High, he was only able to score a 680 (370 verbal and 310 math) out of 1600 on his first attempt, but three months later he was able to raise his score to 890 (520 verbal and 370 math). Multiple test takers also benefit from the NCAA admission policy that allows the student-athlete to combine section scores from separate tests. This is illustrated by the composite test score of Andre Ville, a junior at Northern who was born in Haiti. His first test score was 700 (310 verbal and 390 math), his second increased to 720 (270 verbal and 450 math). His composite test score was 760 (310 verbal and 450 math). The student-athletes are also instructed in procedural information such as how to sign up for the tests, how to apply for fee waivers, and how to forward their scores to the appropriate universities. This program is not a mandatory part of the football program, but it is necessary for the student-athlete to take one of these two tests to be admitted to college.

\section{College admissions}

The academic advisor and the coaching staff work together to help the studentathlete obtain admission into college either as a student or student-athlete. This process

${ }^{12}$ See Appendix C 
begins as soon as the student-athlete becomes part of the football team. As stated above, the academic advisor creates a file for each student-athlete including both his academic and conduct files. Each semester these files are updated to include current g.p.a., courses taken, test scores, and any athletic or academic honors accrued by the student-athlete. This file becomes an important source of information for the student-athlete as he prepares for the process of college admissions. This file is also necessary for both the individual college football recruiters who want to take a look at an athlete and for the NCAA Clearinghouse. The NCAA Clearinghouse is the department of the NCAA that verifies and authorizes all high school grades and test scores for incoming Division I student-athletes. Without the Clearinghouse's authorization the student-athlete is not eligible for athletic scholarship. The academic advisor and the head coach are also instrumental in assisting the student-athlete in completing college application forms, letters of interest, financial aid applications, and other procedures necessary for college admission.

I attended a financial aid session at Northern and was amazed at the complicated nature of the application forms. Ms. Webb was explaining the twelve page Free Application for Federal Student Aid. ${ }^{13}$ As Ms. Webb explained Section F: 1996 Income, Earnings, and Benefits, which estimates income based on last year's income tax returns, the looks of consternation and frustration on the faces of the student-athletes matched my own reservations on whether I could successfully navigate this bureaucratic nightmare.

\footnotetext{
${ }^{13}$ This application enables the student to be considered for the following Federal Student Aid Programs: Federal Pell Grants; Federal Supplemental Educational Opportunity Grants; Federal Subsidized and Unsubsidized Stafford Loans; Stafford/Ford Federal Direct Subsidized and Unsubsidized Loans; Federal Perkins Loans; Federal Work-Study; Title VII and Public HealthAct Programs.
} 
Ms. Webb pointed out that this process is made even harder as " many of these kids" parents don't speak English." As I saw them fidgeting in their chairs, looking at each other to confirm that they were not alone in their confusion, I wondered how many of their parents had even filed a return last year.

In addition to assistance with classes, tests, and applications there is a concerted effort by the head coach to promote the student-athlete to the college football programs most likely to extend scholarship offers. Most large Division I universities have extensive scouting programs and possibly know more about the student-athletes than the kids themselves, but the smaller colleges, those at the Division I-AA, II, III, NAIA, and JUCO level don't have those resources. ${ }^{14}$ It is to these smaller colleges that the majority of these student-athletes who get athletic scholarships will be going. This is based both on the past history of these high school football programs and on the level of academic and athletic talent currently on the teams. So it is important that they get their names and qualifications out to these smaller schools. This is handled in a two step process. First, a letter is sent to the colleges by each student, giving both athletic and academic statistics as well as professing a desire to play for that program. ${ }^{15}$ Second, if there is a reply from the college, a video is sent to the college that highlights the play of the athlete. The cassette is provided by the athlete; the time to put it together is provided by coaches. The school does the mailing of both items.

\footnotetext{
14 These Divisions represent the quality of talent and level of competition in The National Collegiate Athletic Association. Division I-A represents the top 112 programs in the country, such as Florida or Michigan. From Division I-AA to Division III the talent level decreases. The National Athletic Intercollegiate Association is a separate entity whose programs are on par with the NCAA's Division II and III. There is also the Junior College league, whose athletes have typically had academic problems in high school.

${ }^{15}$ See Appendix D
} 


\section{Academic Component as Information Channel}

The academic component is primarily an information channel. Through a network initiated in the pursuit of athletic goals, information vital to the academic success and advancement of the student-athlete is conveyed. According to Ms. Webb, the academic advisor at Northern High, this information is often not readily available or easily deciphered:

When I first became academic advisor I was amazed at the administrative obstacles that these students face. I made so many mistakes those first few years. With the requirements for high school graduation, college admissions, and financial aid applications being so complicated I wonder how the average student does it. It's a shame. They make it so hard for these kids to get ahead. It took me almost three years to truly understand the intricacies of this process. Most of that was just trying to get the information. And then they change the rules from time to time to make it interesting.

By creating this channel of information embedded in a network of exchange that is ostensibly football-oriented, the coaches and academic advisors provide an invaluable source of human and cultural capital not available to the average student. These resources can influence a student-athlete's academic orientation and decisions pertaining to academics by making it possible for him to achieve success. But because of their different positions in the school structure the coach and the academic advisor have different primary motivations to provide these resources. 
The coach defers time and energy away from the athletic aspect of the program so that his student-athlete can meet the new academic requirements discussed earlier. ${ }^{16}$ For the student-athlete to remain academically eligible to play, graduate, and receive athletic scholarships to college he must meet these requirements. All three affect the coach's ability to maintain a successful program. This is not to say that the coaches do not have the interest of the student-athlete in mind, but that the advent of the new requirements has clearly expanded the traditional responsibilities of the coach and made a desire an imperative.

With their job performance not tied to the academic success of the student-athlete, the academic advisors' motivations and rewards are less tangible than the those of the coaches. The satisfaction of helping these students, the prestige of being the advisor, and the opportunity to help the football team bring glory to the school are all fine yet capricious motivations. Given the general lack of formal recognition and compensation by the schools, the academic advisors and the teachers they recruit to help are the most uncertain link in the social network. Their participation can delineate between an academic component that actually has the resources and one that merely looks good on paper. The information they possess, the time and effort they invest in both learning the information and making it accessible are important resources the coach needs for the success of his program. In this case the coach is not only a facilitator of access to resources, but also a claimant as he requests the resources of others within the school structure.

16 See Appendix A 
The student-athlete, who is being asked to spend time and effort to achieve academically, must also have incentive to lay claim to these resources. His primary motivations are connected to his desire to play football, graduate and receive an athletic scholarship which all rely on his academic performance as well as his athletic. But, because the rewards of this type of investment are not as immediately apparent or reinforced as those in athletics the student-athlete tends to need incentives that emanate from the coach and the team. This is especially true for those student-athletes who bring a negative orientation towards academics into the football program. The coach provides constant reminders of the importance of education and disciplinary measures for those who do not participate fully in the academic component. The student-athletes, especially those with a positive academic orientation, can apply peer pressure on an individual to perform academically. This peer pressure can be highly effective in small adolescent sub-cultures (Coleman, 1961, Willis,1991), and can be in the form of verbal sanctions and the development of a positive group orientation towards academic.

\section{Normative Component}

A large part of the football coach's responsibilities centers on the creation of norms and the distribution of both positive and negative sanctions. The norms can be team or classroom specific, but they are consistently oriented towards team success and the development of human and cultural capital in the student-athlete. 


\section{Team}

Team rules are often expressed formally in letters of obligation and commitment. ${ }^{17}$ These guidelines cover areas such as g.p.a. requirements, effort, obedience, and decorum. These letters are signed by the coach, student-athlete and parent and are mandatory for participation. Team rules are also expressed informally through constant verbal reminders of required conduct. These reminders can include comments on punctuality, commitment, attitude, and appropriate behavior.

Transgressions can result in negative sanctions ranging from public censure to removal from the team. Most rules and guidelines are reinforced daily through verbal instructions and the presence of written slogans and aphorisms throughout the locker room:

"No Pain, No Gain!"

"Winners never quit, and Quitters never win!"

"There is no I in team!"

"You must attend class to attend practice. You must practice to play!"

“What it takes to be No. 1. You've got to pay the price." 18

The themes of these maxims are similar to those found in the research on dressing room slogans by Eldon Snyder discussed earlier (1972). As such they reflect the ideals of the majority culture that are represented in Harry Edwards' Sports Creed (1973). These are

\footnotetext{
${ }^{17}$ See Appendix E

18 This is the title of Vince Lombardi's essay on what it takes to be a winner on the field or in life. This essay, in full, is displayed prominently in all three locker rooms. I must add that I have a personal fondness for these words, having on display in my own home a plaque of this very essay. For a look at the complete text see appendix F.
} 
daily reminders to the student-athletes of what is expected from them and what is necessary for success.

\section{Classes}

In addition to official school regulations and requirements, the student-athlete is subject to class specific rules imposed by the football program. These rules may be conveyed both formally through letters of obligation and commitment or informally through verbal reminders of expected behavior. These regulations can be as vague as urging the student-athlete to put forth effort in class to specific instructions such as requiring the student-athlete to sit in the front row or to speak only when addressed by the teacher. The grades, effort, attendance and behavior of the student-athlete are monitored

weekly by the coaching staff and academic advisor through the use of progress reports. ${ }^{19}$ These progress reports ask the student-athlete's teacher to evaluate the player's performance in class in regards to these three areas. The student-athlete is then required to turn these reports in to the coach or academic advisor. This formal process is augmented by an informal exchange between the faculty and coaches. According to one teacher at Northern High, this informal exchange is a direct result of the cooperation and trust created from the formal progress reports:

At first I didn't think these progress reports were anything but show. That changed when I wrote a negative behavior comment about one of the players. That day Coach Prince came by the Language Arts department and spoke to me about the student.

${ }^{19}$ See Appendix G 
Inever had trouble with that student again. I don't know what he said to that kid but it worked. Now anytime I'm having trouble with one of his players and I see coach in the halls I make a mention of it. He always seems to appreciate it and the problem is usually resolved.

Unsatisfactory reports can lead to negative sanctions such as the running of extra laps, public censure or even dismissal from the team. Often the coach will contact the teacher to elaborate on an unsatisfactory mark. Less frequently, but perhaps more importantly, the coach may call the parent if a problem is severe or incessant.

This process is illustrated in a situation that arose at King High. As Coach Alexander and I were walking through the halls toward the field house one of the physical education teachers came up to talk to the coach. One of the J.V. players, Emmanuel Caldwell, has given the P.E. teachers a note from his mom that says that on game days he cannot dress out. The concern here is that by dressing out, or changing into gym clothes and participating in physical education he may injure himself and not be ready for the game. This is part of a larger problem that includes six no dresses in seven weeks and a possible failing grade. Coach Alexander tells the teacher that game day is no excuse for not dressing out and that, "I will address this situation immediately, and in no uncertain terms." While the teacher's expression has changed from concern to satisfaction, the coaches' demeanor has gone in the opposite direction. Laughing and joking with me about the upcoming Florida-South Carolina football game before this conversation, he is now quiet, determined and walking considerably more quickly towards the field house. 
When we walk into the field house we find a noisy, raucous crowd, which seems to put Coach Alexander in an even worse mood. He goes into his office and calls the mother of the student and basically explains the situation to her and tells her that "if Emmanuel is not a student he is not a football player at King. Small problems build into larger issues," and he just wanted let her know. He is attempting to emphasize the importance of passing classes, whether they are physics or physical education. After he hangs up, coach lets me know that the mother was appreciative, as are most of the parents he calls. Coach Alexander believes it is his responsibility to intervene in these situations and communicate with the parents. He states that, "If we can all work together these kids will have a better chance." Some parents even come out to school after his calls to talk to him and other teachers. The fact that this is an aberration as opposed to the norm is troubling in light of the problems that these kids are facing. But Coach Alexander says that "a lot of these parents are working 2-3 jobs and just don't have the time." This statement further illustrates the need for the type of relationships being developed in the football program.

After our conversation, Coach walks out into the locker room. He surveys the scene and in an extremely authoritarian voice calls out "Emmanuel Cauldwell." He does this exactly three times. By the third time the locker room is silent and all eyes are on Emmanuel. Coach Alexander brings him up to the front and in front of the entire football team and staff. He then in a calm yet severe voice asks if the student in fact gave this note to the P.E. teacher and if he hadn't dressed out six days. As the student squirms Coach Alexander launches into him and through him into anyone else who believes that they can get away with this type of behavior: 
You are a student first and foremost and there will be no toleration of this type of behavior. Emmanuel Cauldwell you do not play today and until you show to me that you have committed yourself to school you will not play.

Emmanuel Cauldwell, as a starting and star wide receiver for J.V., will be missed. This sends an extremely clear message to the entire team. The locker room is like a tomb, and Emmanuel has become a pariah of sorts. Having been sanctioned by the coach he is now being sanctioned by the team. According to Louis, another J.V. player, Emmanuel "hurt the team. He screwed-up." When I asked Louis if Coach Alexander was too harsh his answer was "Maybe, maybe he doesn't do it in front of the team, but not really. Manny really screwed up." Surprisingly, this was similar to Emmanuel's responses, "He didn't have to do that in front of everyone" and "yeh, I fucked up. I fucked up hard."

This manner of interaction between the significant others in the life of the studentathlete represents a type of social capital that can be used to develop norms and sanctions. It also enables the coach to teach all the student-athletes an important lesson without having to sanction each one of them. The creation of norms and effective sanctions is a primary function of social capital (Coleman, 1988; Portes, 1998). The strength of this form of social capital, as well as networks of exchange and to a lesser extent transference of information, is dependent on a concept which Coleman calls "closure" (Coleman, 1990). It is generally understood that for the development of norms it is necessary to have action that imposes external effects on others, but this condition alone is not entirely sufficient (Coleman, 1988). While norms often do arise as attempts to limit negative 
external effects or encourage positive ones, they do not emerge in all social structures. The missing component in the social structure is closure.

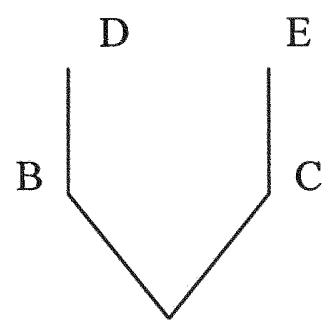

A

(a)

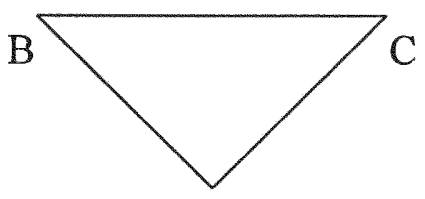

A

(b)

Figure 1 illustrates why. In an open structure like that of figure 1a, actor A, having relations with actors $\mathrm{B}$ and $\mathrm{C}$, can carry out actions that impose negative externalities on B or C or both. Since they have no relations with one another but with others instead (D and E), then they cannot combine forces to sanction $A$ in order to constrain the actions. Unless B or C alone is sufficiently harmed and sufficiently powerful vis-à-vis $\mathrm{A}$ to sanction alone, $\mathrm{A}$ 's actions can continue unabated. In a structure with closure, like that of figure $1 \mathrm{~b}, \mathrm{~B}$ and $\mathrm{C}$ can combine to provide a collective sanction, or either can reward the other for sanctioning A.

(Coleman, 1988)

This basic model of closure can be used to analyze all types of social structures, such as the situation described above with the student-athlete, parents, coaches, and teachers as the nodes of the network. Coleman refers to this as "intergenerational closure", and while the structure itself may become more complex, the presence or absence of links between its components is still the crucial factor (1990). The existence 
of these links provides the parent, coach, or teachers with social capital they can use to develop norms and effective sanctions to both encourage and constrain the studentathlete's behavior. It also plays a role in the development of networks of exchange by increasing the trustworthiness of the social environment, and helps transfer information throughout the social structure (Coleman, 1990).

In many cases it is not productive to penalize the kids who bring back negative progress reports. There may be an underlying problem such as a limited language proficiency, lack of understanding of the subject matter, or a personal conflict with the teacher. In this case, other non-punitive solutions must be considered. In conferences with the student-athlete and the teachers, at times together and others apart, the coach tries to discern the underlying issues. If the problem is due to some type of academic or language deficiency in the student-athlete the coach attempts to enlist the help of the teacher and the academic advisor to assist the student-athlete in his studies. If the issue is one of personal conflict there is an attempt by the coach to act as mediator between the two. He also often plays the role of surrogate parent, as he ensures the teacher of a change in the adolescent's behavior while taking measures to affect that change.

\section{Normative Component as Creator of Norms and Effective Sanctions}

The normative component permeates all aspects of the football program. Even more than the benefits accrued from the athletic or academic components, many of these student-athletes are in desperate need of the type of normative cultural capital developed through the guidance of an adult significant other. But this level of need is matched by a degree of difficulty in establishing a set of positive norms that requires a constant 
commitment by the coaching staff and faculty to be effective. The following are comments by Coach Thom from Norwood, and Coach Alexander from King on the level of need in the student-athlete, the amount of effort necessary to make a difference and the coaches' motivation for putting forth this effort.

Coach Thom:

I spend more time teaching these kids how to act than how to block. They just don't know. It's going to hurt them. So we try to let them know how they're suppose to act. You must give respect to get respect. We try to be role models for these kids... but sometimes we fail. And some of these kids don't want to be saved. And From Coach Alexander:

These kids are not prepared for the real world. What they're learning from their friends and t.v and even their parents isn't gonna make it. They treat people like they've been treated. Like shit. Now the Haitian kid is better. They are quieter, show respect, you can see they've been brought up differently. But it doesn't always last. Kids who came here as proper little freshman are..." (at this point we are interrupted by one of the players). There is no knock at the office door, or an "excuse me". The player, a Haitian junior, begins by saying, "Coach, I gotta talk to you. I...". The player makes eye contact with the coach. Coach Alexander's entire body communicates his displeasure at the intrusion. He is sitting straight up in his chair leaning slightly forward, his jaw is set, his brow is furrowed, and his arms are folded against his chest. This contrasts sharply to the easy manner that he was displaying just prior to the interruption. The player begins to stumble on his words, knowing that he has made a mistake. Coaches' 
words are slow and deliberate, "Jules, the first thing you are going to do is apologize to Coach Dobey and me, and then you are going to walk out the way you came in. I will speak to you later about this and whatever it is you need to talk to me about. Okay?" Jules apologizes and leaves in a much more subdued manner than he came in with. Coach and I look at each other and both of us express disbelief at the eerie timing of the interruption, coming as it did in the middle of this particular discussion, and Coach Alexander says, "See what I mean."

Also from Coach Alexander, specifically regarding the effort put forth on the progress reports:

When I get a bad progress report I begin by talking to the teacher. I want to see what's happening. Then I talk to the kid. A lot of time it's little stuff like talking in class, or coming in late. But we don't tolerate that kinda of stuff. I let them know that. I try to call the parents when I can. Sometimes they get angry with me for bothering them. Can you believe it. But most parents appreciate it. Some parents even come to school after one of my calls to talk to me or their sons' teachers. The progress reports are my best tool in keeping these guys in line in the classes. The teachers appreciate it. The kids know they have to answer to me if they screw up. It takes up more time than coaching football sometimes, and it's probable the hardest part of what I do as a coach. Not all of the kids want the help. To some of them playing football is about football and nothing else. I have a dilemma. If I keep those kids on the team they may negatively influence the 
program. If I kick them off I might have taken away their only chance at something.

The coaches recognize the need for a strong commitment to the normative component. They have also come to the realization that this aspect of the football program may be the most time consuming and the most difficult to succeed at. But they all have the desire to reach out to and help these kids develop the human and cultural capital necessary for them to become successful adults.

This form of social capital provides the coach with a mechanism to behaviorally influence the student-athlete. By communicating norms and monitoring and disciplining his student-athletes, the coach is providing the adolescent with benefits by virtue of his membership on the team. This is not to say that the student-athlete always recognizes it as benefit, but that it does provide an opportunity for the adolescent to develop both human and cultural capital. This form of social capital also benefits the coach by giving him a bargaining tool, the progress reports, with the teachers. By promising that he will discipline his student-athletes if they misbehave in class or do not perform academically, he may be able to exchange that resource for the teachers help in the academic component of his program.

The incentive for the teachers to participate in this form of social capital is relatively straightforward. They are provided with a resource, by virtue of their membership in the social network, with which to control the behavior and help ensure the academic focus of a population that has been characterized as unruly and lacking in academic objectives. This level of participation does not require a large amount of time and effort on their part and the returns are significant. 
The student-athlete's motivation for participating in this aspect of the football program is also fairly simple. He wants to play football. He doesn't necessarily want his coaches, teachers and possibly parents knowing what he is doing, or to be required to act in a certain manner, but this is the price he pays to play football. While he does not normally recognize this as a benefit of being on the team, the consistent reinforcement of desired and acceptable behavior from a significant other can influence his decision making and be extremely important to his development of human and cultural capital. This is illustrated in a discussion I had with Keith Carson, a senior at Northern who emigrated from Jamaica in 1989. We were discussing the difficulties he had with keeping himself focused in classes:

Me: Do you find it hard to stay focused everyday?

Kevin: Sometimes.

Me: How do you get refocused?

Kevin: I usually don't. Coach usually yells at me or something when he gets a bad (progress) report back.

Me: That helps you stay focused?

Kevin: You ever had him yell at you?

\section{Summary}

This model of the football program represents an extensive network of dense relationships with rich resources. Beginning with the network of exchange developed from the athletic component the coach can create access to resources in the academic and normative component necessary for the development of human and cultural capital in the student-athlete. The components of the football program must work together to develop 
human and cultural capital in the student-athlete. But for the components to work effectively it is necessary for all members of the network to put forth time and effort to make resources available and to use them to their fullest extent. These individuals can play multiple roles in the creation of social capital and their motivations to do so can vary in both type and quality. Together with the resources in the network these motivations represent variables in the creation of social capital. This suggests differentiation in the social capital of a particular football program and the resources it can make available. So

while I have presented an "ideal type" football program there is clearly the possibility and likelihood of dissimilarity between actual football programs. As a prelude to the account of the three programs I would like to address one variable that is under-represented in the discussion of social capital: the motivations of the claimant, or in this case the studentathlete, and how these motivations may affect the creation of social capital and the subsequent development of human and cultural capital.

\section{Student-Athlete Response Profiles}

While discussing the motivations of the individuals involved in the creation of social capital Portes states that the, "Recipient's desire to gain access to valuable assets is readily understandable" (1998;5). This would imply a static, passive role on the part of the student-athlete as the coach and academic advisors laid the resources before them. But it takes time, effort, and commitment on the part of the student-athlete to develop skills in football, improve on SAT scores, and break from patterned social behavior. If the benefits he receives from the investment of his resources are not perceived as sufficient, his participation will diminish. Also differences in the student-athletes' needs, 
their ability to obtain resources from alternative sources, and cultural differences in the tendency to ask for aid or value the resources being offered can affect the benefits they lay claim to (Coleman, 1988). These two factors can also affect the ability of the coach to develop social capital by making it an unwanted and underused resource. By viewing the student-athlete as an active and variable aspect in the creation and effects of social capital a clearer understanding of the results of his athletic participation can be achieved.

In each of the three components I have indicated the student-athlete's motivations to lay claim to the resources made available to him. For each individual the combination and intensity of the motivations for joining the team and participating in the programs vary. These motivations factor into the relationship the student-athlete develops towards the coach, his teammates, and the social capital made available to him. While conducting this study I found that each student-athlete's relationship to the football program is unique. Each individual had a status on the team and a need for and a reaction to the social capital just discussed. Statuses ran the gamut from the star player to the bench sitter, from the emotional leader to the team clown. The needs of the student-athletes are also diverse. Among the student-athletes are individuals who are involved in advanced placement programs along with those in remedial classes. Individuals with arrest records and drug problems are playing side by side with dedicated members of the neighborhood church. The student-athlete's reactions to the different components of the football program ranged from enthusiastic acceptance to rejection and contempt. Since the student-athlete's relationship toward the program can affect the development of human and cultural capital it is necessary to discuss these needs and attitudes. 
I have collapsed the wide range of relationships into three ideal-types. These ideal-types are based on two criteria: perceived need of assistance and orientation toward the programs. Perceived need was measured by the student-athlete's g.p.a.. A g.p.a. below 2.0 ( the level needed for new participation and graduation requirements) was considered an indication of extreme need. A g.p.a. higher than 3.0 was perceived as a relative lack of need for assistance. While this measure indicates a disposition toward the academic component I found justification in my research for this bias. Given the poverty in the neighborhoods surrounding these schools, few if any of these student-athletes have access to a weight room comparable to those at the high schools. Also, the opportunity for college athletic scholarships was virtually limited to those who play high school athletics. This created a common need among the student-athletes for the athletic component of the football program. In regards to the normative component I found a positive correlation between g.p.a. and behavior, reminiscent of Coleman's findings in The Adolescent Society (1961). The higher the g.p.a. the more receptive the studentathlete was to the normative component of the football program. This situation clarified the process of categorization and allowed me to capture the majority of student-athletes with the simple distinction of those who have a perceived need for assistance and those who don't based on g.p.a.

The student-athlete's orientation toward the program was determined by his actions and attitudes. Behaviors such as high involvement in the off-season conditioning programs, a strong commitment to improving his g.p.a. and test scores, and a consistent adherence to the normative codes of the program constitute a positive orientation. Comments that reflect contempt or disregard for the football program would constitute 
a negative orientation. Obviously each student-athlete was not always consistently positively or negatively oriented toward the football program. I determined a studentathlete's orientation by his aggregate actions and attitudes. By analyzing and combining the levels of need and the orientations of the student-athletes I have devised three idealtype relationships that represent the wide range of variations in the study population:

1. Student-Athletes who have a perceived need and have a negative orientation toward the program.

2. Student-Athletes who have a perceived need and have a positive orientation toward the program.

3. Student-Athletes who do not have a perceived need, but do have a positive orientation toward the program.

What follows are profiles of three individuals who are reflective of these idealtypes. Included in the profiles are both researcher's observations and student-athlete's comments. Specific details, such as names, have been altered to protect confidentiality, otherwise the profiles are presented as recorded.

\section{Reggie}

Reggie is an African-American. He is 18 years old, 6'2" and $195 \mathrm{lbs}$. His hair is "corn-rowed", and he has a large diamond stud earring in his left ear. Reggie plays linebacker at Norwood and has a reputation, both on and off the field, for fighting. Reggie was the student-athlete who was involved in the altercation with the coach described at the beginning of this thesis. He rarely if ever speaks, unless it is to "crack" on someone or something, and always finds his way to the back of the class, huddle, or any situation. He lives with his mother and father, both of whom work for the county, 
and feels "that they always tryin' to get all up in my bisness." He has a 1.7 grade point average.

In addition to the fight described at the beginning of this thesis there was a situation in study hall that further convinced me that Reggie had a negative orientation towards the football program. While I was supervising study hall one of the AfricanAmerican sophomore players asked me for help with Algebra. This is when Reggie and I first began to get to know each other.

Reggie: Nigger, you better ask for help 'cause you too small to be a football player. You better leave playing to me.

Me: I bet you he'll get into college before you will.

Reggie: Aw man, get real.

Me: What's your g.p.a.?

Reggie: It don't matter.

Me: Have you taken the SAT's or ACT's?

Reggie: Not yet.

Me: Are you in the test prep class.

Reggie: No

Me: Looking down at the student I'm trying to help, but in a voice loud enough for everyone to hear I say, “Don't worry he'll treat you better when you ask him to super size your value meal."

This statement provoked an angry look from Reggie and laughter from the rest of the team at his expense. This laughter had a peculiar affect on Reggie. After looking around at his teammates laughing at him he broke into a smile. I took this smile as an 
acknowledgment of my verbal sparing victory. I believe it was my ability to deliver that comeback that allowed me to get closer to Reggie and many of his teammates.

The implicit message behind Reggie's statements was that if you had the athletic talent it wasn't necessary to apply yourself in the classroom. This attitude is an indicator of an adolescent sub-culture that is detrimental to the development of human and cultural capital. As a result of Reggie's comment and the subsequent attention the student-athlete who originally asked me for help declined my assistance after the exchange. He stated, "No that's okay, I figured it out." It is more likely that he was intimidated and embarrassed.

Reggie's life away from school revolves around hanging out with his friends, girls and drinking. This is vividly illustrated by an account of a trip to a strip club. This conversation was overheard during the summer while I and about thirty members of the Norwood football waited for a coach to show up and unlock the weight room.

It seems that at least three of the players, including Reggie, had been hanging around the neighborhood one night getting drunk on Chivas Regal and decided that they were going to go to a strip club they had frequented before. Their description of the women was graphic, "That fuckin' whore had a huge pussy. That pussy would eat your Nigger ass right up!" The other students were alternately in awe of the three and disbelieving that they even went. When one of the younger doubters suggested that he come along next time Reggie responded "Nigger you just a child. You ain't even got dirt yet." Dirt referring to a beard or mustache. Talking to Reggie later on about this he intimated that he is seeing one of the girls and that is how he and his friends get in. 
Reggie expects to get a football scholarship and play professional football somewhere, anywhere. "The CFL, Arena, over in Europe it don't matter. As long as I get paid." According to Coach Thom, Reggie has the size and talent to be recruited by a small Division I or I-AA team. In fact two I-AA teams have expressed an interest, Samford and Alcorn State, but when they reviewed his academic file they declined to offer a scholarship. Mr. Banner points to Reggie's declining g.p.a. and his reluctance to take one of the standardized tests as the reasoning behind the recruiter's decisions:

They're looking for someone who, if not a scholar is at least showing an effort, some improvement. Reggie seems to be going in the wrong direction. When the recruiters came and told him his grades were the only thing holding him back, he would try for a week or two. You could see it. But it doesn't last. And I can't seem to help him.

Reggie doesn't like to talk about his parents. He believes that they are out of touch and have no idea what it's like to be a Black teenager. He has even gone so far as to call his father an "Oreo" (Black on the outside, White on the inside), because of his supervisory position with the county and his disdain for the African-American street culture Reggie embraces. This conflict between the two has led to Reggie moving out on several occasions to live with friends and girlfriends. He was living at home at the time of this study.

For Reggie football is a means to play more football. He has not attempted to access the resources made available to him, except those of an athletic nature, despite reminders by his coach, academic advisor, his parents and myself that at the very least he needs to achieve in school to obtain an athletic scholarship. The situations described 
above and at the beginning of this thesis indicate that he, and individuals like him, can create an atmosphere within the football program that limits the ability of the coach to develop strong social capital by discouraging others to lay claim to the resources made available to them.

Reggie's participation in the football program has not led to the development of human and cultural capital, but may in fact have negatively affected that development. By maintaining the illusory goal of the riches and fame of a professional football career, he most likely sentences himself to the reality of a more desperate life. According to some of his teammates Reggie moved in with his stripper girlfriend immediately after graduation. He is working as a bouncer at the strip club and another bar in the area. According to Coach Thom, Reggie never did take the SAT or ACT, and for all practical purposes dropped out of school after the football season. He was able to graduate. Repeated attempts to contact him have been fruitless.

\section{Roland}

Roland is an 18 year old African-American. At 5'11" and 210lbs., he is a large young man, although he does run more towards obese than muscular, which might explain his being a back-up offensive lineman at King High. He is a fun and boisterous individual who could easily be designated the team clown. But this attitude, as well as his inclination to use profanity, tends to get Roland into trouble in class and on the team. The second day I was at practice, he stood next to me and announced to everyone that I was from the Herald and I was here to interview him. Coach Alexander overheard him and said "Yes, they're doing a story on kids who ride the pine!" to which everyone including Roland laughed. He lives with his mother and father who are both self- 
employed. He has a good relationship with both of his parents and currently has a 1.8 g.p.a.

Despite his frequently foolish behavior, Roland has a positive attitude towards the football program. After letting me attend a summer school class with him and witness the tedious and unruly nature of his class he had this to say:

I'm taking English IV to get ahead. Ms. Johnson (academic advisor) says if I can get $a B$ in this class and then concentrate on my math and science courses next semester I could get my g.p.a. over 2.0. With a decent SAT score maybe I can get into college somewhere. This is want I want. Coach tells me that if I work out over the summer, get my grades up, I can maybe get picked up by someone. It doesn't matter who. Coach is helping me out. He says he'll talk to recruiters for me. But, he says I gotta act straight. That's the hardest part. Man, I like to have fun. But he's right. I gotta get this thing going.

Roland likes to "hang" with his friends when he is away from school. Some of these friends attend King, some go to Eastern. Eastern is the high school that also serves Liberty City. Two of the Eastern students play high school basketball. None of his friends play high school football. Having seen Roland with his King friends I was able to witness a harder side to Roland. He cusses constantly, throws disses (insults) around, and even changes his walk to more of a strut. He says that his friends play ball, hang-out, maybe drink a little, smoke a "blunt" (marijuana). When I expressed some concern over this he said, "It's just fun, man. We're not crack heads or nothin'."

Both of Roland's parents encourage him to get an education. He says that they are disappointed with his poor performance in school, but "they're not dicks about it." 
Although he has had disagreements with them over curfews, his friends, school, he believes that they are "just being parents, doing that parent thing. That's cool. It's nice to know they care."

For Roland football is a means to get a college education. He says, "We don't have a lot of money. If I can get someone to pay for my college then I don't have to bother my parents about it. If I don't I'll still try to go to school." During summer double sessions practices Coach Alexander commented that Roland's improvement both mentally and physically was "encouraging. Maybe I can get him into Division III or a junior college somewhere. He's got decent size. Maybe we can stretch him out somehow to 6' or 6'1. Maybe he'll grow a little. That would help. But he's showing academic improvement that's the most important thing."

Roland's motivation for playing football wasn't always centered on getting a college education:

I started playing football with my friends when we were like 9 or something. It was fun. Then in high school we wanted to get some play (popularity with women) and so we played sports. I didn't dig the idea of running up and down that damn court so I played football. Some of my friends played football some played basketball. All my football friends quit with all the losin' and stuff. My parents encouraged me to keep playing ball. They were always talking to Coach Evans. I don't know, I just stuck with it. And here I am sitting on the bench talking to you!

Roland isn't playing football for anyone. But he enrolled at Miami-Dade community college in the summer of 1998 and plans to get a degree in business after 
finishing his A.A. He comes back to King often to lift and to talk to coach. This is where I saw him in August. We lifted together and talked about the decisions he had made in his life and the situation he now finds himself in. He said he likes where he's at, he knows he's headed in the right direction, but "I wish I had started getting it together earlier."

Roland's motivations for participating in the program changed from being focused on the immediate benefits of playing football such as recognition and popularity, to more long-term goals of getting an education both at the secondary and college levels. This type of student-athlete represents the largest percentage of the studies population. Individuals such as Roland, given access to the resources to succeed, can begin to develop meaningful human and cultural capital.

\section{Len}

Len was born in Jamaica in 1982 and moved to Miami in 1992 to live with his grandmother. He has dark black eyes and skin, with short black hair. A talented running back on a below average team, Len is $5{ }^{\prime}{ }^{\prime \prime}$ ' and $1751 \mathrm{bs}$., and has 4.4 speed in the 40 yard dash. He now lives with his mother, who "is my closest friend." He has a 3.1 g.p.a.

Len is articulate with a quiet, yet intense demeanor, and while somewhat guarded he is amiable once he gets to know you. His position as a team leader and his orientation towards the football program were illustrated by the way he introduced himself to me. At the second study hall I supervised he stepped up and asked "Coach Dobey can you help me with factoring radicals?". He said this loud enough for the entire locker room to hear. Not having factored radicals for about 12 years it took me a few minutes to refresh my memory. He stood there patiently, with his back to the other student-athletes, as I 
studied the problems. Once I figured out the necessary operation, I explained it to him in simple terms. He responded with a louder than necessary "Thanks a lot," and walked back to his locker. He was the first student to ask me a question and it was only after this that I began to get a steady stream of students. In a later conversation he confirmed a hunch I had that he had staged the whole thing:

Oh yeah. I knew how to factor radicals. But you looked so lonely up there I had to do something (He says this with an impish grin on his face). I also wanted to find out if you knew what you were talking about. It's important that these guys get help. I knew if I went up there others would follow. From what I hear you've been doing a good job.

Football is an outlet for Len. It allows him to "relax" and just concentrate on running the ball. His mother encouraged him to play football when she came over from Jamaica in 1993 to join him and his grandmother. He had played some soccer in Jamaica, but didn't participate in organized sports in the U.S. His mom thought "football would keep me off the streets and help me fit in." He is proud of his athletic abilities but believes that academics are much more important. Coach Alexander and the football program "reminds me on a daily basis that I need to work hard. Sometimes I need that. I can get lazy sometimes." Len wants to use his football abilities to provide opportunities for his mind.

Len wants to become a doctor. To that end he is taking pre-med courses at the University of Miami. Between these classes, studying for high school, and football "I don't have the time do much else." Len is encouraged in this endeavor by his Mom, who 
is a nurse, an uncle who is a doctor in Jamaica, and his grandmother who he says is "constantly on my butt about my grades."

Len's motivations to play football are complex, but clearly the primary goal is to use it as an opportunity to get a medical degree. As you might expect, these types of student-athletes are few in number within the population of this study; but they can have a strong positive affect on the football program by being team leaders. Just as the coach's job may be hampered by Reggie-type student-athletes, his ability to create social capital and influence the student-athletes is aided by individuals such as Len.

Len has received a full athletic scholarship at a Division I university and is currently enrolled in a pre-med curriculum.

\section{Summary}

While the student-athlete response is ostensibly a function of the social capital and resources being made available, it must also be taken into account that these individuals come into the program with prior experiences and preconceived ideas about football, education, and conduct. These can affect the orientation of the student-athlete towards the opportunities and resources being made available to them. This orientation and the behavior that springs from it can have a dual impact on the effects of the studentathlete's participation in the football program. First, the student-athlete's orientation towards the resources being made available to him can determine the extent to which he will lay claim to these resources. If the student-athlete is not motivated to lay claim to the resources made available to him due to his membership in this football-related network the benefit of his participation in the football program is diminished. This negative orientation may also affect what can be made available to him. As mentioned 
earlier the motivations to make resources available to the student-athlete can be instrumental or expressive in nature. In either case the coaches and staff are trying to achieve certain goals or fulfill their needs. If the student-athlete refuses to use the resources being made available or reacts to them in a negative manner, this would diminish the motivations of the adults by negating their ability to reach their objectives. The former situation is a key characteristic of social capital; it diminishes or dissolves without constant use and reinforcement (Bourdieu, 1983; Coleman, 1990). The latter scenario is best illustrated by a quote from a teacher at Norwood who had occasionally agreed to tutor the varsity football players, but has recently declined to do so:

That whole academic initiative thing is just lip service. The coaches don't really care about education just about grades. And it shows in the kids. I'd go in there to tutor them for the SAT's and it was like a zoo. If they showed any interest, it was in how to beat the system. The tricks. After a few days of that I didn't want to go back. I thought maybe it was me, but some other teachers said the same thing. That made me feel better. It's not like we don't want to help, but you know, you can't force it down their throats. (The individual asked to remain anonymous) It follows then that a higher proportion of student-athletes who have or develop a positive orientation towards the academic component make it easier for the coaches and staff to provide those resources. On the other hand, the larger the number of studentathletes with negative orientations can also affect the creation of social capital by developing an environment and group mentality that is hostile towards accessible resources and the individuals making them available. These scenarios can pertain to any of the three components, although the likelihood that the student-athlete will have a 
negative response to the athletic component is less than towards the academic or normative. It must also be understood that the student-athlete may have conflicting responses to different aspects of the same component. This is best illustrated in the athletic component where the student-athlete may have positive responses to the games and the workout sessions, but despises the practices. The creation of motivation in the student-athlete by the coach and staff through verbal and written reminders, sanctions, and incentives must be a high priority when dealing with negative individuals. The interplay of the three components in creating and reinforcing these motivations is an integral aspect in the development of social capital in the football program. 


\section{Chapter VII: CASE STUDIES}

The argument of this thesis is that it is the level and type of social capital and the resources it makes available in the football programs that is a deciding factor in how participation affects the development of human and cultural capital in a group of Black minority males in Miami-Dade County. Having described the types of social capital that can be created in these programs and illustrated typical student responses, it is now necessary to begin the depiction of the social capital and resources present in each program.

For this thesis I will be concentrating on three aspects of the conceptual model discussed earlier that I believe are reflective of the overall social capital existing in each football program: the summer workout program, progress reports and the involvement of the academic advisor. The summer workout program is for many student-athletes the first experience they have with the football program. It provides an opportunity for the coach and the student-athlete to develop a relationship based on trust and the exchange of obligations. Progress reports monitor the grades, behavior and effort of the studentathlete in his daily classes. The reports are part of the normative component of the football program and rely on closure to create norms and effective sanctions. The involvement of the academic advisor is a vital part of the football program's academic component and can play a significant role in the normative component. Not only is the advisor a primary source of information and assistance, but can also facilitate the involvement of other teachers into the program. I will use the behavior of the studentathletes in the respective study halls as an indicator of both their reactions to the 
resources made available to them and the effects of their behavior on the creation of social capital.

\section{King}

The summer workout program of the King High football team began on June 16 and ended on August 8. There were two workout sessions each day, at 10-12 p.m. and 68 p.m. These times were determined to accommodate those student-athletes who worked and/or went to summer school. These sessions were held four days a week Monday through Thursday, for a total of 64 possible workout sessions available to the studentathlete. The student-athlete was required to attend three workout sessions a week. These sessions consisted of conditioning and lifting regimens that were both prescribed and monitored by the coaching staff. Each student-athlete was tested for strength and conditioning at the beginning of the summer, urged to progress during the summer, and then tested again for improvement at the end of the summer. Both attendance and physical achievements (i.e. bench press, squats) were documented on a large poster board in the weight room. Coach Alexander believes "games are won or lost in the off season...they're going to have to give me everything they've got and I'll do the same." Of the 64 possible sessions only 6 were canceled (three of those due to repairs being made on the field house). Of the thirty-six players who started the summer program, twenty-eight averaged three sessions a week. Four players moved away, and four players quit. The coaches offered their time, expertise on lifting and conditioning, access to the weight room, and from time to time counseling. They created and demanded a businesslike, hardworking environment in the weight room and did not tolerate horseplay or 
loafing. Those student-athletes who were disruptive of this atmosphere were asked to leave and were not given credit for attendance that day. With the exception of the head football coach, there was no monetary compensation for the four coaches who were the most instrumental in ensuring this program's success. The three volunteer coaches were, as one of the coaches stated, unanimously motivated by a "desire to help these kids out. We are the men of this community and it's about time we give something back to it." Only one of the coaches expressed an interest in coaching as a profession. In return the majority of the student-athletes were willing to give their time, effort, and commitment to improve themselves and the team. This exchange accomplished two things. It provided the access to resources both the student-athlete and the coaching staff need for their success and it created a dense network of exchange built on trust that could be used to facilitate the other two components of the football program.

Coach Alexander handles all progress reports for the King High football team. Each Monday afternoon during both Fall and Spring semesters the student-athlete is given a blank progress report to be filled out by his teachers and returned on Wednesday afternoon. By requiring that the report be back on Wednesday during the season Coach Alexander is able to respond to a negative progress report before the game each week. Responses can vary from situation to situation depending on the nature of the problem. If a student neglects to turn in a progress report, or turns in an incomplete form, he is held from that week's game. This ensures $100 \%$ participation from the student-athletes, because they know from the summer sessions that if the coach says he's going to do it he will. 
A negative progress report resulting from a lack of effort, attendance or improper behavior typically initiates a two-step process. The first step involves Coach Alexander consulting with both the student-athlete and the teacher as to the reason behind the negative report. The second step is the action taken to help resolve the problem. When Donald, a Haitian-American senior, turned in a progress report indicating that he was involved in improper behavior over the last week Coach Alexander spoke with his math teacher the next day. According to the teacher Donald likes to sit in the back of the class and "chatter away all period." Coach Alexander indicates that Donald has broken two teams rules. First, all football players are required to sit in the front of the class. Secondly, by talking out of turn in class "he has embarrassed the team and himself by his behavior." Coach Alexander ends the discussion with the teacher by letting her know that "this behavior will not be tolerated." It is his practice to try and talk to the teacher before he talks to the student-athlete because, " usually the kid will first try to deny everything. If I can say I've already talked to Ms. So-and-so, it usually takes a lot out of him. I can then get his side and try to figure out what to do about it." In this case Donald was re-instructed to sit in the front of all his classes and to show respect to the teacher, the team, and himself by not acting-up in class. He was also told he would be doing double the amount of sprints in practice that day.

This was not a serious offense and obviously did not warrant a severe response. But as seen in the situation involving Emmanuel Cauldwell in the normative component section, Coach Alexander is capable of meting out stronger penalties if he feels the situation requires it. He also does not hesitate to inform parents of the situation when he feels it is appropriate. Coach Alexander has been successful in creating closure in the 
social relations of the student-athlete within the context of school. He has also attempted to extend that closure to the most significant adult(s) in the student-athlete's life. This closure creates a dense and extensive network that enables him to enforce norms that assist the student-athlete in understanding what behaviors are appropriate and which ones will be detrimental to his development.

Progress reports also record the student-athlete's academic performance. If the student-athlete receives a negative mark for grades Coach Alexander attempts to enlist the help of the teacher to assist the student-athlete in his studies. Coach tries to accommodate the teacher's schedule by allowing the student-athlete to miss parts of practice if this is the only time the teacher can tutor the player. Coach Alexander laments the time taken away from practice but is forced into this arrangement because, " $I$ haven't been able to get the teachers who tutored for Coach Evans to continue. Most of them say that they were really too busy to do it in the first place, but that Coach Evans was, you know, really insistent." The information channel was embedded in the relationship between Coach Evans and the teachers. Now that he is gone that social capital has dissolved, to the detriment of the student-athlete. Coach Alexander says he might have a couple of teachers who are going to try and help but for now he has to rely on the student-athlete's teachers and on my help in study hall. This lack of assistance limits the amount of resources available to student-athletes most noticeably in the area of preparation for college exams. The student-athletes at King do not receive any tutorial instructions in regards to the SAT or ACT exams. With these test scores being so important to the distribution of athletic scholarships and college acceptance this is a major weakness in King's academic component. Because the assistance the teachers 
provided was not a formalized or institutionally controlled program, Coach Alexander must begin to develop obligations and trust between himself and the teachers, so that he can lay claim to their resources in the name of the student-athletes. His prompt handling of problems presented through the progress reports is a good beginning. He must convince the teachers that either they owe him and his student-athletes assistance because of this, or that providing resources to the student-athlete will reward them sufficiently to compensate for the time and energy spent in the manner of social approval or personal satisfaction. Until he is able to do so there is for the student-athlete a deficiency in social capital in regards to the academic resources that exist within the network.

This situation has been partially caused by the fact that the football team's academic advisor is no longer in a position to be able to conduct study halls or tutoring sessions. Ms. Johnson, as the new head of the guidance department, wishes she could do more to help the players but, "I just don't have the time. Last year, before I became head of the department, we had several teachers who helped out, but now they're no where to be found, and I'm up to my ears in paperwork." In the role of academic advisor Ms. Johnson counsels the student-athletes on curriculum choices and college admission requirements. She is also able to instruct the team on applications for the entrance exams, financial aid, and college admission, but unlike the last three years she is unable to provide tutoring on the college entrance exams. Two years ago she had begun to keep records of the student-athletes' academic and athletic accomplishments for college recruiters, but is admittedly "falling farther and farther behind." While Ms. Johnson understands that more needs to be done for these student-athletes she believes that this program makes a difference: 
The earlier we can reach these kids with the facts about school and

graduating the better chance we have of setting them on the right course. We also have to provide them with the necessary instructions and tools. There is an old adage that says "You can lead a horse to water, but you can't make him drink." Well if there is no water it doesn't matter if he wants to drink or not. Without this help, you know, by the time they get to be seniors it's too late.

Ms. Johnson's statement's reflects a key aspect of this thesis: The student-athletes must be provided with the necessary resources for them to develop human and cultural capital. This fact stands apart from any discussion of the student-athlete's motivations and shifts the onus of education back towards the school and its staff as opposed to the individual student-athlete. This does not relieve the student-athlete of responsibility, but merely points to the interaction between the members of the network as they try to achieve certain goals.

The majority of student-athletes at King High were eager to lay claim to any resources that are made available to them. This was evident during the time I spent as supervisor of their study hall. Held in the locker room, which is filled with reminders of academic requirements and exhortations to excel on and off the field, these one-hour sessions between the end of the school day and the beginning of practice gave the student-athlete an opportunity to work on his class assignments. Because of the lack of teacher assistance these sessions were normally supervised by a coach and did not involve tutoring. One day each week I took over the supervision of the session and attempted to assist the student-athletes with their studies. I observed a number of reoccurring behaviors that lead me to believe that there had been what is referred to as an 
"internalization" of the norms and importance of education emphasized by Coach

Alexander. I found that many of the student-athletes, especially those seniors who had been in the program four years, had made the decision to invest their time and effort in the development of important human and cultural capital. The first of these situations involved the role of the senior team leaders in keeping their teammates quiet and focused on their studies. With over 60 players, both the varsity and junior varsity squads, in the one room it can get rather loud. Whenever the senior players sensed that the noise level was beyond acceptable levels one of them would step to the middle of the locker room and calmly say "keep it down, get it straight." When I asked Len what "get it straight" meant he said, "it means get your head straight, study." Often the player didn't have to even say a word, as the locker room would quiet down as he walked to the center of the room. Of the twelve times I supervised study hall the coach only had to step out of his office once to quiet the room.

There was also an eagerness to ask for my assistance. The seniors and juniors initiated the process, Len's little act being the first and most visible, but they also encouraged others to step forward and participate. This allowed others to follow suit without fear of ridicule or derision. In fact those who didn't step forward or were not studying were subject to verbal sanctions by their teammates. This took the form of little jabs like, "What, are you too stupid to ask questions?" or even, "What, are you afraid of the white man?" The latter made me a bit uncomfortable, but it seemed to work and not be too militant as it was delivered in a playful manner like a parent talking to a child about the monster underneath its bed. 
Finally, whenever I missed a day or had to switch my schedule I always received feedback from the student-athletes: "Where were you man? I needed your help," "What did you forget about us?" or "Are you slacken' off again?" They were negatively sanctioning me for not providing them with a resource they wanted. Had they been indifferent or had access to the same resources from another source, I doubt I would have been subject to this banter.

These three sets of behaviors indicated to me that getting an education had become a priority in their lives. They were also aware of and willing to enforce normative behaviors that were conducive to this goal. The coaches at King High had been able to not only convince the student-athletes of the importance of education, but had also provided the necessary resources to make investing time and effort into getting an education a rational choice. ${ }^{20}$

\section{Discussion}

The social network of the King football program is extensive but lacks the participation of a segment of its members in the creation of certain forms of social capital. Through the athletic component Coach Alexander has been able to develop trust and obligations between his staff and the student-athletes and is then able to use that relationship as a network of exchange for other resources. He has also been able to maintain the closure achieved during Coach Evans' tenure, necessary for the creation of norms and effective sanctions.

Unfortunately, he has been unable to get the teachers to agree to provide access to

\footnotetext{
${ }^{20}$ Here I'm taking into account that these juniors and seniors had possibly $2-3$ three years of access to a wider set of academic resources under the previous coach, which differentiates them from those studentathletes who have just begun their participation.
} 
resources such as tutoring and preparation for college entrance exams that are vital to his student-athletes' academic success. This has diminished the amount and type of resources he is able to make available to his student-athletes. The resources available to the student-athlete are thus diminished not by a lack of resources within the network per se, but because they do not possess accessibility to them or in other words social capital. This lack of accessibility is rooted in the nature of the relationship between the Coach Alexander and the teachers. This assertion is based on the fact that a number of the teachers who had provided these resources to Coach Evans and his student-athletes attributed their participation to Coach Evans' insistence. The change in the coaching position, coupled with the changing role of Ms. Johnson, has created instability in the network to the detriment of the social capital and resources the program could provide.

Nevertheless, Coach Alexander was able to place five out of his twenty seniors in college with athletic scholarships. This is from a team that went 2-8 in his first year and $0-10$ the previous year. Also six others have registered for college on their own and all 20 seniors graduated high school that year.

\section{Northern}

The summer workout program at Northern began June 9 and ended on August 8 . There were five sessions a week, Monday through Friday, from 6-9 p.m. Coach Prince created this schedule because, "most of my kids go to summer school or work, and all my coaches have jobs." Out of the 45 possible sessions only three were canceled, one of those due to an electrical outage. Coach Prince was assisted in supervising by two assistant coaches who were employed at Northern as security guards. These individuals 
also receive compensation during the regular school year as varsity assistant coaches. The student-athletes were required to attend three sessions a week. Unfortunately attendance was taken erratically and even some of these sheets were lost. Coach Prince was able to informally monitor the attendance of the student-athletes and a number of times I overheard him counseling a student-athlete on his "commitment to the team and himself". The atmosphere in the weight room at Northern was decidedly different from at King. With at least two radios playing at all times, the room seemed more like a disco than a weight room. The kids were loud and rambunctious, constantly jawing at each other and practicing feats of one-upmanship as they lifted. The coaches were for the most part oblivious to this cacophony, attempting to quiet the din only when Coach Prince appeared or when they couldn't hear themselves speak. I only saw one studentathlete asked to leave, and then it was only when he began to pick a fight with another player.

Despite the dissimilarities between the two programs there were three aspects of these summer sessions that were the same. First, the student-athlete could almost always count on access to the weight room at the scheduled time. Second, there was a great deal of work being done in both programs--different styles, but the physical improvement of these athletes was impressive. Finally, there was no cursing, no loafing, the coach was not someone to disrespect, and there were no fights or altercations. Both programs were building networks of trust and exchange and helping the student-athlete develop human and cultural capital by giving him access to the weights and acceptable norms.

Progress reports are handled initially by the academic advisor, Ms. Webb. Each Friday morning during the football season the student-athlete is required to pick up a 
progress report from her classroom and return it, completed, by Monday afternoon. After reviewing the progress reports she sends the negative reports to Coach Prince.

At this point the process at Northern for handling negative attendance, effort, and behavioral reports is similar to that just described for King High. There are two significant differences. First, Coach Prince is more draconian in his punishment, especially for behavioral problems. If a student-athlete has a negative behavior report, coach will often require the player to perform extra running drills after each practice until the student-athlete turns in a positive report the next week. He says this "helps remind them of what their goal is." Secondly, Coach Prince does not involve the parents as much as Coach Alexander. When asked about this he replied, "I try to keep it between the kid, his teacher and me. That way the kid doesn't think I ratted him out." This practice limits the amount of closure for the relationships involving the student-athlete. But, Coach Prince has been successful in creating a high level of closure within the school context. This closure and the effort put forth by Coach Prince allows for the development of strong norms and effective sanctions through a dense and extensive network. This was best illustrated by the teacher's comments in the normative section where she stated that after sending in a negative report to the coach that she, "never had trouble with the student again."

The academic component at Northern High is superior to that at King High. This is due mainly to Ms. Webb's involvement. She has implemented every aspect of the academic component described above. She persuades teachers to help with tutoring through constant persistence and the motto, "Let's help someone before they develop a problem." Ms. Webb instructs the student-athletes on health and nutrition, exhorting her 
kids not to skip breakfast. She has helped some of the players get on the free lunch program. She handles the instruction for college applications, financial aid forms, and recruitment letters. Ms. Webb counsels the student-athlete on what courses to take so that they can meet the NCAA requirements. She discusses the graduation rates and attributes of colleges that recruit the student-athletes in her program. Ms. Webb handles the tutoring for the English section of the standardized tests as well as coaching on test taking skills. She enlists a few of the math teachers, and at times me, to help these kids with the math sections. She does all this because, "It makes me sick when I see a kid who could go to college and make something of himself fail to get the help he needs."

The commitment by both Coach Prince and Ms. Webb is crucial in helping these student-athletes develop human and cultural capital. By working together they create a dense network rich in resources not normally available to many students. Michael, a Jamaican-American senior at Northern, illustrates the effect that this social capital has on his life when he describes the differences between the football program at Northern and the one he was in at Beach High for his freshman and sophomore years.

At Beach it was all about being a man on the field. That's all that mattered. No one ever talked about grades. No one ever said you've got to do this and this to get into college. When we moved into this area and I found out I was going to have to switch schools I was pissed. I was going to be a starter at Beach. And when I got here people started talking to me about my grades and how I acted in class, man I don't know. But thank God it happened. I have a chance now to go to college. I wouldn't have had that chance at Beach. I had like a 1.7 at Beach 
now I have a 2.2. If I can work hard these last two semesters and do well on the

ACT I'm there man. If I had stayed at Beach I would have been going nowhere.

Because of the extensive involvement of Ms. Webb the seniors and juniors at Northern have tutoring sessions each day instead of study hall. ${ }^{21}$ As mentioned above these sessions touch on numerous subjects and allow the student-athlete access to important information. The response of the majority of the student-athletes to this form of social capital is overwhelmingly positive. They bring their athletic competitiveness into the classroom and try to outdo each other by answering questions correctly, performing better on the SAT/ACTs, and reaching higher g.p.a. levels. Many of these student-athletes have taken the college entrance exams several times in the hopes of improving their scores. They ask each other about their grades and scores not only while in these sessions, but at practice, in the locker room and in the halls.

Getting an education is part of these student-athlete's discourse. They give each other a hard time if they think that someone is slacking off. They have developed a group mentality that, having been initiated by the coach and academic advisor, has now taken on a life of its own that fosters a positive academic orientation and the development of human and cultural capital. While I found a similar situation at King, the student-athletes at Northern have taken it to another level. This level of commitment and enthusiasm for

\footnotetext{
21 The freshman and sophomores attend a more traditional study hall. Once or twice a week Ms. Webb is able to arrange for an English or Math teacher to attend the study hall and tutor the student-athletes. I only attended three of these sessions, one with a teacher and two with a supervisory coach, and found them to be louder and less focused than those at King. I believe that the younger players suffered somewhat from the lack of leadership from the older players and had not been part of the football program long enough to develop actions and decisions in reaction to the expectations and obligations set forth by the coaches.
} 
education makes Ms. Webb's task that much easier, and enables her to convince other teachers that assisting these kids will be a rewarding experience.

\section{Discussion}

The football program at Northern is a dense network, rich in resources of the type necessary for the development of human and cultural capital in the student-athlete. This level of social capital is made possible through the cooperation and commitment of Coach Prince and Ms. Webb. In fact, it is Ms. Webb's contribution to the academic and normative components that sets this football program apart from the other two. Through her own efforts, her ability to recruit other teachers, and the five years of stability that she brings to the program, Ms. Webb has been able to build upon the network of exchange developed by Coach Prince in the athletic component. The two individuals have also been able to create closure in the student-athlete's network, which allows the creation of effective norms.

The student-athletes have responded by making concerted efforts to lay claim to the resources that are made available to them. Subsequently, Coach Prince and Ms. Webb were able to place six out of the sixteen seniors from a 1-9 team in college with athletic scholarships and another four are known to have registered for college on their own. In addition all seniors who started the season with the program graduated.

\section{Norwood}

The summer workout sessions at Norwood did not, for all practical purposes, exist. Scheduled to begin on June 16 and run until August 8, four days a week from 6:30- 
8 p.m., there were only seven workout sessions out of the possible thirty-two. One of those workout sessions resulted in the fight documented at the beginning of this thesis. I was able to attend only two sessions all summer, where both the coaches and studentathletes showed-up, and found discipline and a work ethic to be lacking as compared to the other two programs. Once having shown up for a scheduled session and finding only twelve student-athletes and no coaches outside the gym, I spent some time asking them what they do when the coaches don't show. Three mentioned that they go over to a friend's house that has a bench press but no squat rack or leg equipment, "it sucks man, coach tells us you get all the power from your legs and then we can't get to the stuff'. Three said that their parents had bought them a membership to a gym so they just head over there. Two said they'll just go home and watch t.v., and four stated that they "were just gonna cruise around" in one of their cars. When I asked them what "just cruise around meant" one of them kind of laughed and said "we gonna get us a forty (a forty ounce beer) and smoke a little blunt (pot)". Having smelled marijuana coming from this kid's car before I did not doubt the likelihood of this scenario. The coaching staff is limiting access to important resources, thus losing an opportunity to develop trust and a network of exchange. And it may also be contributing to the development of negative human and cultural capital by allowing negative behavior to occur within its workouts and by not providing its student-athletes with an alternative to detrimental behavior. This last aspect is addressed by Coach Alexander at King High who says, "By providing these kids a place to go each day and requiring that they be here, maybe we can keep them from doing things out in the streets that are gonna hurt them." 
When I talked to Coach Thom about the weakness of the summer program he mentioned that, "It's hard to get guys out here to coach. I don't have any money for them. It's hot. After ten years here I'm running out of steam, and if I can't do it how can I get someone else to. We had problems this summer. A lot of problems." Coach Thom's lack of ability to motivate himself and others to create this type of social capital has led to diminished access to resources for the student-athlete.

At Norwood High progress reports are handled initially by the academic advisor Mr. Flagg. The student-athlete is required to pick up a progress report on Friday mornings during the football season and return it, completed, on Monday afternoon. The problem is that a majority of the student-athletes fail to follow this program. One Monday afternoon when I asked Mr. Flagg if I could look at that week's progress he handed me twelve progress reports. This is out of approximately forty-five studentathletes on the team at the time. When I asked him when he expected the rest, he smiled and said, "This has been a good week already." He says he averages about ten a week, mostly from juniors and those seniors who are making a conscious effort to get into college. There does not seem to be penalties for not turning in a progress report. When I asked Coach Thom about this he says that, "Mr. Flagg handles the academics and I handle the football. We work better that way." It seems that over the past seven years they have been working together there has been contention over Mr. Flagg's insistence that academics play a larger role in the football program. Mr. Flagg jokes that each year "coach fires me as advisor and then hires me again." When a negative report does come in Mr. Flagg speaks with the teacher and attempts to arrange tutoring sessions if the problem is academic. I say attempts because as Mr. Flagg states, "I have a difficult time 
convincing either the kid or the teacher to take the time to get this done." Mr. Flagg does not tutor the team himself. If the problem is non-academic he conveys the teacher's complaint to Coach Thom, who then counsels and disciplines the student-athlete. In the entire season I only witnessed one incidence where a negative progress report led to disciplinary measures. This was a moderate infraction, being late to class several times that week, and it resulted in the student-athlete doing extra laps after practice.

In addition to the progress reports Mr. Flagg advises the students on curriculum choices, standardized test applications and college admission forms. He conducts a seminar for the student-athletes and their parents each semester, which is according to him not well attended by the parents. While he does not tutor the student-athletes for the standardized tests, he does recommend that the student-athlete take the SAT prep courses. These courses are available and recommended at all three high schools and do not represent a resource specific to Norwood. Mr. Flagg keeps a file on each student-athlete containing both academic and athletic records, but he does not become actively involved in the writing of recruitment letters or the evaluation of prospective schools.

The lack of closure and effort in regards to the progress reports is indicative of the coach's inability to create norms and apply sanctions. This is nowhere more evident than in study hall. As stated earlier, during the study halls and tutoring sessions at the other two schools the majority of student-athletes respond to tutoring and the chance to study in a positive manner. The opposite is true at Norwood. Many of the student-athletes don't even bother to bring study materials to study hall. The session is thought of as a time to sleep, get caught up with what happened that day, or figure out what they're going to do that night. There is a cycle where the group becomes louder and louder, testing the 
boundaries until $\mathrm{I}$, or one of the coaches, must shout them down, only to begin the testing again. Norwood's student-athletes are derisive and at times harass those few individuals who ask for help. This was illustrated in the example situation discussed in Reggie's profile. The most telling aspect of the study hall is that it is the older players who are harassing the younger players as they try to study or ask for help. As an individual who was offering my resources to these kids, I found their behavior detracted from my desire to invest the time and effort. I can understand why teachers would be hesitant to give their assistance to the program. This contrasts with the juniors and seniors at King and Northern, who having constantly been shown the importance of an education, asked to meet requirements, and given access to resources necessary to meet these requirements, are making decisions and behaving in a manner conducive to getting an education.

Joseph, a Haitian-American senior, talks about the problems on the team and more specifically with the African-American players:

They're all crazy. Crazy and lazy. They want everything given to them as if they don't have to work for anything. In Haiti you respected your coach, you respected your teachers. Not here. You see them. They act like animals. It's much harder in Haiti. These guys wouldn't last a minute. I don't know why coach puts up with it.

The response of the student-athletes to study hall indicates that the program at Norwood has not been successful in encouraging and facilitating behavior that simultaneously represents cultural capital and allows for the development of human capital in the form of an education. 


\section{Discussion}

At Norwood the limited commitment from and coordination between Coach

Thom and Mr. Flagg has resulted in a lower level of access to resources for the studentathletes. Coach Thom has failed to develop trust or a sense of obligation between him and his student-athletes through the athletic component. This has inhibited the development of social capital and the exchange of resources in two interrelated ways. First, it has not allowed Coach Thom to develop closure in regards to the progress reports. This has diminished his effectiveness in creating norms, thus depriving the student-athlete and the football program of this valuable resource. Secondly, the absence of norms conducive to the pursuit of education has discouraged members of the school staff from granting access to the resources they possess.

The lack of this type of normative social capital decreases the positive impact participation in high school sports can have on the student-athlete. In fact, by implicitly condoning inappropriate behavior by not penalizing it, this program may be negatively impacting these student-athletes. This is despite the seemingly stable situation at Norwood, where you have two individuals who have occupied the key positions in the football program for eight continuous years. This potential for social capital has been undermined by conflict between Coach Thom and Mr. Flagg, the budding apathy of the former and the lack of involvement of the latter.

It must be noted that the negative responses of the student-athletes to the football program are partially a function of their preconceived negative orientations to the resources it makes available and this has a detrimental impact on the development of social capital. At King and Northern this problem has been overcome, but at Norwood 
this situation is exacerbated by the failings of the program itself. The intention of this study was not to delineate between the ethnic groups represented in this study, but there are indications that the differences in student-responses run roughly along ethnic lines. Those Black student-athletes who were born outside of the U.S. exhibit behavior that indicates a more positive academic orientation than their African-American counterparts. This corresponds to literature that indicates that African-Americans are more likely to have a negative academic orientation as compared to first-generation immigrants (Ogbu, 1987). My assertion is not based exclusively on behaviors observed at Norwood, but is a result of both my own observation and comments made by coaches, staff and studentathletes at all three schools. Also I want to state that each group does include a mix of positive or negative academic orientations and is not singular in orientation. A comment by Coach Evans, the former African-American head football coach at King, illustrates the changes he has seen in the student-athlete as the student population at King changed from African-American to primarily Haitian:

Now the Haitian child, he shows respect. Yes sir, No sir. He knows that education is important. Their parents are all for education. They don't come in here all complaining that you gave their kid a D. They let the kids have it. But, I've seen them (Haitian kids) change too. The longer they're here the more they start back talking and acting like niggers. Now I don't like using that word but that's what they're acting like. They start slackin' off acting cool. Back in the 80s and maybe until about I don't know '91, '92, I had mostly Black (AfricanAmericans) kids on the team. I won more games, but let me tell you I'd rather be coaching these kids I have now. 
Given the overwhelmingly African-American make-up of the Norwood football team, the coaches may be facing resistance to the creation of social capital that their counterparts at King and Northern aren't encountering in similar intensity. The two negative forces may have contributed to a downward spiral in the Norwood football program where each group, coaches/staff and the student-athletes, creates situations that reinforce and bring about negative behavior in the other. This is in contrast to a seemingly upward, positive spiral of interaction in the other two schools.

Despite posting a better record (4-6) than either King or Northern, Coach Thom and Mr. Flagg were only able to place two of the seventeen seniors in college with athletic scholarships. In addition only two other members of the team have registered for college on their own and only fifteen of the seventeen seniors graduated from high school. 


\section{Chapter VIII: CONCLUSION}

What are the effects of athletic participation on the development of human and cultural capital in the Black male adolescent? This ethnographic view of the football program leads me to believe that the football experience and its effect on the adolescent is not a constant, but can vary at both the program and individual levels. Participation can provide the resources and encouragement necessary to develop important human and cultural capital. It can also detract from the mission of the school and become a detriment to the development of the adolescent by subverting time and energy away from educational pursuits and introducing and reinforcing negative behavioral patterns. But while this study mirrors the variety of results in current literature it begins to illustrate the determinants for the frequently contradictory effects of athletic participation. These differences are due to two interrelated elements. First are the level and types of social capital and resources made available to the student-athletes. Second are the responses of the student-athletes to the social capital and resources provided to them.

The social capital and resources available in each program is contingent on three variables: the coach and staff, resources, and the student-athlete. It begins with the willingness and ability of the coach and staff to create a network of exchange that gives the student-athlete access to resources. In this paper I have designated three components of the football program that approximate the type of social capital and resources necessary to develop human and cultural capital in the Black male adolescent: athletic, academic, and normative. While the latter two are more clearly engaged in the development of human and cultural capital, the success of these two components begins with the relationships built in the locker room and on the field. In the athletic component 
the coach and his staff have the opportunity to build a network of exchange between themselves and the student-athlete. This is not contingent on a winning record, but more on the development of relationships built on trust, obligations and expectations. If the coach and staff fail in this task the network of exchange so vital for the transference of resources is diminished thus limiting the resources that can be made accessible to the student-athlete.

When the network achieves closure through the efforts of the individuals within the network, the student-athlete is exposed to a higher level of resources. In this case study closure presented itself in two forms: internal and external. Internal closure refers to the complete interconnection between those individuals directly linked to the football program, such as student-athletes, coaches and staff. External closure refers to the inclusion of those outside the football program, namely the student-athletes' parents and friends, into an integrated network. External closure promises a high level of information exchange and potential for behavior modification, especially in the normative component, but its creation is inhibited by the enormous effort and cooperation necessary to develop an maintain it. Internal closure, while not commonplace, is a more practical and sufficiently efficient form of insuring access and use of resources available in the network.

The resources that are embedded in this network also play a vital role in the level and type of social capital and resources in the football program by either limiting or enabling the coach and staff to create social capital and by also being the commodity being offered. The time, effort, and information necessary to coach, tutor, and guide these student-athletes are scarce resources. If these resources are in short supply there is 
at once a diminished ability to create social capital and a lack of resources to give access to if a network of exchange is constructed. When these resources are present they can help the student-athlete develop human and cultural capital only when they are given access to them. The irony is that while the student-athletes are part of a social organization (school) whose primary function it is to educate them, they may be receiving a great deal more support from a social network that originates in a social group (football) that has been accused by many to detract from the school's mission.

The response of the student-athlete to the social capital and resources available in each program has both structural and individual implications. At the structural level the student-athlete's response to the efforts of the coaches and staff can affect the extent to which these individuals are willing to give access to their resources. Negative responses in the form of disrespect or indifference can de-motivate the coach or teacher to put forth the effort. As Bourdieu states, "The reproduction of social capital presupposes an unceasing effort of sociability, a continuous series of exchanges in which recognition is endlessly affirmed and reaffirmed" (1983;250). This can diminish the resources being made available to the other student-athletes and therefore can have detrimental effects on the level of social capital within the football program. This is in contrast to a positive orientation towards the program which can induce coaches and staff to provide resources, as well as create a positive environment for other student-athletes to lay claim to the resources being made available.

A more direct result of a student-athlete's negative response to the resources being made available is the lack of benefit he receives from his membership in the football program. Full participation in the three components can help him develop the 
human and cultural capital he will need to succeed on the football field, classroom, and workplace. A lack of involvement inhibits any positive effects of his participation and may lead to negative results if there is an overemphasis on the athletic component as compared to the academic or normative.

The football experience becomes a dynamic interplay of the coaches and staff, the resources they make available, and the responses of the student-athletes. This suggests both changes over time as well as differences between and within programs as to the effects of athletic participation. Over time these three variables can cause an upward or downward spiral as they react to and reinforce each other. Changes in the composition of the three variables, be it a coaching change, an increase in resources, or a change in the student population, can also effect the ability of the program to develop human and cultural capital in the student-athlete. Since each program has its unique set of circumstances under which it is operating the effects of athletic participation can be dramatically different if not in fact contradictory from program to program.

While this study does provide insight into the subject, it also begs a new set of questions. I think the most important center on the student-athlete. First, what are the reasons for the differences in the student-athletes' responses? Are these differences based on ethnicity, socio-economic level, aspects of the family, past education experiences? Second, do the student-athletes perform differently than those students who are not part of the football team? What is the quantitative impact on the adolescent's human and cultural capital? Finally, what if any are the long-term effects of athletic participation where there is a high level of social capital and resources? Do the lessons and skills learned in the program translate to decisions and actions once the student- 
athlete graduates? Given that the football program is not a static structure and that these questions address issues beyond academic achievement and the spatial and temporal high school experience, any study developed to examine these questions must be longitudinal in design.

This exploratory research addresses the question of the effects of athletic participation by illustrating the role that social capital plays in the development of human and cultural capital of Black male student-athletes. It also helps further our understanding of the issue through a discussion of the important part the student-athlete takes in both the creation and maintenance of social capital, as well as his own human and cultural development. In doing so this paper contributes to two areas within sociological literature. First, it increases the amount of knowledge regarding the effects of athletic participation on minorities, an area in which research is lacking. It also raises questions about, and extends the boundaries of, our conceptualization of social capital. This thesis therefore expands our understanding of the process by which athletic participation affects the development of human and cultural capital in Black male adolescents. 


\section{LIST OF REFERENCES}

A Vision for America's Future, An Agenda for the 1990s: A Children's Defense Budget. Washington, D.C.: Children' Defense Fund, 1989.

Bandura, Albert. 1977. Social Learning Theory. Englewood Cliffs, New Jersey: Prentice-Hall, Inc.

Bandura, Albert and R.H. Walters. 1959. Adolescent Aggression. New York: Ronald Press.

. 1963. Social Learning and Personality Development. New York: Holt, Rinehart \& Winston.

Becker, Gary. 1964. Human Capital. New York: National Bureau of Economic Research.

Benedict, Ruth. 1950. Patterns of Culture. New York: New American Library.

Bourdieu, Pierre. 1985. "The Forms of Capital." In Handbook of Theory and Research for the Sociology of Education, ed. JG Richardson, pp.241-258. New York. Greenwood.

Bourgois, Phillipe. 1995. In Search of Respect: Selling Crack in the Barrio. New York, NY: Cambridge University Press.

Braddock, J.H., II. 1980. "Race, sports, and social mobility: A critical review." Sociological Symposium, v.30: 18-38.

. 1981. "Race, athletics, and educational attainment." Youth \& Society, v.12: 335-350.

. 1991. "Bouncing Back: Sports and Academic Resilience among African American Males." Education and Urban Society, v24 n1 (Nov): 113-31.

Bronfenbrenner, U. 1979. The Ecology of Human Development. Cambridge, MA: Harvard University Press.

Chakravarty, Subrata N. and Katherine Weisman. 1988. "Consuming Our Children?" Forbes, v.42: 222-232.

Christoffel, Katherine.Kaufer. 1990. "Violent death and injury in U.S. children and adolescents." American Journal of Diseases of Children, v.144, no. 6: 697-706. 
Coakley, Jay. 1978. Sport in Society. Saint Louis: C.V. Mosby Co.

Coleman, James S. 1961. The Adolescent Society. New York: The Free Press.

. 1988. "Social Capital in the Creation of Human Capital." American Journal of Sociology. V.94 supplement: s95-s120.

. 1990. Foundations of Social Theory. Cambridge: Belknap Press of Harvard Press.

Collins, Randall. 1994. Four Sociological Traditions. New York, NY: Oxford University Press.

Cote, James E. and Anton L. Allahar. 1994. Generation On Hold: Coming of Age in the Late Twentieth Century. New York: New York University Press.

DiCindio, Linda A.; Floyd, H. Hugh; Wilcox, Jerry and Dennis R. McSeveney. 1983. "Race Effects in a Model of Parent-Peer Orientation." Adolescence, v.18, no. $70: 369-380$.

Dienhart, Tom. "Scouting The Nation." The Sporting News: 1997 College Football, 24 June 1997: pp.11-16.

DiMaggio. Paul. 1982. "Cultural Capital and School Success: The Impact of Status Culture Participation on the Grades of U.S. High School Students." American Sociological Review, v.47: 189-201.

Dryfoos, Joy G. 1998. Safe Passage: Making It Through Adolescence In A Risky Society. Oxford: Oxford University Press.

Edwards, Harry. 1973. The Sociology of Sport. Homewood, 11.: Dorsey Press.

Ekeh, Peter W. 1974. Social Exchange Theory. Cambridge, Massachusetts: Harvard University Press.

Eckert, Penelope. 1989. Jocks \& Burnouts: Social Categories and Identity in the High School. New York, N.Y.: Teachers College Press.

Fasik, Frank A. 1984. "Parents, Peers, Youth culture and Autonomy in Adolescence." Adolescence, v.19, no.73: 143-158.

Fishkeller, JoEllen. 1997. "Everyday Learning about Identities among Young Adolescents in Television Culture," Anthropology \& Education Quarterly, v.28 (4). 
Fejgin, Naomi. 1994. "Participation in High School Competitive Sports: A Subversion Of School Mission or Contributions to Academic Goals?" Sociology of Sport Journal, v.11, no.3: 211-230.

Fonteboa, Pedro F. "Looking for a state title? Then you go through Dade." Miami Herald, 4 September 1997: 1(FB).

Fordham, S. 1988. "Racelessness as a factor in black students' school success: Pragmatic Strategy or Pyrrhic Victory?" Harvard Educational Review, v.58, no.1: $54-84$.

Fox, J. 1996. Trends in Juvenile Violence. Washington D.C.: U.S. Bureau of Justice Statistics.

Friedman. Debra and Michael Hechter. 1988. "The Contibution of Rational Choice Theory in Macrosociological Research." Sociological Theory, 6:201-218.

Fuchs, Victor R. 1988. Women's Quest for Economic Equality. Cambridge, Mass.: Harvard University Press.

Furstenberg, Frank F. And Christine Winquist Nord. 1985. "Parenting Apart: Patterns of Childrearing after Marital Disruption." Journal of Marriage and the Family v.47, no. 4.

Gallon, Arthur J. 1980. Coaching: Ideas and Ideals. Prospect Heights, Ill: Waveland Press Inc.

Gallagher, Bernard J. 1979. "Attitude Differences across Three Generations: Class And Sex Components." Adolescence, v.14, no.55: 503-516.

Giroux, Henry and David Purpel. 1983. The Hidden Curriculum and Moral Education. Berkeley, CA: McCutchan Publishing Corporation.

Goffman, Erving. 1959. Presentation of Self in Everyday Life. Garden City, N.Y.: Anchor.

Granovetter, Mark. 1985. "Economic Action, Social Structure, and Embeddedness." American Journal of Sociology v.91: 481-510.

Greendorfer, S.L. 1987. "Psycho-social correlates of organized physical activity." Journal of Physical Education, Recreation, and Dance v.58: 59-64.

Gunter, Bernie and H.A. Moore. 1975. "Youth, Leisure, and Post-Industrial Society: Implications for the Family." Family Coordinator v.24. 
Hall, G. Stanley and G. Lindzay. 1970. Theories of Personality. New York: John Wiley And Sons.

Hanks, Michael P. 1979. "Race, sexual status and athletics in the process of educational achievement." Social Science Quarterly, v.60: 482-496.

Hanks, Michael P., and Bruce K. Eckland. 1976. "Athletics and Social Participation in the Educational Attainment Process." Sociology of Education, v.49: 271-294.

Havighurst, R.J. 1972. Developmental tasks and education. $3^{\text {rd }}$ ed. New York: McKay.

Haynes, Leonard L., III. 1990. "Athletics vs. Academics: A Focus on the Future." NASSP Bulletin, v.74, no.530: 26-31.

Hechter, Michael, ed. 1983. Microfoundations of Macrosociology. Philidelphia: Temple University Press.

Hewlett, Sylvia Ann. 1991. When The Bough Breaks: The Cost of Neglecting Our Children. New York: HarperCollins Books.

Homans, George C. 1974. Social Behavior: It's Elementary Form. Rev. ed. New York: Harcourt, Brace \& World.

Jeffery, Robert W. 1976. "The Influence of Symbolic Motor Rehearsal on Observational Learning." Journal of Research in Personality, v.10, no.1: 116-127.

Jeziororski, Ronald M. 1994. The Importance of School Sports in American Education and Socialization. Lanham, Maryland: University Press of America Inc.

Kennedy, E. 1995. "Correlates of perceived popularity among peers: a study of race and gender differences among middle school students." Journal of Negro Education, v.64, no. 2: 186-196.

Landers, Daniel, Deborah L. Feltz, George E. Obermeier, and Thomas R. Brouse. 1978. "Socialization via Interscholastic Athletics: Its effects on Educational Attainment." Research Quarterly, v.49: 475-483.

Lapchick, Richard E. 1989. Pass to play: student athletes and academics. Washington D.C.: NEA Professional Library. 
LeMasters, E.E. 1974. Parents in Modern America: A Sociological Analysis. Homewood, Ill.: Dorsey Press.

Long Robert Emmitt ed. 1991. The State Of U.S. Education. New York: The H.W. Wilson Company.

Males, Mike A. 1996. The Scapegoat Generation: America's War On Adolescents. Monroe, Maine: Common Courage Press.

Marsh, Herbert W. 1993. "The effects of participation in sport during the last two years of high school." Sociology of Sport Journal, v.10: 28-43.

Mattox, W. 1990. “America's Family Time Famine.” Children Today, v.19.

McPherson, Barry D. 1980. "Sport in the educational milieu: Unanswered

Questions and untested assumptions." Phi Delta Kappan, v.6: 606-606.

1986. "Socialization Theory and Research: Toward a

'New Wave' of Scholarly Inquiry in a Sport Context." In Sport and Social

Theory, pp. 111-134, ed. C. Roger Mees and Andrew W. Miracle. Champaign IL: Human Kinetics Inc.

Mead, Margaret. 1970. Culture and Commitment: A Study of the Generation Gap. Garden City, N.Y.: Doubleday.

Melnick, Merrill J., Donald F. Sabo, and Beth Vanfossen. 1988. "Develpmental effects of athletic participation among high school girls." Sociology of Sport Journal, v.5: 22-36.

Miami Herald, The. 1999. "10 counties have high percentage of poor kids." 6 February, $5[\mathrm{~B}]$.

Murray, John P. 1993. The Developing Child in a Multimedia Society. In Children and Television: Images in a Changing Sociocultural World. Gordon L. Berry and Joy Keiko Asamen. eds: Newbury Park,CA:Sage Publications.

National Commission on Excellence in Education. 1983. A Nation at Risk: The Imperative for Educational Reform. Washington D.C.: U.S. Government Printing Office.

Nixon, Howard L II. 1979. The Small Group. Englewood Cliffs, N.J.: Prentice-Hall. 
Nixon, Howard L II. and James A. Frey. 1996. A Sociology of Sport. Belmont, California: Wadsworth Publishing Company.

Noddings, Nel. 1992. The Challenge to Care in Schools: An Alternative Approach to Education. New York: Teachers College Press.

Nord, W. "Adam Smith and contemporary social exchange theory."

The American Journal of Economics and Sociology, v.32: 421-436, 1973.

Ogbu, John U. 1987. "Variability in Minority School Performance: A Problem in Search of an Explanation." Anthropology and Education Quarterly, v.19:312-334.

Osofsky, Joy D. ed. 1997. Children in a Violent Society. New York, NY: The Guilford Press.

Otto, Luther B. and Duane F. Alwin. 1977. "Athletics, Aspirations, and Attainments." Sociology of Education, v.50: 102-115.

Piaget, Jean and Inhelder Barbei 1969. The Psychology of the Child. New York: Basic Books.

Picou, J.S. 1978. "Race, athletic achievement, and educational aspiration." The Sociological Quarterly, v.19: 429-438.

Picou, J.S. and S. Hwang. 1982. "Educational aspirations of "educationally disadvantaged" athletes." Journal of Sport Behavior, v.5: 59-76.

Picou, J.S., V. McCarter, and F.M. Howell. 1985. "Do high school athletics pay? Some further evidence." Sociology of Sport Journal, v.2: 72-76.

Pounds, Ralph L. and James R. Bryner. 1973. The School in American Society. New York: The MacMillan Company.

Portes, Alejandro. 1998. "Social Capital: Its Origins and Applications in Modern Sociology." Annual Reviews in Sociology, 24:1-24.

Portes, Alejandro and Alex Stepick. 1993. City on the Edge: The Transformation Of Miami. Berkeley, CA: University of California Press.

Portes, Alejandro and Min Zhou. 1993. "The New Second Generation: Segmented Assimilation and its Variants among Post-1965 Immigrant Youth." The Annals of the American Academy of Political and Social Sciences, November 530: 74-97. 
Rees, C.R., Howell, F.M. and Miracle A.W. 1990. "Do high school sports build character? A quasi-experiment on a national sample." The Social Science Journal, v.27: 303-315.

Rice, F. Philip. 1987. The Adolescent: Development, Relationships, and Culture. $5^{\text {th }}$ ed. Newton, Massachusetts: Allyn and Bacon Inc.

Rizter, George, ed. 1990. Frontiers of Social Theory. New York: Columbia University Press.

Ritzer, George. 1996. Modern Sociological Theory. New York: McGraw Hill Inc.

Robinson, John P. and Geoffrey Godbey. 1997. Time for Life: The Surprising Ways Americans Use Their Time. University Park, Pennsylvania: The Pennsylvania State University Press.

Rock, James M. ed. 1991. The Debt and the Twin Deficits Debate. Mountain View, C.A: Bristlecone Books/Mayfield.

Ruffin, Santee C. Jr. 1986. "Minimum Academic Standards: Yes." NASSP Bulletin v70, n492 (Oct) : 6-8.

Sage, George H. 1987. "The Social World of High School Athletic Coaches: Multiple Role Demands and Their Consequences." Sociology of Sport, v.4: 213228.

. 1990. "High School and College Sports in the United States." Journal of Physical Education, Recreation \& Dance, v.81: 59-63.

Scott, Jack. 1971. The Athletic Revolution. New York: Free Press.

Scott, John Finley. 1971. Internalization of Norms: A Sociological Theory of Moral Commitment. Englewood Cliffs, N.J.: Prentice Hall Inc.

Soltz, Donald F. 1986. "Athletics and Academic Achievement: What is the Relationship?" NASSP Bulletin, v70 n492 (Oct): 20-24.

Snyder, Eldon E. 1972. "Athletic Dressing Room Slogans as Folklore: A Means of Socialization." International Review of Sport Sociology, v.7: 89-102.

.1972. "High School Athletes and Their Coaches: Educational Plans and Advice." Sociology of Education, v.45: 313-325. .1975 " Athletic Team Involvement, Educational Plans, and the Coach- 
Player Relationship." Adolescence, v.10: 191-200.

Snyder, Eldon E. and Elmer A. Spreitzer. 1989. Social Aspects of Sport. New York: St. Martins Press.

.1990. "High school athletic participation as related to college attendance among black, Hispanic, and white males: A research note." Youth and Society, v. 21: 390-398.

Soltz, Donald F. 1986. Athletics and Academic Achievement: What is the Relationship? NASSP Bulletin, v.70, no.492: 20-24.

Spady, W.G. 1970. "Lament for the Letterman: Effects of peer status and extracurricular activities on goals and achievement." American Journal of Sociology, v.75: 670-702.

Spreitzer, Elmer, and Meredith Pugh. 1973. "Interscholastic Athletics and Educational Expectations." Sociology of Education, v. 46: 171-182.

Stark, Rodney. 1992. Sociology. Belmont, California: Wadsworth Publishing Company.

Stepick, Alex . 1998. Pride Against Prejudice: Haitians in the Untied States. Needham Heights, Massachusetts: Allyn and Bacon.

Stepick, Alex, Bowie, Stan L., and Carol Dutton Stepick. 1995. Producing Human Capital: Social \& Cultural Capital in the Academic Orientation of Minority Adolescents. Research Proposal.

Stepick, Alex, Bowie, Stan L., and Carol Dutton Stepick. 1996. Interaction among Native-born and Immigrant Minority Adolescents. Research Proposal.

Stevenson, C.L. 1975. "Socialization effects of participation in sports: A critical review of the research." Research Quarterly, v.46: 287-301.

Swartz, David. 1997. Culture \& Power: The Sociology of Pierre Bourdieu. Chicago, Illinois: The University of Chicago Press.

Swindler, Anne. 1986. "Culture in Action: Symbols and Strategies." American Sociological Review, v.51:273-86.

Taylor, George R. 1997. Curriculum Strategies: Social Skills Intervention for Young African American Males. Westport, Connecticut: Preager Publishers.

Weinberg, Robert S. and Daniel Gould. 1995. Foundations of Sport and 
Exercise Psychology. Champaign, Ill.: Human Kinetics.

Weiner, Mickey. 1997. Toward an Understanding of How Individuals Overcome Challenges to Development: A Phenomenological Study of an Inner-City Student's Attitude Toward Academic Orientation and Life. Dissertation. Florida International University.

Wells, R.H., and J.S. Picou. 1980. "Interscholastic athletes and socialization for educational achievement." Journal of Sport Behavior, v.3: 119-128.

Wentworth, W. 1980. Context and Understanding: An Inquiry Into Socialization Theory. New York: Elsevier.

Williams, Robin. 1970. American Society. New York: Alfred A. Knopf.

Willis, Peter. 1981. Learning to Labor: How Working Class Kids Get Working Class Jobs. New York: Columbia University Press.

Wright, Willie J. 1992. "The Endangered Black Male Child." Educational Leadership, v.49: no.4.

Zigler. Edward F. and Mary E. Lang. 1991. Child Care Sources: Balancing the needs of Children, Families and Society. New York: The Free Press. 
APPENDICES 


\section{NEW STATE LAW TO CHANGE FHSAA, ACADEMIC ELIGIBILITY REQUIREMENTS}

URGENT-MEMORANDUM

TO: The Principal and Athletic Director of Each Member School

The Superintendent of Each District School System

The Chairperson of Each District School Board

The County Athletic Director of Certain District School Systems

The News Media

April 24, 1997

FROM: Ronald N. Davis, Commissioner

RE: Changes to Academic Eligibility Requirements Effective with the 1997-98 School Year

On April 2, 1997, Governor Chiles signed into law Senate Bill 458, which was passed by the Florida Legislature on March 27. The provisions of this bill amends section 232.425,Florida Statutes, 1996 Supplement, and will significantly change academic eligibility for all extracurricular activities, including interscholastic athletics, as we currently know it. The law will take effect Julyl and its requirements will impact students during the upcoming 1997-98 school year.

This memorandum provides you with the language of the new law and our staff analysis of it. Attached you will also find illustrations of how the new academic eligibility requirements will affect students in certain case studies. Please review this information carefully. I suggest each principal meet with his/her athletic director and entire coaching staff to discuss the new requirements.

Here is the new language for s. 232.425 :

"To be eligible to participate in interscholastic extracurricular student activities, a student entering the 9th grade during the 1997-1998 school year and thereafter must maintain a cumulative grade point average of 2.0 or above on a 4.0 scale, or its equivalent, in the courses required by s. 232.246(1). In order to be eligible under this section, students who entered the 9th grade prior to the 1997-1998 school year must maintain a cumulative grade point rage of 2.0 or above on a 4.0 scale, or its equivalent in the courses required by s.232.246(1) that are taken after July 1, 1997 or have an overall cumulative grade point average of 2.0 or above. Eligibility for the first semester of the 1997-1998 school year for those students who entered the 9th grade prior to the 1997-1998 school year shall be based on the school board's policy in effect for the 1996-1997 school year. Additionally, a student must maintain satisfactory conduct and, if a student is convicted of, or is found to have committed, a felony or a delinquent act which would have been a felony if 
committed by an adult, regardless of whether adjudication is withheld, the student's participation in interscholastic extracurricular activities is contingent upon

established and published school board policy.

Academic Eligibility Requirements

After consulting with the Department of Education, here is how the FHSAA Office will interpret this new law for all member schools:

1. Students entering the ninth grade for the first time must be regularly promoted from the eighth grade to be eligible during the fall semester. Regularly promoted means promoted in accordance with the public school district's or private school's pupil progression plan. It does not mean administratively placed. To be eligible during the spring semester and each semester thereafter, incoming ninth graders must maintain a cumulative grade point average of 2.0 or higher in the core courses identified in s. $232.246(1)$.

Example: Johnny is entering the ninth grade for the first time. He was regularly promoted from the eighth grade. During the fall semester, he earns an overall cumulative GPA of 2.3, but his cumulative GPA in core courses only is 1.8 . According to the new law, Johnny will be academically eligible for the entire 18 weeks of the fall semester, but will become academically ineligible at the beginning of the spring semester and will remain academically ineligible for each subsequent semester that his core GPA remains below 2. 0 .

2 Students who entered the ninth grade for the first time prior to the 1997-98 school year (i.e. 10th,11th, and 12th graders) must have earned credit in five unit subjects and earned a 1.6 g.p.a. (or higher if required by the public school district or private school) during the 1996-97 school year to be eligible during the fall semester. To be eligible during the spring semester and each semester thereafter, these students must either:

(a) Maintain a cumulative grade point average of 2.0 or higher in the core courses identified in s.232.246(1), which are taken after July 1, 1997; or

(b) Maintain a cumulative grade point average of 2.0 or higher in all courses - both core and elective - which are taken after July 1, 1997.

Example: Sally is entering the 11th grade. During the 1996-97 school year, she earned a 1. 7 GPA-and passed four courses. During the fall semester, Sally earn a cumulative GPA in core courses of 1.9, but her overall cumulative GPA is 2.2. According to the new law, Sally will be academically ineligible for the entire 18 weeks of the fall semester, because she did not pass five subjects last year. However, Sally will become academically eligible for the spring semester because her overall cumulative GPA for courses taken after July 1, 1997 is 2.2, even though her cumulative GPA in the core courses taken after July 1 is only 1.9.

3. Cumulative grade point average means the grade point average for all semesters in high school, not just for work completed the previous semester. Therefore, it will be 
possible in future years for a student to earn a 3.0 grade point average for a semester's work, but remain ineligible for the following semester because his/her cumulative grade point average remains below 2.6. For 10th, 11 th and 12th graders, schools may use the overall cumulative grade point average of all courses taken after July 1.1997 OR the cumulative grade point average for all core courses taken after July 1.1997, whichever works to the benefit of the student. For incoming ninth-graders, schools must use the cumulative grade point average of core courses which are taken only after July 1, 1997. 
4. The core courses identified in s.232.246(1) are:

$\begin{array}{ll}\text { Course } & \text { Credits } \\ \text { English } & 4 \\ \text { Mathematics } & 3 \text { (including 1 in Algebra I or } \\ \text { Science } & 3 \\ \text { American History } & 1 \\ \text { World History } & 1 \\ \text { Economics } & 1 / 2 \\ \text { American Government } & 1 / 2 \\ \text { Practical Arts Career Ed } & 1 \\ \text { or Exploratory Career Ed; } & \\ \text { or Performing Fine Arts } & \\ \text { Life Management Skills } & 1 / 2 \\ \text { Physical Education } & \underline{1 / 2} \\ & \mathbf{1 5}\end{array}$

5. Schools which currently do not offer this core curriculum must do so effective with the 1996-97 school year, or their incoming ninth graders will not be eligible for extra-curricular activities beginning with the second semester.

6. For incoming ninth graders, grades earned in the nine electives cannot be applied to the cumulative grade point average since elective courses are not considered part of the core.

7. Each member school must conform to the grading scale mandated in s. 232.2463, which is as follows:

$\begin{array}{lll}\text { Grade } & \text { Percent } & \text { GPA } \\ \text { A } & 94-100 & 4.0 \\ \text { B } & 85-93 & 3.0 \\ \text { C } & 77-84 & 2.0 \\ \text { D } & 70-76 & 1.0 \\ \text { F } & 0-69 & 0.0\end{array}$

Please feel free to call this office with any questions you might have about the interpretation of this new law. 
NOTE

DATE: $\quad$ May 1, 1997

TO: $\quad$ All Athletic Directors

All Business Managers

FROM: $\quad$ Cheryl Golden

Athletics/Activities and Accreditation

\section{SUBJECT: FHSAA Fall of 1997 Eligibility Rules}

Attached is the letter from the FHSAA regarding the new academic eligibility requirements according the state law change.

\section{ELIGIBILITY FOR INCOMING 9TH GRADERS}

1. Fall of 1997-98 Requirements

- Must be regularly promoted to 9 th grade.

- No administrative placement to 9th grade allowed.

- No social or age promotion to 9th grade allowed.

- No GPA requirements.

- No requirement to pass 5 out of 6 classes.

2. Second Semester Eligibility Requirements (February 4, 1998) of 1997-98 school year and subsequent years.

- Cumulative GPA of 2.0 or higher in identified core courses, taken after July 1,1997 . This GPA will include all core courses taken in Summer School, July 1997.

- Dade County requirement of $2.0(12 \mathrm{pts}$.) in conduct.

\section{ELIGIBILITY FOR 10TH. 11TH AND 12TH GRADERS}

\section{Fall 1997-98 Requirements}

- Based on final grades of the 1996-97 school year.

- Pass 5 full units from 1996-97 school year.

- GPA of 1.6.

- Dade County requirement of 2.0 (12pts.) in conduct. 
NOTE

DATE: $\quad$ May 1, 1997

TO: $\quad$ All Athletic Directors

All Business Managers

FROM: $\quad$ Cheryl Golden

Athletics/Activities and Accreditation

SUBJECT: FHSAA Fall of 1997 Eligibility Rules

Attached is the letter from the FHSAA regarding the new academic eligibility requirements according the state law change.

\section{ELIGIBILITY FOR INCOMING 9TH GRADERS}

1. Fall of 1997-98 Requirements

- Must be regularly promoted to 9 th grade.

- No administrative placement to 9th grade allowed.

- No social or age promotion to 9 th grade allowed.

- No GPA requirements.

- No requirement to pass 5 out of 6 classes.

2. Second Semester Eligibility Requirements (February 4, 1998) of 1997-98 school year and subsequent years.

- Cumulative GPA of 2.0 or higher in identified core courses, taken after July 1,1997 . This GPA will include all core courses taken in Summer School, July 1997.

- Dade County requirement of 2.0 (12pts.) in conduct.

\section{ELIGIBILITY FOR 10TH. 11TH AND 12TH GRADERS}

\section{Fall 1997-98 Requirements}

- Based on final grades of the 1996-97 school year.

- Pass 5 full units from 1996-97 school year.

- GPA of 1.6.

- Dade County requirement of 2.0 (12pts.) in conduct. 
2. Second Semester Eligibility Requirements (February 4, 1998) of 1997-98 school year and subsequent years.

- Cumulative GPA of 2.0 or higher in identified core courses, taken after July 1,1997. This GPA will include all core courses taken in Summer School, July 1997.

- OR Cumulative GPA of 2.0 or higher in all courses, both core and elective taken after July 1 , 1997. This GPA will include all courses both elective and core taken in Summer School, July 1997.

- Dade County requirement of 2.0 (12pts.) In conduct. 


\section{The Rules That Govern College Athletics}

(Provided to the student-athletes at Northern High)

Proposition 48: The original NCAA ruling that set standards for incoming college freshmen who wished to partake in athletics. It called for a minimum of a $2.0 \mathrm{GPA}$, a minimum score of 700 on the SAT (eventually raised to 820 ), and a 17 on the ACT. It established that the student would have had to maintain a certain GPA in 11 "core" courses.

Proposition 16: It upped the ante for incoming college freshmen. It raised the minimum GPA to a 2.5 and the ACT score to a combined 68 . It also set up a sliding scale to qualify. If a student had only a $2.0 \mathrm{GPA}$, they could get in with a 1,010 on the SAT. And there were many scenarios in between. It also upped the number of mandatory core courses to 13 from 11 taken in high school.

Proposition 42: It was the NCAA's policing effort to make sure all incoming college freshmen had met their requirements. This document was the ruling that said the incoming student-athlete will not be given a scholarship if he or she has not met the minimum requirements. This legislation established the NCAA Clearinghouse. 


\section{APPENDIX B}

Case Number

Student Questionnaire

FOR EACH QUESTION, PLEASE CHECK THE CORRECT ANSWER OR WRTTE NEATLY IN THE SPACE PROVIDED

1. What is your full name?

\section{(Please print clearly)}

2. What is your age?

3. What grade are you in?

4. Where do you live?

\section{Address}

\section{City}

Zip Code

5. What is your telephone number?

6. What is the name of your school?

7. What is your GPA? Core

8. What is your GPA? Overall

9. If not the born in the U.S., please indicate which country you were born in

10. If not born in U.S., when did you arrive in this country?

11. Are you a U.S. citizen? 
12. Please indicate the number of individuals in each category that reside in your home. Please indicate 0 if none reside in your home.

\begin{tabular}{|c|c|c|}
\hline Mother & Aunt & other male adults \\
\hline Father & Uncle & other female adults \\
\hline Stepmother & Sister & \\
\hline Stepfather & Brother & \\
\hline Grandmother & other female children & \\
\hline Grandfather & other male children & \\
\hline
\end{tabular}

13. Which of these individuals is your legal guardian?

14. Does your family rent or own the house or apartment that you live in? Rent Own

15. Who owns your residence or contributes to the rent? Please check all that apply.

\begin{tabular}{|c|c|c|}
\hline Mother & Aunt & other male adults \\
\hline Father & Uncle & ther female adults \\
\hline Stepmother & Sister & \\
\hline Stepfather & Brother & \\
\hline Grandmother & other female children & \\
\hline Grandfather & other male children & \\
\hline
\end{tabular}

16. What do you think your family's economic situation is?
1. Wealthy
2. Upper-middle class
3. Middle class
4. Lower-middle class
5. Poor

17. Do you have a paying job at present?

1.Yes

2. No

1 . If yes, how many hours a week do you work?

2. If yes, how much do you get paid per hour?

18. If yes, what is your job?

19. If no, will you get a job after football season? 1. Yes

2. No

1. If yes, how many hours a week will you work?

20. What type of job will you be looking for? 
21. What is the highest level of education that you would like to achieve?
1. Less than high school
2. Finish high school
3. Finish some college
4. Finish college
5. Finish a graduate degree (masters. Doctor, etc.)

22. Realistically speaking, what is the highest level of education you think you will get?
1. Less than high school
4. Finish college
2. Finish high school
5. Finish a graduate degree (masters. Doctor, etc.)
3. Finish some college

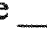

23. What job would you like to have as an adult?

24. How do you see your chances of getting this job?
1. Very poor
2. Poor
3. Good
4. Very Good

PLEASE INDICATE HOW MUCH YOU AGREE OR DISAGREE WITH THE FOLLOWING STATEMENTS :

25. Playing football keeps me from getting better grades.
1. Agree a lot
2. Agree a little
3. Disagree a little
4. Disagree a lot

26. I study more at home than in study hall.
1. Agree a lot
2. Agree a little
3. Disagree a little 4. Disagree a lot

27. As long as I have the grades to play it is unimportant to me if I get higher grades. 1. Agree a lot 2. Agree a little 3. Disagree a little 4. Disagree a lot

28. Progress reports do not affect my performance in class.

1. Agree a lot 2. Agree a little 3. Disagree a little 4. Disagree a lot

29. If I don't do well on the football field it is my fault.

1. Agree a lot 2. Agree a little 3. Disagree a little 4. Disagree a lot

30. Are there family rules about any of the following activities?
1. Maintaining a certain grade point average
2. Doing homework
Yes
Yes
No
3. Conduct in school
Yes
No

31. How often does someone at home discuss your daily experiences in school with you?

1. Not at all

2. Rarely

3. Occasionally

4. Regularly 
21. What is the highest level of education that you would like to achieve?
1. Less than high school
2. Finish high school
3. Finish some college
4. Finish college
5. Finish a graduate degree (masters. Doctor, etc.)

22. Realistically speaking, what is the highest level of education you think you will get?
1. Less than high school
4. Finish college
2. Finish high school
5. Finish a graduate degree (masters. Doctor, etc.)
3. Finish some college

23. What job would you like to have as an adult?

24. How do you see your chances of getting this job?
1. Very poor
2. Poor
3. Good
4. Very Good

PLEASE INDICATE HOW MUCH YOU AGREE OR DISAGREE WITH THE FOLLOWING STATEMENTS :

25. Playing football keeps me from getting better grades.
1. Agree a lot
2. Agree a little
3. Disagree a little
4. Disagree a lot

26. I study more at home than in study hall.
1. Agree a lot
2. Agree a little
3. Disagree a little
4. Disagree a lot

27. As long as I have the grades to play it is unimportant to me if I get higher
grades.
1. Agree a lot
2. Agree a little
3. Disagree a little
4. Disagree a lot

28. Progress reports do not affect my performance in class.

1. Agree a lot

2. Agree a little

3. Disagree a little

4. Disagree a lot

29. If I don't do well on the football field it is my fault.

1. Agree a lot 2. Agree a little__ 3. Disagree a little

4. Disagree a lot

30. Are there family rules about any of the following activities?
1. Maintaining a certain grade point average
2. Doing homework
Yes
3. Conduct in school
Yes
No
Yes
No
No

31. How often does someone at home discuss your daily experiences in school with you?
1. Not at all
2. Rarely
3. Occasionally
4. Regularly 
32. How often does someone at home talk to you about your future educational future?

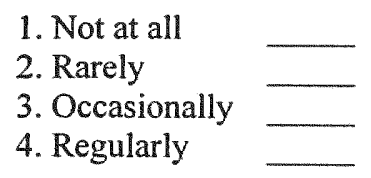

33. How often does someone at home help you with your homework?
1. Seldom or never
2. Once or twice a month
3. Once or twice a week
4. Almost every day

34. At home, who do you talk to the most frequently about school?

35. How many hours a week do you study for school?
1. Less than 5 hrs per week
2. More than 5 but less than 10
3. More than $10 \mathrm{hrs}$ per week

PLEASE INDICATE HOW MUCH YOU AGREE OR DISAGREE WITH THE FOLLOWING STATEMENTS:

36. Playing football makes me feel good about myself.
1. Agree a lot
2. Agree a little
3. Disagree a little
4. Disagree a lot

37. The new 2.0 minimum gpa requirement for graduation is too high.
1. Agree a lot
2. Agree a little
3. Disagree a little
4. Disagree a lot

38. The better I do academically the better chance I have of attaining my goals in life.
1. Agree a lot
2. Agree a little
3. Disagree a little

4. Disagree a lot

39. If I don't do well in school it is my own fault.
1. Agree a lot
2. Agree a little
3. Disagree a little
4. Disagree a lot

40. The new minimum gpa requirements will help me get a better education.

1. Agree a lot 2. Agree a little

3. Disagree a little 4. Disagree a lot

41. An education is more important to me now than it was when I was a freshman.
1. Agree a lot
2. Agree a little
3. Disagree a little
4. Disagree a lot

42. Which of the following groups had the greatest impact on your attitude towards education and which group the least. Please rate the groups from 1 to 6 with 1 having the highest impact.

1. Family

4. Coaches 


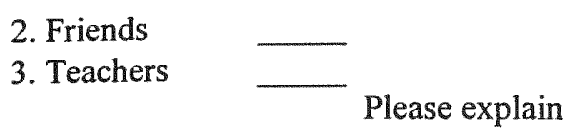

43. Is there a difference between a good education and a good gpa?

1.Yes 2. No

44. If you can not get an athletic scholarship will you still go to college?

1. Definitely 2. Probably 3. Probably not 4. Definitely not

45. If you think that you will not go to college, which of the following keeps you from going?
1. Grades
2. Money
3. Lack of desire
4. Other
Please explain

46. Have you, or are you planning on taking either the SAT or ACT?
1. Yes
2. No

47. John and Pierre are both high school seniors. An older friend who just opened a store offers them both jobs as salesmen. He argues that they will be better off going to work for him rather than staying in school because they will earn money and learn the business.

John says: "I'll take the job, it's better than just sitting in class and I'll learn about the real world."

Pierre says: "I'll stay in school, in the long run getting a degree will be better for me."

Who do you think is right?
1. John
2. Pierre
3. Neither Explain

PLEASE INDICATE HOW MUCH YOU AGREE OR DISAGREE WITH THE FOLLOWING STATEMENTS:

48. It is important to my family that I get a good education.
1. Agree a lot
2. Agree a little

3. Disagree a little

4. Disagree a lot 
49. It is important to my teachers that I get a good education.

1. Agree a lot 2. Agree a little 3. Disagree a little 4. Disagree a lot

50. It is important to my friends that I get a good education.
1. Agree a lot
2. Agree a little
3. Disagree a little
4. Disagree a lot

51. It is important to my coaches that I get a good education.

1. Agree a lot

2. Agree a little

3. Disagree a little

4. Disagree a lot

52. The new 2.0 minimum gpa requirement for sports participation is too high.

1. Agree a lot 2. Agree a little

3. Disagree a little 4. Disagree a lot

53. The education that I get now will affect my opportunities in the future.

1. Agree a lot 2. Agree a little

3. Disagree a little 4. Disagree a lot

54. For Juniors only: By Spring I will have the necessary 2.0 gpa to participate in Spring football.

Yes_ No

55. For Juniors only: By next Fall I will have the necessary 2.0 gpa to participate in the Fall football season.

Yes _ No

56. For Juniors only: Even if I don't have the grades to participate I will continue to work with my teachers and coaches to increase my gpa, and get back on the team.

1. Definitely 2. Probably 3. Probably not 4. Definitely not

Thank you very much for your time. Your answers will be very helpful to my study. Good Luck. 
49. It is important to my teachers that I get a good education. 1. Agree a lot _2. Agree a little 3. Disagree a little 4. Disagree a lot

50. It is important to my friends that I get a good education.
1. Agree a lot
2. Agree a little
3. Disagree a little
4. Disagree a lot

51. It is important to my coaches that I get a good education.
1. Agree a lot
2. Agree a little
3. Disagree a little
4. Disagree a lot

52. The new 2.0 minimum gpa requirement for sports participation is too high.

1. Agree a lot 2. Agree a little

3. Disagree a little 4. Disagree a lot

53. The education that I get now will affect my opportunities in the future.

1. Agree a lot 2. Agree a little 3. Disagree a little 4. Disagree a lot

54. For Juniors only: By Spring I will have the necessary 2.0 gpa to participate in Spring football.

Yes__ No _ _

55. For Juniors only: By next Fall I will have the necessary 2.0 gpa to participate in the Fall football season.

Yes

No

56. For Juniors only: Even if I don't have the grades to participate I will continue to work with my teachers and coaches to increase my gpa, and get back on the team.

1. Definitely 2. Probably 3. Probably not 4. Definitely not

Thank you very much for your time. Your answers will be very helpful to my study. Good Luck. 


\section{APPENDIX C}

\section{ATHLETE'S REVIEW OF THE SAT AND ACT TESTS}

STRUCTURE AND REVIEW OF THE SAT

A. 30 QUESTION VERBAL-30 MINUTES

1. 9 SENTENCE COMPLETION

2. 6.ANALOGIES

3. 15 READING COMPREHENSION

a. ARRANGED ACCORDING TO PASSAGE

b. EASIEST PASSAGE FIRST

B. 35 QUESTION VERBAL-30 MINUTES

1. 10 SENTENCE COMPLETION

2. 13 ANALOGIES

3. 10 ANALOGIES (EASY-MEDIUM-HARD)

4. 12 READING COMPREHENSION-ONE PASSAGE -

C. 13 QUESTION VERBAL- 15 MINUTES

1.13 READING COMPREHENSION QUESTIONS ON TWO PASSAGES

D. 25 QUESTION MATH-30 MINUTES

E. 25 QUESTION MATH-30 MINUTES

1. 25 STANDARD MULTIPLE CHOICE
a. $\quad \operatorname{EASY}(\# 1-8)$
b. MEDIUM (\# 9-17)
c. HARD (\# 18-25)

F. 10 QUES71ON STANDARD MULTIPLE CHOICE-1 5 MINUTES

G. EXPERIMENTAL SECTION

1. THIS IS HOW SAT TESTS FUTURE QUESTIONS

2. CAN'T BE IDENTIFIED BY TEST TAKER

3. CAN BE ANY SECTION

4. YOU MUST EXECUTE ONE SECTION STRATEGY TWICE

TIME ALLOWED FOR EACH SECTION AND QUESTION TYPE

A. MATH QUESTIONS

1. 72 SECONDS AVERAGE FOR STANDARD MULTIPLE CHOICE

2. 36 SECONDS AVERAGE FOR QUANTITATIVE COMPARISONS

B. VERBAL QUESTIONS VARY ACCORDING TO TYPE

1. SENTENCE COMPLETION-40 SECONDS EACH

2. ANALOGIES-30 SECONDS EACH

3. READING COMPREHENSION-80 SECONDS EACH

a. INCLUDES READING TIME

b. EXAMPLE: A PASSAGE WITH 5 QUESSTIONS

(1) 5x80-400 SECONDS-7 MIN. (APPROX.)

(2) 3x80-240 SECONDS-4 MINUTES (APPROX)

SCORING ON THE SAT

A. MATH AND VERBAL ARE THE SAME

B. \# CORRECT-(\# WRONG DIVIDED BY 4)

C. BLANKS DO NOT COUNT FOR OR AGAINST YOU

D. IMPORTANT EXAMPLE

I. MATH-37 RIGHT, 23 WRONG-490

2. MATH-37 RIGHT, 23 BLANK-550

E. IT PAYS TO LEAVE THE HARD QUESTIONS BLANK

L MOST STUDENTS GET THEM WRONG

2. YOU LOSE POINTS FOR THE INCORRECT ANSWERS

3. YOU WASTE TIME YOU SHOULD SPEND GETTING EASIER QUESTIONS RIGHT

4. ALL QUESTIONS COUNT THE SAME

DEVELOPING YOUR STRATEGY

A. VOCABULARY BUILDING

1. THE HARDEST AND MOST IMPORTANT

2. PREFIXES AND ROOTS (FROM BARRON'S)

a. MAKE YOUR OWN FLASH CARDS

(1) ROOT AND EXAMPLE WORD ON ONE SIDE

(2) MEANINGS OF BOTH ON OTHER SIDE

(3) WORK WITH FELLOW ATHLETES

b. HIGH FREQUENCY WORDS (FROM BARRON'S) 
B. LEARNING QUESTION TYPES AND STRATEGIES

1. HELPS WITH GUESSING

2. LEARN TYPES OF READING COMPREHENSION QUESTIONS

3. PRACTICE EXERCISES FOR EACH TYPE OF QUESTION

C. LEARNING TEST STRUCTURE

I WHICH QUESTIONS TO ANSWER

2 WHICH QUESTIONS TO LEAVE BLANK

a. DETERMINE STRENGTHS AND WEAKNESSES IN EACH TYPE

b. USE BARRON'S PRACTICE EXERCISES

c. TAKE PRACTICE TESTS

3. PRACTICE YOUR STRATEGY ON PRACTICE TESTS

a. BARRON'S

b. 10 SATS

SAMPLE STRATEGY

A. YOU MUST PLAN ON ANSWERING THE EASY AND MEDIUM QUESTIONS

B. YOU CAN STILL GET SOME WRONG AND GET A 900

C. MATH

1. 25 STANDARD MULTIPLE CHOICE QUESTION SECTION

a. WHAT TO ANSWER

(1) ANSWER THE FIRST 16 QUESTIONS

(2) LEAVE THE LAST 9 BLANK

(3) YOU WILL HAVE ALMOST TWICE AS MUCH TIME TO DO EACH ONE

2. 25 QUESTION SECTION WITH 15 QUANTITATIVE COMPARISONS AND 10 STUDENT RESPONSE

a ANSWER THE FIRST 10 QUANTITATIVE COMPARISONS

b. ANSWER THE FIRST 6 OF THE STUDENT PRODUCED RESPONSE

c. YOU WILL HAVE ALMOST TWICE AS MUCH TIME TO DO THEM

3. 10 STANDARD MULTIPLE CHOICE QUESTION SECTION

a. ANSWER THE FIRST 6 QUESTIONS

b. YOU WILL HAVE ALMOST TWICE AS MUCH TIME TO DO THEM

D. VERBAL

130 QUESTION SECTION

ANSWER FIRST 6 SENTENCE COMPLETION

ANSWER FIRST 4 ANALOGIES

ANSWER FIRST ALL OF FIRST READING COMPREHENSION

ANSWER I OR 2 OF SECOND READING COMPREHENSION

(1) DEPENDS ON \# OF QUESTIONS WITH EACH PASSAGE

(2) DONT ANSWER THE HARD INEERENCE QUESTIONS WITH EACH

PASSAGE

2. 35 QUESTION VERBAL

ANSWER FIRST 7 SENTENCE COMPLETION

ANSWER FIRST 8 ANALOGIES

ANSWER FIRST 8 READING COMPREHENSION

(1) DEPENDS ON \# OF QUESTIONS WITH EACH PASSAGE

(2) DO NOT ANSWER THE DIFFICULT INFERENCE QUESTIONS WITH THE PASSAGE

3. 13 QUESTION READING COMPREHENSION

ANSWER ONLY THE QUESTIONS ABOUT EACH PASSAGE, NOT THE COMPARISONS (9)

E. FOR EXPERIMENTAL SECTION USE ONE OF THESE STRATEGIES AGAIN 
1. GENERAL

A. FOUR SECTIONS OF THE TEST

1. MATH-60 MINUTES/60 QUESTIONS

a. 1/3 ARITHMETIC

b. 1/3 PRE-ALGEBRA AND ALGEBRA

c. LESS THAN $1 / 3$ GEOMETRY

(1) PLANE

(2) COORDINATE

d. A FEWTRIGONOMETRY

2. ENGLISH USAGE-4,5 MINUTES/75 QUESTIONS
a. GRAMMAR
b. SENTENCE STRUCTURE
c. PUNCTUATION
d. RHETORICAL
e. STYLE
f. ORGANIZATION

3. SCIENCE-35 MINLITES/40 QUESTIONS
a. NO SCIENTIFIC KNOWLEDGE IS NECESSARY
b. 7 SETS OF INFORMATION
c. GRAPHS
d. TABLES
e. RESEARCH SUMMARIES
f. CONFLICTING VIEWPOINTS

4. READING-35 MINUTES140 QUESTIONS
a. 4 PASSAGES-700 WORDS LONG
b. ONE FICTION
c. ONE HUMANITIES
d. ONE SOCIAL SCIENCE
e. ONE SCIENCE
f. VARYING ORDER

B. SCORING OF THE TEST

1. RANGE OF $1-36$

2. AVERAGE $=20.6$

3. YOU CAN DECIDE WHICH SCORE YOU WANT REPORTED

4. SOME DATES OFFER RELEASE OF INFORMATION

a. COPY OF ANSWER SHEET

b. COPY OF QUESTIONS

c. ACT OR SAT?
1. STRONG VOCABULARY, WEAK USAGE $=S A T$
2. STRONG USAGE, WEAK VOCABULARY $=A C T$
3. ARITHMETIC BUT NOT HIGHER LEVEL $=S A T$
4. SCIENCE AND READING COMPREHENSION =ACT D. GENERAL STRATEGIES

D. GENERAL STRATAGIES

1. GUESSING AND PROCESS OF ELIMINATION

a. IF YOU ELIMINATE AN ANSWER A CHOICE, CHANCES GO UP

b. NO PENALTY FOR GUESSING

c. SCIENTIFIC GUESSING

(1) FIND THE ANSWER THAT IS USED THE LEAST

(2) FILL THAT LETTER IN FOR ALL THOSE YOU DON'T KNOW

2. GOING THROUGH THE FIRST TIME TO FIND EASY QUESTIONS

a. CIRCLE ONES YOU CAN'T DO AND COME BACK

b ANSWER AND SPEND TIME ON ONES YOU KNOW

3. WARMING UP THE MORNING OF THE TEST

a. SAVE A FEW OF EACH TYPE OF QUESTION

b BAD IDEA TO WARM UP ON THE REAL TEST

II. SCORING

A. WHAT YOU NEED TO SCORE A 17

B. 38-40 CORRECT OF THE 75 QUESTIONS ON THE ENGLISH TEST- 17

C. 18-19 CORRECT OF 60 QUESTIONS ON THE MATH TEST $=17$

D. 17 CORRECT OF THE 40 QUESTIONS ON THE READING TEST- 17

E.16-17 CORRECT OF THE 40 QUESTIONS ON THE SCIENCE TEST- 17 
PREFIXES

AS, ABS-AWAY FROM

$A D, A C, A G, A L, A N$.

AP, AR, AS, AT-TOWARD

ANTE-BEFORE

BI-TWO BICYCLE-TWO

WHEELS

BI-TWO

CIRCUM-AROUND

CON, COL, COM-WITH

CONTRA-AGAINSTDE-DOWN FROM

DIS, DIF-APART, AWAY

DYS-BAD

EX, E-OUT

HOMO-SAME

HETERO-DIFFERENT

HYPER-ABOVE. OVER

IN, IL, IM, IR-NOT

IN, IL, IM, IR-INTO

INTER-BETWEEN

MACRO-LARGE

MAL-BAD

MICRO-SMALL

MIS-WRONG

NEO-NEW

NON-NOT

PER-THROUGH

POLY-MANY

POST-AFTER

PRE-BEFORE

PRO-FORWARD

RE-AGAIN. BACK

SE-AWAY

SEML-HALF

SUB, SUP-UNDER

SUPEA-ABOVE

TRANS-ACROSS

UNI-ONE

UN-NOT

WITH-AGAINST, AWAY

ROOTS

AG, ACT-DO

AM-LOVE

ANIM-MIND

ANTHROP-MAN

AUD, AUDIT-HEAR

AUTO-SELF

BELLI-WAR

BEN, BON-GOOD. WELL

BIO-LIFE

CAD, CAS-FALL

CAPT, CEPT. CIP. CAP.TAKE

CEO, CESS-GO, YIELD

CHRON-TIME

CID, CIS-CUT, KILL

CIT, CITAT-START, CALL OUT

COGNIT-KNOW

CORD-HEART

CORPOR-BODY

CLAM, CLAMAT-GRY OUT

CLAUD. CLAUS. CLUD,

CLOS-CLOSE

CRED-BELIEVE

CUR, CURS-RUN

DEM-PEOPLE

DIC. DICT-SAY

DOC, DOCT-TEACH

FAC, FIC, FEC-MAKE, DO

FALL-DECEIVE

FER, LAT-BEAR, CARRY 
FLECT, FLEX-BEND

FRAG, FRACT-BREAK

FUS-POUR

JAC, JECT, JACT-THROW

LEG. LEX. LECT-READ

LOG-STUDY

LOQU. LOCU-TALK

MAN-HAND

MIT, MISS-SEND

MOB. MOT, MOV-MOVE

MORPH-SHAPE

PAR-EQUAL

\section{ROOTS}

PASS, PATH-FEEL

PEL. PULS-DRIVE

PET, PETIT-SEEK

PHIL-LOVE

PLIC-FOLD

PORT. PORTAT-CARRY

POS, PON-PUT

POTEN-ABLE, POWERFUL

ROG. ROGAT-ASK

SCRIS. SCRIPT-WRITE

SENT, SENS-THINK

SECU. SEQU-FOLLOW

SPECT-SEE

STAS, STAT. SIST-STANO

STRU, STRUCT-BUILD

TANG. TACT, TING-TOUCH

TEN, TENT-HOLD

TRACT-PULL

TRUD, TRUS-PUSH

VAD, VAS-GO

VENI, VENT, VEN-COME

VER-TRUTH

VERS. VERT-TURN

VID, VIS-SEE

VOC, VOCAT-CALL

VOL-WISH

VOLV, VOLUT-ROLL

THE STUDY OF WORD PARTS REPRESENT THE MOST PRODUCTIVE WAY TO INCREASE YOUR VOCABULARY YOU CAN PICK OUT WORD PARTS IN WORDS YOU DON'T KNOWAND GET A FEELING FOR THE MEANING OF THE STRANGE WORD. 


\section{APPENDIX D}

To Whom It May Concern:

I am a student athlete at

Northern Senior High School who will graduate in June of 1998. For the last years, I have played for the Pioneer football team. I have also participated in the varsity program.

I am years old, weigh pounds and am tall. I bench press jump is and I run 40 in - My vertical seconds.

At the present time, my core GPA is taking which will apply toward . I am currently my core. My previous SAT (or ACT) combined score was and I will re-take the SAT (or ACT) on

My coaches and I are in the process of preparing a tape illustrating my football skills which I will be happy to send to you when it is complete. You may also contact Coach Walter Prince or Coach Lee Garret at 981-6590 extension 331 for additional information.

I definitely wish to continue my education as a student athlete, and I would really like to become a part of the football program. 


\section{APPENDIX E}

\section{MIAMI KING SENIOR HIGH \\ FOOTBALL PROGRAM}

\section{LETTER OF OBLIGATION AND COMMITMENT}

$$
\text { I }
$$
agree to the following regulations and policies as established by Coach $\overline{\text { Alexander: }}$

on this day of 19

1. I will adhere to all rules and regulations as established by the Red Raider Football Program.

2. I will maintain a 2.5 overall GPA at all times, while participating in Red Raider Football.

3. I will endeavor to maintain proper decorum while in the eye of public scrutiny.

4. I will never knowingly or unknowingly bring to question the integrity of the Red Raider Football Program.

5. I will put forth $400 \%$ effort at all times, on and off the field.

6. I will respect myself and others at all times.

7. I will never quit or give up in my endeavor to achieve my goals in life.

8. I will relentlessly pursue excellence at all times.

9. I will never behave in a manner to embarrass myself, family, community, or the Red Raider Football Program.

If I fail to adhere to the above regulations, I will cease all involvement with the Red Raider Football Program.

HEAD COACH

DEF COORDINATOR

AREA COACH

PARENT

STUDENT ATHLETE
DATE

DATE

DATE

DATE

DATE 


\section{APPENDIX F}

\section{What It Takes To Be No. 1 by Vince Lombardi}

\section{You've got to pay the price.}

"Winning is not a sometimes thing; it's an all the time thing. You don't win once in a while, you don't do the things right once in a while, you do them right all the time. Winning is a habit. Unfortunately, so is losing.

There is no room for second place. There is only one place in my game and that is first place. I have finished second twice in my time at Green Bay and I don't ever want to finish second again. There is a second place bowl game, but it is a game for losers played by losers. It is and always has been an American zeal to be first in anything we do and to win and to win and to win.

Every time a football player goes out to ply his trade he's got to play from the ground up - from the soles of his feet right up to his head. Every inch of him has to play. Some guys play with their heads. That's O.K. You've got to be smart to be No.1 in any business. But more important, you've got to play with your heart-with every fiber of your body. If you're lucky enough to find a guy with a lot of head and a lot of heart, he's never going to come off the field second.

Running a football team is no different from running any other kind of organization - an army, a political party, a business. The principles are the same. The object is to win- to beat the other guy. Maybe that sounds hard or cruel. I don't think it is." 
"It's a reality of life that men are competitive and that the most competitive games draw the most competitive men. That's why they're there-to compete. They know the rules and the objectives when they get in the game. The objective is to win-fairly, squarely, decently, by the rules-but to win.

And in truth, I've never known a man worth his salt who in the long run, deep down in his heart, didn't appreciate the grind, the discipline. There is something in good men that really yearns for, needs, discipline and the harsh reality of head-to-head combat. I don't say these things because I believe in the 'brute' nature of man or that men must be brutalized to be combative. I believe in God, and I believe in human decency. But I firmly believe that any man's finest hour-his greatest fulfillment to all he holds dear-is that moment when he has worked his heart out in a good cause and lies on the field of battle-victorious." 


\section{APPENDIX G}

\section{WEEKLY ATHLETIC PROGRESS REPORT}

NAME

CLASS

VARSITY
Sport

Position

J.V.

\section{COMMITMENT TO ACADEMICS AND ATHLETICS}

NORWOOD FOOTBALL

\section{$\underline{\mathrm{ACADEMICS}}$}

1. Do not be satisfied with being average.

2. Attend all classes on time avoid being tardy and absent.

3. Earn a grade of $\mathrm{C}$ or higher for each class.

4. Never be seen in C.S.I. or on the suspension Iist.

5. Attend study hall, in order to receive academic help,

6. Have yourself ready to qualify for an academic scholarship.

\section{ATHLETICS}

1. Set high goals for yourself.

2. Give $110 \%$ each and everyday.

3. Become a unified team, and not an individual.

4. Become a unified team player and not an individual player.

5. At all times be a role model of the student athlete. 6. Set your sights on the district and state titles. WEEK OF

\section{RESPONSIBILITIES}


1. Pick up your weekly progress report on Friday from Mr Flagg.

2. The room is 809 .

3. Turn in the progress report by Monday of the next week by $2: 30$ P.M.

4. Thank your teachers for taking the time to fill out this report.

ACADEMIC CONDUCT EFFORT PROBLEMS TEACHER SIGNATURE

$$
\begin{aligned}
& 1^{\text {st }} \\
& 3^{\text {nd }} \\
& 4^{\text {th }} \\
& 5^{\text {th }} \\
& 6^{\text {th }}
\end{aligned}
$$

